\title{
Polymers as Advanced Materials for Desiccant Applications: 1987
}

\author{
A. W. Czanderna
}

December 1988

Prepared under Task No. SB307151

Solar Energy Research Institute

A Division of Midwest Research Institute

1617 Cole Boulevard

Golden, Colorado 80401-3393

Prepared for the

U.S. Department of Energy

Contract No. DE-AC02-83CH10093 


\section{NOTICE}

This report was prepared as an account of work sponsored by an agency of the United States government. Neither the United States government nor any agency thereol, nor any of their employees, makes any warranty, express or implied, or assumes any legal liability or responsibility for the accuracy, completeness, or usefulness of any information, apparatus, product, or process disclosed, or represents that its use would not intringe privately owned rights. Reference herein to any specific commercial product, process, or service by trade name, trademark, manufacturer, or otherwise does not necessarily constitute or imply its endorsement, recommendation, or favoring by the United States government or any agency thereof. The views and opinions of authors expressed herein do not necessarily state or reflect those of the United States government or any agency thereof. 


\section{LIST OF FIGURES}

3-1 Block Diagram Showing the Principal Components of a Quartz Crystal Microbalance Apparatus.......................... 13

3-2 Schematic of Vacuum System for QCM Apparatus.................. 14

5-1 Water Vapor Sorption Isotherm for PSSASS at $22.1^{\circ} \mathrm{C} \ldots \ldots \ldots \ldots \ldots \ldots$

5-2 Water Vapor Sorption Isotherm for SPSS at $22.1^{\circ} \mathrm{C} \ldots \ldots \ldots \ldots \ldots \ldots \ldots$

5-3 Water Vapor Sorption Isotherm for PACM at $22.1^{\circ} \mathrm{C} \ldots \ldots \ldots \ldots \ldots \ldots$

5-4 Water Vapor Sorption Isotherm for PAAAS at $22.1^{\circ} \mathrm{C} \ldots \ldots \ldots \ldots \ldots \ldots$

5-5 Water Vapor Sorption Isotherm for PMAASS at $22.1^{\circ} \mathrm{C} \ldots \ldots \ldots \ldots \ldots$

5-6 Water Vapor Sorption Isotherm for PVAVSSS at $22.1^{\circ} \mathrm{C} \ldots \ldots \ldots \ldots \ldots$

5-7 Water Vapor Sorption Isotherm for PAASs at $22.1^{\circ} \mathrm{C} \ldots \ldots \ldots \ldots \ldots \ldots . \ldots 27$

5-8 Water Vapor Sorption Isotherm for Csss at $22.1^{\circ} \mathrm{C} \ldots \ldots \ldots \ldots \ldots$

5-9 Water Vapor Sorption Isotherm for MC at $22.1^{\circ} \mathrm{C} \ldots \ldots \ldots \ldots \ldots \ldots \ldots$

5-10 Water Vapor Sorption Isotherm for PVP at $22.1^{\circ} \mathrm{C} \ldots \ldots \ldots \ldots \ldots \ldots$

5-11 Water Vapor Sorption Isotherm for PAA at $22.1^{\circ} \mathrm{C} \ldots \ldots \ldots \ldots \ldots \ldots$

5-12 Water Vapor Sorption Isotherm for PEO at $22.1^{\circ} \mathrm{C} \ldots \ldots \ldots \ldots \ldots$

5-13 Water Vapor Sorption Isotherm for PEG at $22.1^{\circ} \mathrm{C} \ldots \ldots \ldots \ldots \ldots \ldots$

5-14 Water Vapor Sorption Isotherm for PVSPS at $22.1^{\circ} \mathrm{C} \ldots \ldots \ldots \ldots \ldots \ldots$

5-15 Water Vapor Sorption Isotherm for PFSA at $22.1^{\circ} \mathrm{C} \ldots \ldots \ldots \ldots \ldots \ldots \ldots$

5-16 Water Vapor Sorption Isotherm for PHMA at $22.1^{\circ} \mathrm{C} \ldots \ldots \ldots \ldots \ldots \ldots$

5-17 Water Vapor Sorption Isotherm for PVSASS at $22.1^{\circ} \mathrm{C} \ldots \ldots \ldots \ldots \ldots \ldots$

5-18 Water Vapor Sorption Isotherm for PSMQ at $22.1^{\circ} \mathrm{C} \ldots \ldots \ldots \ldots \ldots \ldots$

5-19 Water Vapor Sorption Isotherm for AMBH at $22.1^{\circ} \mathrm{C} \ldots \ldots \ldots \ldots \ldots$

5-20 Water Vapor Sorption Isotherm for CA at $22.1^{\circ} \mathrm{C} \ldots \ldots \ldots \ldots \ldots \ldots \ldots \ldots$

5-21 Water Vapor Sorption Isotherm for PBM at $22.1^{\circ} \mathrm{C} \ldots \ldots \ldots \ldots \ldots \ldots \ldots$ 


\section{LIST OF FIGURES (Concluded)}

Page

5-22 Water Vapor Adsorption by PMAASS and PSSASS at 70\%, 40\%, and 9.5\% R.H. after Pressure Increases from $60 \%, 30 \%$, and $5 \%$ R.H., respectively.

5-23 Water Vapor Desorption by PAAAS, PVAVSSS and CSSS at $70 \%, 50 \%$, and 5\% R.H. after Pressure Decreases from 80\% 60\%, and 60\% R.H.

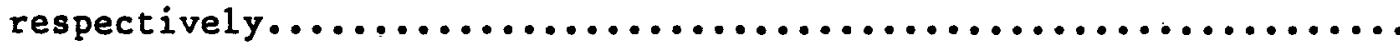

5-24 Water Vapor Sorption Isotherms for SPSS at $22.1^{\circ} \mathrm{C}$

(Three Cycles)......................................... 36

5-25 Water Vapor Sorption Isotherms for PAAAS at $22.1^{\circ} \mathrm{C}$

(Three Cycles)......................................... 36

5-26 Water Vapor Sorption Isotherms for CSSS at $22.1^{\circ} \mathrm{C}$

(Three Cycles)...................................... 37

5-27 Water Vapor Desorption Isotherms for SPSS at $22.1^{\circ} \mathrm{C}$

(Three Cycles)........................................

5-28 Water Vapor Desorption Isotherms for PAAAS at $22.1^{\circ} \mathrm{C}$

(Three Cycles).......................................... 38

5-29 Water Vapor Desorption Isotherms for CSSS at $22.1^{\circ} \mathrm{C}$

(Three Cycles)...................................... 38

5-30 Water Vapor Sorption Isotherms for PEO at $22.1^{\circ} \mathrm{C}$

(Four Cycles)....................................... 39

5-31 Block Diagram of Arrangement of a Combined QCM and SM Apparatus.... 39 


\section{SUMMARY}

The scientific objective of this task is to determine how the desired sorption performance of advanced desiccant materials can be predicted by understanding the role of their surface phenomena and the materials modifications. The technological objective is to identify a next-generation, low-cost material with which solar energy or heat from another low-cost energy source can be used for regenerating the water vapor sorption activity of the desiccant.

This research is concerned with solid materials used as desiccants for desiccant cooling systems (DCS) that process water vapor in an atmosphere to produce cooling. The purpose of the Advanced Desiccant Materials (ADM) project during 1987 was to evaluate the sorption performance of polymeric materials for their potential application in solid commercial desiccant cooling systems (CDCS). An ADM can advance solar buildings technology not only by lowering the cost of CDCS to compete with conventional air-conditioning but also by eliminating the need for adding peak-load generating capacity by electric utilities.

Background information is presented that includes an introduction to DCS and the role of the desiccant as a system component. The purpose, background, rationale, and long-term technical approach for studying advanced desiccant materials are reported including using polymers as ADM and the key research issues concerning polymers. The experimental method for measuring water vapor sorption by desiccants is described for a quartz crystal microbalance (QCM). Improvements needed for the experimental measurements are cited based on 1 imitations actually encountered in 1987 in using the QCM.

The water vapor sorption performance criteria are identified for narrowing the potential ADM to a few candidate ADM. The sorption performance includes the sorption capacity from $\overline{5 \%}$ to $80 \%$ relative humidity, isotherm shape, rate of adsorption and desorption, and cyclic stability of the ADM in water vapor. These criteria are in addition to the key materials parameters for ranking potential ADM, which are also listed from a previous report. The procedures used for preparing 23 polymers for studies with the QCM are discussed in general and given specifically for 5 different types of polymers.

Measurements are presented for the sorption performance of 23 potential commercially available polymeric ADM materials with the QCM. The data include sorption isotherms, the rate of adsorption and desorption at each pressure increment or decrement, cyclic stability, and qualitative evaluation of the permeation rate. The criteria cited above were then applied to narrow the 23 potential ADM to 9 candidate ADM. The candidate polymers are polystyrenesulfonic acid sodium salt, sodium polystyrene sulfonate, polyacrylamide-carboxyl modified, polyacrylic acid ammonium salt, poly(methacrylic acid) sodium salt, poly(n-vinylacetamide, vinyl sulfonate) sodium salt, polycrylic acid sodium salt, cellulose sulfate sodium salt, and methyl cellulose. The remaining polymers studied or considered for study that are of no further interest are also listed. Additional commercially available polymers identified in a 1987 update of the original 1985 literature search are 1 isted.

Future activities for the project are addressed. The priority need for modifying existing polymers and/or "molecularly engineering" the preparation of polymers to serve as an ideal desiccant are highlighted. 
A five-page summary of the project, which has been prepared for an industrial peer review panel, is included in Appendix $E$. The reader may find it helpful to read Appendix $E$ before plunging into the detail of the entire report. 
CONTENTS

Page

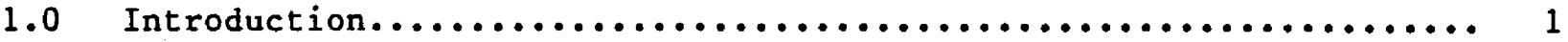

1.1 Objectives and Previous Reports..................... 1

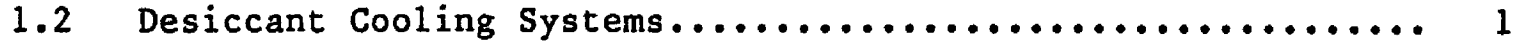

1.3 Purpose of Advanced Desiccant Materials Research........... 2

1.4 Relationship of Desiccant Materials to Desiccant Cooling Systems .................................... 3

1.5 Background for Studies of Advanced Desiccant Materials...... 3

1.6 Polymers as Advanced Desiccant Materials................. 6

1.7 Goals/Specific Objectives......................... 7

1.8 Technical Approach for Studying Advanced Desiccant

Materials................................... 7

2.0 Criteria for Identifying Potential and Candidate Advanced

Desiccant Materials.................................... 10

2.1 Criteria Used for Ranking Potential Candidate

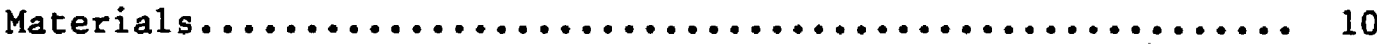

2.2 Performance Criteria for Advanced Desiccant Materials....... 10

3.0 Experimental Measurement of Water Vapor Sorption by Desiccants..... 12

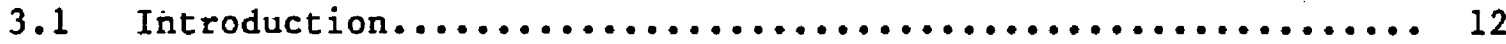

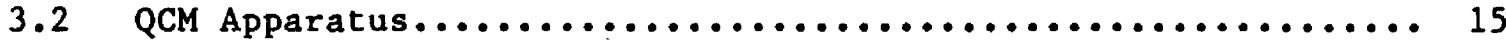

3.3 Procedures Used for Determining Isotherms and Rates of

Mass Change.................................... 15

4.0 Selection and Preparation of Polymers for Sorption

Characterization with the QCM Apparatus..................... 16

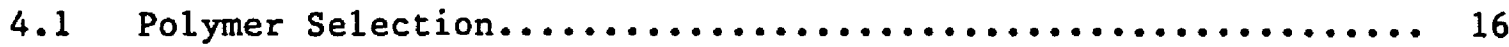

4.2 Preparation of Polymers for QCM Studies................. 16

5.0 Experimental Results and Discussion...................... 21

5.1 Isotherms of Polymers Studied..................... 21

5.2 Kinetics of Sorption and Desorption by Polymers That Are Candidate ADM................................... 22

5.3 Cyclic Stability Studies.......................... 22

5.4 Accuracy of Measurements and Need for Measurements on Larger Samples.................................. 23

5.5 Literature Search Update.......................... 24 
CONTENTS (Concluded)

6.0 Candidate Advanced Desiccant Materials/Synthesis of New Materials............................................ 42

6.1 Candidate Advanced Desiccant Materials................. 42

6.2 Synthesis of New Polymeric Materials.................. 42

7.0 Future Activities................................ 43

8.0 References......................................... 44

Appendix A Leading Organic Polymers as Potential Advanced Desiccant Materials for Use in Desiccant Cooling Systems............ 46

Appendix B Possible Candidates for an Advanced Material for Use in Desiccant Cooling Systems........................ 47

Appendix C Procedures Used to Dissolve Several Polymers before Coating Them onto a Quartz Crystal.................... 48

Appendix D Additional Classes of Polymers Identified in 1987 as Potential ADM.................................... 49

Appendix E Project Summary $1985-1987 \ldots \ldots \ldots \ldots \ldots \ldots \ldots \ldots \ldots \ldots \ldots \ldots \ldots$

Appendix F Polymers that are Candidate ADM and those of Little Further Interest....................................... 55

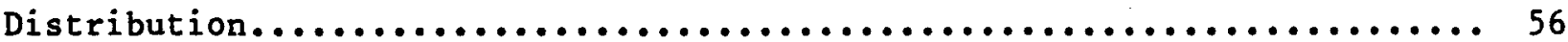




\section{PREFACE}

In keeping with the national energy policy goal of fostering an adequate supply of energy at a reasonable cost, the U.S. Department of Energy (DOE) supports a variety of programs to promote a balanced and mixed energy resource system. The mission of the DOE Solar Building Research and Development Program is to support this goal by providing for the development of solar technology alternatives for the buildings sector. It is the goal of the program to establish a proven technology base to allow industry to develop solar products and designs for buildings that are economically competitive and can contribute significantly to building energy supplies nationally. Toward this end, the program sponsors research activities related to increasing the efficiency, reducing the cost, and improving the long-term durability of passive and active solar systems for building water and space heating, cooling, and daylighting applications. These activities are conducted in four major areas: (1) Advanced Passive Solar Materials Research, (2) Collector Technology Research, (3) Cooling Systems Research, and (4) Systems Analysis and Applications Research.

Advanced Passive Solar Materials Research. This activity area includes work on new aperture materials for controlling solar heat gains and for enhancing the use of daylight for building interior lighting purposes. It also encompasses work on low-cost thermal storage materials that have high thermal storage capacity and can be integrated with conventional building elements, and work on materials and methods to transport thermal energy efficiently between any building exterior surface and the building interior by non-mechanical means.

Collector Technology Research. This activity area encompasses work on advanced low-to-medium temperature (up to $180^{\circ} \mathrm{F}$ useful operating temperature) flat-plate collectors for water and space heating applications, and mediumto-high temperature (up to $400^{\circ} \mathrm{F}$ useful operating temperature) evacuated tube/concentrating collectors for space heating and cooling applications. The focus is on design innovations using new materials and fabrication techniques.

Cooling Systems Research. This activity area involves research on high performance dehumidifiers and chillers that can operate efficiently with the variable thermal output and delivery temperatures associated with solar collectors. It also includes work on advanced passive cooling techniques.

Systems Analysis and Applications Research. This activity area encompasses experimental testing, analysis, and evaluation for solar heating, cooling, and daylighting systems for residential and nonresidential buildings. This involves system integration studies, the development of design and analysis tools, and the establishment of overall cost, performance, and durability targets for various technology or system options. 
SEP

PR -3308

This report documents the work accomplished during calendar year 1987 as a continuation of a subtask begun in 1985 in the Solar Desiccant Cooling Program. The work was carried out by T. M. Thomas, Y. Shinto, and A. W. Czanderna. The author emphasizes that this is a progress report on the advanced desiccant materials research subtask, and therefore includes material not normally presented in a technical report. Since it is still a relatively new area of research to the program, the author has included background infornation about the importance of advanced desiccant materials research, the rationale for the long-term technical approach, and the importance of quartz crystal and beam microbalance measurements.

Acogndema

A. W. Czanderna

Approved for

SOLAR ENERGY RESEARCH INSTITUTE

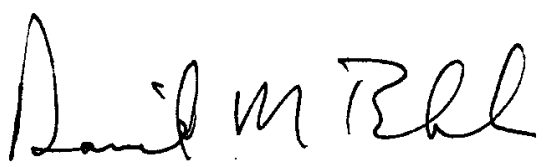

Daniel M. Blake, Manager

Materials Research Branch

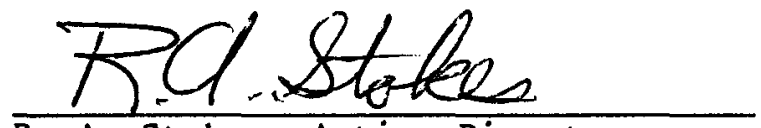

R. A. Stokes, Acting Director Solar Heat Research Division

iv 


\section{LIST OF TABLES}

Page

4-1 Polymers Characterized for Water Vapor Sorption Performance....... 17

5-1 Summary of Isotherm Data for 23 Polymers Studied as Potential

Advanced Desiccant Materials............................. 40 


\section{ACRONYMS}

ADM advanced desiccant material(s)
CDCS commercial desiccant cooling system(s)
COP coefficient of performance
DCS desiccant cooling system(s)
DOE Department of Energy
GPC gel permeation chromotography
GRI Gas Research Institute
IR $\quad$ infrared
MW $\quad$ molecular weight
PV $\quad$ photovoltaics
QC $\quad$ quartz crystal
QCM quartz crystal microbalance
R.H. relative humidity
SEM scanning electron microscopy
SERI Solar Energy Research Institute
SM $\quad$ Sartorius beam microbalance




\subsection{INTRODUCTION}

\subsection{Objectives and Previous Reports}

\subsubsection{Objectives}

The scientific objective of this task is to determine how the desired sorption performance of advanced desiccant materials can be predicted by understanding the role of their surface phenomena and the materials modifications. The technological objective is to identify a next-generation, low-cost material with which solar energy or heat from another low-cost energy source can be used for regenerating the water vapor sorption activity of the desiccant.

\subsubsection{Previous Reports}

In our first annual report, we presented background information that included a brief introduction to desiccant cooling systems (DCS) and the role of the desiccant as a system component (Czanderna and Thomas 1986a). In calendar year 1986, we prepared two papers for publication, "Polymers: Options as Advanced Desiccant Materials" (Czanderna and Thomas 1986b); and "A Quartz Crystal Microbalance Apparatus for Water Sorption by Polymers" (Czanderna and Thomas 1987b). In calendar year 1987, we completed our second annual report, "Advanced Desiccant Materials Research-1986" (Czanderna and Thomas 1987a). Since many readers might not have a complete set of these previous reports, the most important introductory detail is integrated in this report. Where detail about other aspects of the previous work (e.g., experimental apparatus, design, and construction) is not crucial to understanding the results and discussion of the progress made in calendar year 1987, which is the subject of this report, the reader is referred to the appropriate previous document.

\subsection{Desiccant Cooling Systems}

This research is concerned with solid materials used as desiccants for DCS that process water vapor in an atmosphere to produce net cooling. Since mass transfer occurs between the system and its environment, these systems are commonly referred to as "open-cycle" systems (Collier, Barlow, and Arnold 1982). All these systems use a liquid or solid material called a desiccant to remove water vapor from the air either by adsorption onto or into a solid desiccant or by absorption into the liquid desiccants. This report will focus on the solid-type desiccant system although the reader will recognize the opportunity using liquid based systems.

Systems with solid desiccants are currently used in industrial air-drying applications (Bry-Air and Cargocaire 1984) and in DCS. These use a desiccantladen wheel in which air may flow in the axial direction only. The solid desiccant (typically silica gel and/or 1 ithium chloride) is mounted onto a wheel and the air to be dried flows through one side of the wheel, while the desiccant on the other side of the wheel is being dried by an externally heated air stream. These two air streams are kept physically separated to maintain the distinctly separate functions of air dehumidification and desiccant regeneration. The historical development that led to present commercial systems has been summarized (Collier, Barlow, and Arnold 1982). 
The commercial systems are primarily intended for specialized applications that require dehumidifying air and usually do not produce a significant net cooling. There are important differences in design philosophy between solarregenerated desiccant cooling systems and commercial desiccant dehumidifiers. The most important difference involves the thermal and electrical coefficients of performance (COP). For many years, commercial desiccant dehumidifier manufacturers have chosen markets in which vapor-compression equipment cannot compete; i.e., applications where extremely dry air is required or where latent cooling loads are high. The energy requirements to achieve these conditions have not been a major concern, and, as a consequence, the desiccant dehumidifiers often have very low thermal and electrical COPs. Recently, dehumidifier manufacturers, who have been funded by GRI, have entered the Supermarket HVAC business where prospects appear attractive.

Commercial solar-regenerated desiccant cooling machines must compete with vapor compression as well as all other space-cooling technologies, so both electrical and thermal COPs are of primary concern. From thermodynamic analyses of desiccant cooling cycles, it is apparent that the adsorption characteristics of the desiccant can have a large influence on the cooling capacity and COP of the cycle (Collier, Barlow, and Arnold 1982) as also shown by others (Jurinak 1982). This effect was quantified in a recent computer parametric systems analysis study (Collier 1986). Collier concluded that if an ideal desiccant can be identified, the thermal COP of a DCS can be improved from 0.85 to 1.05 , which can now be obtained with silica gel, up to a minimum of 1.3-1.4 or close to the theoretical maximum. At the same time, the cubic feet per minute per ton can be reduced from a range of $310-400$ for silica gel to a range of 200-250 for an "ideal" desiccant. The reduction in cfm/ton must not be overlooked since this factor can reduce the physical size of commercial DCS while keeping electrical parasitic consumption low. If both these factors were achieved, DCS could be cost competitive with other current airconditioning systems; this is not possible for silica gel (Collier 1986).

Silica gel and lithium chloride are now the most widely used desiccant materials used in wheel geometries in DCS. Extensive optimization studies of the engineering design of DCS units have been carried out using silica gel (e.g., Barlow 1982; Jurinak 1982; Pesaran and Mills 1984; Schlepp and Schultz 1984; Pesaran et al. 1986c). Models in systems analysis studies for estimating the achievable thermal and electrical COP also use the properties of silica gel since they have been documented extensively over several decades (Parent 1985). Since the water sorption properties of the desiccant are crucial to the performance of any system, this desiccant materials research effort was initiated to search for and measure the properties of materials that could not only become better desiccants than silica gel but also approach the ideal desiccant material in its sorption performance. In addition, manufacturing methods with new materials could have a profound impact on reducing the dehumidifier cost.

\subsection{Purpose of Advanced Desiccant Materials Research}

One purpose for performing long-range research on materials is to secure an understanding of the behavior of low-cost, high-performance technological materials, with a goal of extending the lifetime of these materials, or to identify new materials that will offer new options for components used in operating systems. The cost-effective deployment of DCS is currently limited 
by the sorption performance, durability, and life cycle cost of the inorganic materials used. Long-term materials research is needed that focuses on improving the properties of advanced desiccant materials (ADM) and on identifying the reasons for degradation of their sorption performance.

The purpose of ADM research and development (R\&D) is to provide new materials options for DCS. The ultimate purpose is to identify materials with optimal performance in the temperature range used in a DCS in which the sorption activity of the desiccant can be routinely regenerated with an appropriate energy source. The performance of these materials can be ranked as compared to the performance of silica gel, which can be used as the standard for comparison. The life-cycle cost (i.e., initial cost, performance, and durability) has a direct relationship to the cost-effective deployment of any regenerative DCS. Identification of materials with extended lifetimes, enhanced reliability, and sustained desirable sorption properties for use in DCS can be anticipated from a sustained R\&D effort. Thus, an ADM can advance solar buildings technology not only by lowering the cost of commercial solid desiccant cooling systems (CDCS) to compete with conventional air-conditioning but also by eliminating the need for adding peak-load generating capacity by electric utilities.

\subsection{Relationship of Desiccant Materials to Desiccant Cooling Systems}

Desiccant materials must have a favorable performance/cost ratio, provide satisfactory performance, and have cost-effective 1 ifetimes; widely available materials need to be certified, modified, or, in some cases, developed specifically for use in DCS. Some of the important parameters for the water soliddesiccant-material system include isotherm shape, sorption capacity, heat of sorption, rate of sorption at or near the desiccant bed temperature $\left(\sim 25^{\circ}-\right.$ $55^{\circ} \mathrm{C}$ ), rate of desorption at an elevated temperature, physical and chemical stability of the desiccant, and cyclic repeatability of the sorption amount and rates. Some important conclusions and recommendations on these parameters were reached in the recent modeling study for regeneration at $160^{\circ} \mathrm{C}$ (Collier 1986), but the possibility of identifying new materials with optimal properties was not considered.

Except for recent work on this project and on manganese oxides (Fraioli 1983), most of the published work in the past decade has been on silica gels and zeo1ites. These materials have performance limitations (e.g., isotherm shape, large heat of adsorption, high regeneration temperatures, and hysteresis on cycling) that restrict their potential for use in DCS (Collier, Barlow, and Arnold 1982; Collier 1986). Therefore, a search for an ADM is a natural research need for enhancing the potential of deploying cost-effective DCS. These results led the Gas Research Institute (GRI) to initiate a multiyear desiccant materials research program in 1986; in 1987, it began supporting work on hydrate-type inorganic materials at Kaiser Chemical, proprietary organic formulations at the Eaton Corporation, and with others.

\subsection{Background for Studies of Advanced Desiccant Materials}

The arguments for desiccating water from air in an open-cycle DCS are well known (Collier, Barlow, and Arnold 1982). The principal limitations are related to finding a desiccant material with the required combination of sorption parameters, such as capacity, sorption heat, sorption rates at the bed 
temperature, desorption rate at a minimally elevated temperature, and cyclic stability. Other parameters or properties of interest have been identified (Czanderna and Thomas 1986a). These sorption parameters are connected with the energetics associated with gas-solid interactions (Gregg and Sing 1982; Czanderna and Vasofsky 1982).

A number of inorganic porous solids available have large internal surface areas and pore volume with an enormous affinity to sorb water. Some types of inorganic solids may sorb up to $40 \%$ of their weight and remain physically dry (Gregg and sing 1982), which is desirable for DCS applications (Collier, Barlow, and Arnold 1982). Some organic polymers may sorb over $50 \%$ of their weight (Bulygin et al. 1983; Czanderna and Thomas 1986a); the uptake of water here is internal to the polymer, and, as with many porous solids, the dynamics of the sorption process is diffusion controlled.

The sorption of water vapor by the desiccant then is given by the reaction scheme:

$$
\begin{aligned}
& \mathrm{D}(\mathrm{s})+\mathrm{H}_{2} \mathrm{O}(\mathrm{v}) \longrightarrow \mathrm{D} \cdot \mathrm{H}_{2} \mathrm{O}_{\text {surface }} \\
& \mathrm{D}(\mathrm{s})+\mathrm{D} \cdot \mathrm{H}_{2} \mathrm{O}_{\text {surface }} \longrightarrow \mathrm{D} \cdot \mathrm{H}_{2} \mathrm{O}_{\text {internal }}+\mathrm{D}(\mathrm{s}),(1-1)
\end{aligned}
$$

where $D(s)$ is a solid desiccant adsorption site. Water vapor adsorbs onto the surface (Eq. 1-1) and permeates into the solid by several possible diffusion processes (Eq. 1-2) to provide the total sorption. Empty surface sites are filled by further adsorption (Eq. 1-1). Desorption of water vapor from the desiccant occurs by the reverse sequence

$$
D \cdot \mathrm{H}_{2} \mathrm{O} \text { surface } \longrightarrow \mathrm{D}(\mathrm{s})+\mathrm{H}_{2} \mathrm{O}(\mathrm{v})
$$

and

$$
D(s)_{\text {surface }}+\mathrm{D} \cdot \mathrm{H}_{2} \mathrm{O}_{\text {internal }} \longrightarrow \mathrm{D} \cdot \mathrm{H}_{2} \mathrm{O}_{\text {surface }}+\mathrm{D}(\mathrm{s})_{\text {internal }}, \quad(1-4)
$$

where empty surface sites are generated (Eq. 1-3) by desorption and water sorbed in the material must first occupy a surface site (Eq. 1-4) before desorption via Equation 1-3.

Although the details of the molecular processes are much more complex than illustrated by Eqs. 1-1 through 1-4, they illustrate that the sorption capacity is gained by at least two kinetic steps involving the rate of adsorption (Eq. 1-1) and the rate of permeation into the solid (Eq. 1-2). Equations 1-3 and 1-4 illustrate the reverse steps of desorption and diffusion. The adsorption and desorption rates are usually much faster than the permeation and diffusion rates. The permeation (diffusion) steps provide the "solid-side" resistance in the sorption-regeneration sequence. The principal limitations are related to finding a desiccant material with the required combination of isotherm shape, sorption capacity, sorption heat, sorption rates at the bed temperature, desorption rate at a minimally elevated temperature, cyclic stability of the sorption properties, and stability of the desiccant itself. These parameters are connected with the energetics and kinetics associated with gas-solid interactions. 
The forces primarily responsible for the sorption processes arise from interactions of the electric field at the surface of the solid/adsorbate molecules, which is water for solid desiccants. Because of its large dipole moment and polarizability, the water molecule produces a large heat of adsorption. The total interaction between the water molecules and the adsorbent surface contains contributions from several types of interactions such as dipole-dipole, dipole-quadrupole, and dipole-induced dipole. Since water is a polar molecule and the sorption sites are primarily ionic, it appears conceivable that the electric field at the surface could be modified by introducing different ions or functional groups at the surface, thus changing the heat of adsorption. On inorganic surfaces, modifications could be done by ion exchange techniques and during the preparation of organic materials. The modifications can also influence the sorption capacity and isotherm shape, so the desired material must have the optimal combination of capacity and adsorbate-binding energy. .

From sorption isotherms, the binding energy of the water adsorbate to the solid can be determined. The rate of diffusion through the porous material can be calculated, and, in principle, the rate of desorption from the solid can be determined and compared with experimental results. The latter must be taken on materials that at least approach the configurations used for the calculations. Practically, the sorption rate processes will be reduced by pore volume diffusion and intraparticle diffusion in a packed bed of particles. Although some sorption data are available in the literature (Gregg and sing 1982) for candidate desiccant adsorbent materials, these data have not been analytically scrutinized to determine the suitability of new materials in advanced desiccant applications.

Recent articles show both experimental activity in water-vapor adsorbent systems and analysis of the associated phenomena (Czanderna and Thomas 1986a). In most of these studies, the conventional volumetric, scanning electron microscopic, and electron microscopic techniques used provide only a limited understanding of fundamental processes. Surface compositional analyses of solids have not been correlated with changes in sorption behavior. Bonding information available from infrared spectroscopy has been coupled with adsorbed amounts in only a few papers. The quartz crystal microbalance (QCM) has not been used extensively to obtain adsorption equilibrium and rates (Czanderna and Thomas 1986a) The great potential of the QCM is being exploited for both screening and evaluating advanced polymeric desiccant materials for this research.

To understand the molecular processes for water-solid adsorbent desiccant systems, there is an obvious opportunity to combine using QCM, infrared (IR), and surface spectroscopies to correlate rates and amount sorbed with the chemical bonds formed (related to heats of adsorption) and surface composition (effects of chemical modification). Furthermore, any changes in the amount sorbed and rate of desorption should result in changes in the bonding at the surface (infrared). Finally, experimental data in the literature are not sufficient for assessing the potential of polymeric materials as desiccants. The objectives of this research have been developed from the obvious unexplored opportunities for providing scientific understanding or information about candidate water-desiccant materials and rationale for modifications of the adsorbents that might be necessary. 


\subsection{Polymers as Advanced Desiccant Materials}

From our 1iterature search (Czanderna and Thomas 1986a), we identified both inorganic and organic (i.e., polymeric) materials as potential candidate ADM for use in DCS. To focus our research, we initially selected 21 commercially available polymeric materials for further study. These are listed in Appendices A and B. The process used to narrow the list of over 300 commercially available polymers to these 21 is summarized (Czanderna and Thomas 1986b, Section 3.0 ). We identified several additional polymers as our studies progressed.

By considering the available polymeric desiccants, we note the following:

- Polymers have the potential of being modified so that sorption isotherms of both the desired shape and heats of adsorption of about $10.8 \mathrm{kcal} / \mathrm{mol}$ are obtained.

- Polymers have the potential for sorbing water from $5 \%$ to more than $80 \%$ of their own weight.

- Polymers have the potential for being readily fabricated into shapes required for DCS; e.g., a honeycomb structure $10 \times 0.04 \times 0.06 \mathrm{in}$.

- Polymer structures have the potential of being synthesized to provide high diffusivities of water vapor through the material.

- Polymers have the potential for being regenerated at temperatures below $80^{\circ} \mathrm{C}$ for thermally desorbing water.

- Polymers have the potential for maintaining long-term stability through thousands of sorption-desorption cycles.

- Commercial polymers are available at less than $\$ 2.00 / 1 b$, or comparable to the cost of commercial-grade silica gel.

Accordingly, polymeric materials could not only serve as both the desiccant and the support structure in a desiccant wheel but also be replaced easily and inexpensively if their water sorption capacity degrades. The initial need of this research is to characterize the water sorption performance of polymeric materials that could serve in an economically competitive DCS.

The key technical questions in seeking candidate polymers for DCS are the following:

- Will any commercially available polymer have the properties required for use in a DCS?

- If commercially available polymers are not suitable, can laboratoryprepared polymers be synthesized with suitable sorption, desorption, and stability properties?

- What impurities in the air stream result in a loss of sorption performance of candidate polymers?

- Are there other degradation processes that cause a candidate polymer to lose sorption performance? 
- Can the polymeric material be modified to improve performance properties such as isotherm shape, heat of adsorption, regeneration temperature, cyclic stability, and diffusivity?

- Do the performance properties depend on the sample size and configuration; e.g., $0.1 \mathrm{mg}$ (QCM), $100 \mathrm{mg}$ (beam microbalance), and SERI test-1oop scale and configuration?

We have initiated work in the past three years that provides a rapid QCM method for evaluating the performance properties of ADM with an emphasis on polymers. These include measuring sorption isotherms, sorption and desorption kinetics, and the cyclic stability of advanced desiccant materials. In the future, polymers need to be studied that are modifications of those commercially available or synthesized specifically to serve as an ideal desiccant. Those polymers with the best properties will be subjected to simulated use conditions, and cause for any performance losses will be identified.

\subsection{Goals/Specific Objectives}

The long-range goal of this research has been developed for providing scientific understanding and information about new desiccant materials and the possibilities for physical and chemical modifications of the adsorbents to optimize their properties. The ultimate goal of this research is to understand the interactions between water vapor and candidate desiccant materials that control the sorption capacity of the material, the kinetics of sorption and desorption, and the stability of these parameters during repeated cycling.

The specific objectives of this multiyear task are: (1) to determine the feasibility for using polymeric materials and chemically modified candidate materials as desiccants; (2) to determine the effect of chemically or physically modified desiccant surfaces on the sorption capacity, the heat of sorption, and the sorption kinetics; (3) to determine if fundamental water vaporsolid interactions 1 imit the stability of naturally occurring and chemically modified candidate desiccant materials; and (4) to study the topographical and compositional changes at or near the water vapor-solid interface of desiccant materials resulting from adsorption/desorption cycles between $25^{\circ} \mathrm{C}$ and a higher temperature. When the objectives are met, there will be a sufficient understanding of the phenomena that are important to improving the performance, selecting materials, and extending the durability of materials for DCS. The research will also provide mechanistic insights into the molecular processes that underpin the potential for predictive lifetime behavior of desiccant beds used in DCS.

\subsection{Technical Approach for Studying Advanced Desiccant Materials}

The key technical questions were used to formulate our technical approach. The multiyear technical approach for studying the water vapor sorption by potential materials for use in regenerative DCS consists of conducting experimental work and interpreting the data; thus, the necessary understanding of the reversible and irreversible processes that take place can be obtained. The following variables and processes are particularly relevant for experimental research on desiccant materials. 
To accomplish the goals and objectives of this research, the technical approach for this project has been and will be to perform the following:

1. Identify, select, rank, and prepare for study potential ADM.

2. Modify polymers and/or inorganic materials to improve their sorption performance and synthesize new polymeric materials that are "molecularly engineered" to function as an "ideal" ADM.

3. Identify the performance criteria of $A D M$ including sorption performance and durability.

4. Identify the necessary measurements for characterizing the water-vapor sorption performance of potential ADM.

5. Design, purchase, construct, instal1, and use experimental apparatus necessary for characterizing the sorption performance and establishing the durability of ADM.

6. Measure the sorption performance and determine relevant physical parameters of potential ADM to establish which materials are candidate ADM based on the criteria in 3 above.

7. Determine the repeatability of the sorption performance of candidate ADM from $1,2,3,4$, and 6 above as a function of sorption-desorption cycles at time intervals corresponding to DCS and at regeneration temperatures planned for use in DCS.

8. Determine the effect of chemical modification of ADM and their surfaces on the sorption performance.

9. Conduct fundamental scientific investigations to understand the interplay among composition, bonding, topography, surface area, pore volume, pore size distribution, morphology, and their changes during cycling and use in real environments.

10. Perform analytical and theoretical work, as needed, to assess the opportunities and limitations of candidate ADM for use in the engineering configurations of contemporary DCS.

11. Cooperate with others performing desiccant research and development to expedite the testing of candidate ADM in engineering configurations.

12. Prepare reports, publications, and make presentations to disseminate the results of the work.

The broad sequence of the research has been to perform a 1 iterature search of the sorption properties of candidate materials (Czanderna and Thomas 1986a), to assist in developing the analytical expressions for modeling the ideal desiccant for water vapor, and then to carry out the experimental work. For the last, the inorganic and organic solids of interest for potential application have been or are being chosen, prepared, and studied.

Two principal activities were addressed during 1985: (1) identification of candidate materials for study, and (2) construction of a QCM sorption apparatus. For the first activity, we completed a literature search, identified polymeric and inorganic materials as potential advanced desiccants, conducted a critical analysis of the literature, and ranked the materials for study. We also developed in detail the opportunities for using polymeric materials as 
ADM. We identified the key materials parameters for ranking potential ADM, and ranked all identified materials of over 300 possibilities.

For the second activity we first identified microgravimetric, compositional surface analytical, infrared spectroscopic, scanning electron microscopic, and thermal gravimetric measurements as the minimum number of techniques necessary for studying desiccant materials and understanding their morphological and surface properties. Then, we designed, purchased, assembled, constructed, installed, and initiated use of a QCM for characterizing the sorption performance of organic (polymeric) and inorganic materials.

The results for identifying the candidate materials and a description of the QCM have been fully documented (Czanderna and Thomas 1986a, Section 2.0). The results for the second activity were also given (Czanderna and Thomas 1986a, Section 3.0).

During 1986, we concentrated on two activities: (1) to improve the operation of the QCM that was assembled in 1985, with an ultimate goal of fully automatic data collection of sorption isotherms and kinetics, and (2) to obtain data on several of the 21 potential candidate polymers to initiate our process of narrowing these to candidate status. For the first activity, we achieved an acceptable level of semi-automatic operation of the QCM but could not obtain complete automation because of funding limitations. For the second activity, we obtained data on three polymers with widely varying sorption capacities. The details for both activities have also been summarized (Czanderna and Thomas 1987a, 1987b). In a related task at SERI, we demonstrated that surface compositional analysis using $x$-ray photoelectron spectroscopy and infrared spectroscopy will be useful for securing both fundamental and technological information about both present and advanced desiccant materials (Pesaran et al. 1986c).

During 1987, we concentrated nearly all our effort on measuring the sorption performance of more than $23 \%$ potential candidate, commercially available, polymeric ADM with the QCM. The measurements include determining sorption isotherms, rate of adsorption and desorption at each pressure increment or decrement, cyclic stability, and qualitative evaluations of permeation rates. We also identified the water vapor sorption performance criteria for narrowing the potential ADM to a few candidate ADM, where the sorption performance includes the sorption capacity from $5 \%$ to $80 \%$ R.H., isotherm shape, rate of adsorption and desorption and cyclic stability of the ADM in water vapor. We used the criteria to narrow the number of polymeric materials to nine candidate ADM.

In addition, we designed a Sartorius microbalance system for use on the project and designed an experimental procedure for an existing thermal gravimetric apparatus for studying the cyclic stability of ADM in humid air. We also initiated cyclic stability studies of several candidate polymeric ADM and established that nine polymers remain as serious candidate ADM.

*This number exceeds 21 because of ongoing literature work. 


\subsection{CRITERIA FOR IDENTIFYING POTENTIAL AND CANDIDATE ADVANCED DESICCANT MATERIALS}

In 1985, about 300 articles were identified in a literature search for potential candidate advanced desiccant materials. Since the sorption capacity of a desiccant is critical for its use in DCS, the computerized literature search was carried out for articles containing the words "water vapor" and "polymers." About half the literature citations were for articles in Japanese, Russian, or Eastern Bloc languages; these were not translated based on our best judgments from the English abstracts. In late FY 1987, the 1iterature search was updated; about 70 additional publications concerning potential polymeric ADM were identified. Nearly all these publications are in foreign languages, especially Japanese and Russian. Copies of the articles have been or are being secured and translations will be obtained where appropriate.

\subsection{Criteria Used for Ranking Potential Candidate Materials}

There are two sets of parameters that could be applied for ranking the identified materials in a list of potential candidate ADM. The first set is as follows: (1) cost, both initial and life cycle; (2) performance; (3) durability, lifetime, and how performance parameters depend on temperature; (4) availability; (5) processibility; (6) modifiability; (7) stability at temperatures below $100^{\circ} \mathrm{C}$; and (8) specific heat. For polymeric materials, the most important initial criterion is (2). As a first approximation, polymers should have relatively uniformly good prospects for $(1),(4),(5),(6)$, and (7), and marginal values for ( 8 ). It was not expected that durability of polymers used as desiccants, i.e., (3), would have been evaluated, and this expectation is correct (Czanderna and Thomas 1986a).

\subsection{Performance Criteria for Advanced Desiccant Materials}

The second set of parameters considered are performance related and were divided into three categories: primary, secondary, and other criteria. These criteria were ranked and reviewed by several members of the SERI desiccant team before they analyzed the available literature references. The criteria, which are more detailed than previous listings, were generated by SERI researchers in 1985 (Czanderna and Thomas 1986a). These now must be modified because of a recent computer parametric study (Collier 1986). The modified criteria 1 isted below are subjectively based on a combination of input obtained by the task leader from several sources, including verbal communications with $\mathrm{K}$. Collier, GRI program managers, Kaiser personnel, Eaton personnel, J. Mitchel1, D. Ruthven, and SERI task team members. The revised criteria are 1 isted below with brief explanatory statements.

Primary criteria for further narrowing the potential of polymeric materials as advanced desiccants are as follows:

(a) Isotherm shape (Type I, Moderate as defined by Collier 1986). Silica gel has a linear type isotherm, which results in an upper limit of 1.05 for the thermal COP. 
(b) Capacity change of at 1 east $6 \%-8 \%$ by weight between $5 \%$ and $60 \%$ R.H. Note that large capacities are not nearly as important as previously thought, which not only enlarges the list of polymeric potential ADM, but also of inorganic materials as well.

(c) Rapid adsorption at $22^{\circ} \mathrm{C}$. Rapid is interpreted to mean that most of the capacity change must be completed in less than five minutes to correspond to the anticipated exposure time in rotary CDSC.

(d) Reversibility on desorption at $22^{\circ} \mathrm{C}$ for isotherm determination. Rapid desorption rates are helpful but not necessary because the desorption kinetics will be increased by elevated regeneration temperatures.

(e) Reproducibility in (a)-(d) above following regeneration up to $80^{\circ} \mathrm{C}$; i.e., the present anticipated regeneration temperature for solar-based DCS. If higher regeneration temperatures are planned, then the $80^{\circ} \mathrm{C}$ must be increased accordingly.

Secondary criteria that will be applied to materials passing (a)-(e) include

(f) Diffusivity of greater than $10^{-9} \mathrm{~m}^{2} / \mathrm{s}$. Qualitative aspects of diffusivity or permeation rates are automatically observed during studies with QCM and SM techniques from (c) and (d) above.

(g) Desorption rates of water at the regeneration temperature that provide sufficient capacity change in less than $5 \mathrm{~min}$.

(h) Heats of adsorption at or near $10.8 \mathrm{kcal} / \mathrm{mol}$, which is the latent heat of vaporization of water. Higher heats of adsorption result.in a decrease in overall DCS efficiencies.

(i) Specific heats with $(\mathrm{dw} / \mathrm{dx}) / \mathrm{C}_{\mathrm{p}}$ greater than $0.5 \mathrm{gK} / \mathrm{J}$ for $5 \%$ to $80 \% \mathrm{R} . \mathrm{H}$. This parameter is now thought to be less important than in 1985, and in fact, does not have a wide range of variability for polymers.

Other criteria, which then need to be applied to materials that remain candidates after applying (a) - (i), include cyclic stability, durability in pure water, synthetic-air environments, and 1 ife cycle costs that are competitive, with or without contamination by use in working environments.

Since the goal of our research is to measure the performance parameters of the material itself, the obvious engineering-related parameters (e.g., bed geometry, material form, desiccant size and shape, packing density, pressure drops, and heat and mass transfer) were not considered, but could easily be factored into future concepts. 


\subsection{EXPERIMENTAL MEASUREMENT OF WATER VAPOR SORPTION BY DESICCANTS}

\subsection{Introduction}

The experimental apparatus for measuring the water vapor sorption by a solid is conceptually simple. An arrangement is needed where a solid can be surrounded by pure water vapor (or a partial pressure of water in the ambient atmosphere) and the number of water molecules that bond to the solid can be measured. A vacuum system can be used to control the gas (vapor) pressure over the solid. There are three basic methods for measuring directly the rate of gas adsorption and the equilibrium amount of vapor adsorbed by a solid: (1) gravimetric, (2) volumetric, and (3) radiotracer. The last is excluded since it would require tritiated water and offers no obvious advantages over gravimetric techniques. Gravimetric techniques have many advantages over volumetric techniques (Gregg and Sing 1982; Czanderna and Wolsky 1980), especially for water vapor sorption studies. Water is one of the most difficult vapors to work with for analysis when using vacuum systems, but the determination of adsorption isotherms and the rate of adsorption and desorption of water can be carried out routinely with gravimetric techniques.

\subsection{QCM Apparatus}

Of the available gravimetric techniques, the beam balance and the QCM are the two best choices when the advantages and limitations of all microbalances are considered (Czanderna and Wolsky 1980). We have chosen to use a QCM for our initial studies because of the commercial availability of QCMs and their ease of use for studying the sorption of water by materials at or near $25^{\circ} \mathrm{C}$ ( Lu and Czanderna 1984). The experimental system, which is shown schematically in Fig. 3-1, consists of a vacuum system, a residual gas analyzer, a QCM, and a temperature bath for the QCM. These components and their operation have been described in detail (Czanderna and Thomas 1986a).

The commonly known QCM is actually a piezoelectric quartz crystal resonator mounted in an appropriate holder. Piezoelectric materials are used extensively as electromechanical transducers and as highly stable oscillators for frequency control. For the latter application, mechanical and thermal stabilities are more important, and materials such as alpha quartz have been found to be valuable. Quartz has the smallest coefficient of the widely used crystalline solids, but the material can still be used in oscillator circuits to secure $\mathrm{pg} / \mathrm{cm}^{2}$ mass sensitivities. The effect of mass added to the frequency of a quartz oscillator has been used since the early days of radio, when frequency adjustment was accomplished by a pencil mark on the crystal.

It was established early that the cut, i.e., the orientation of the quartz crystal plate with respect to the crystallographic axes, had an important effect on the resonance frequency. For use as a piezoelectric crystal detector, only AT- or BT-cut quartz plates are useful. These crystals are two high-frequency mode plates that vibrate in a shear mode about an axis parallel to the major surface; these plates have low or zero temperature coefficients at the temperature of use, and have surfaces that are antinodal in displacement. The temperature coefficients are a critical function of the angle of cut. The AT-cut is superior in temperature coefficient and in mass sensitivity. The crystals used most frequently are 10- to 16-mm disks, squares, or rectangles that are approximately $0.19 \mathrm{~mm}$ thick. The metal electrodes are 300 


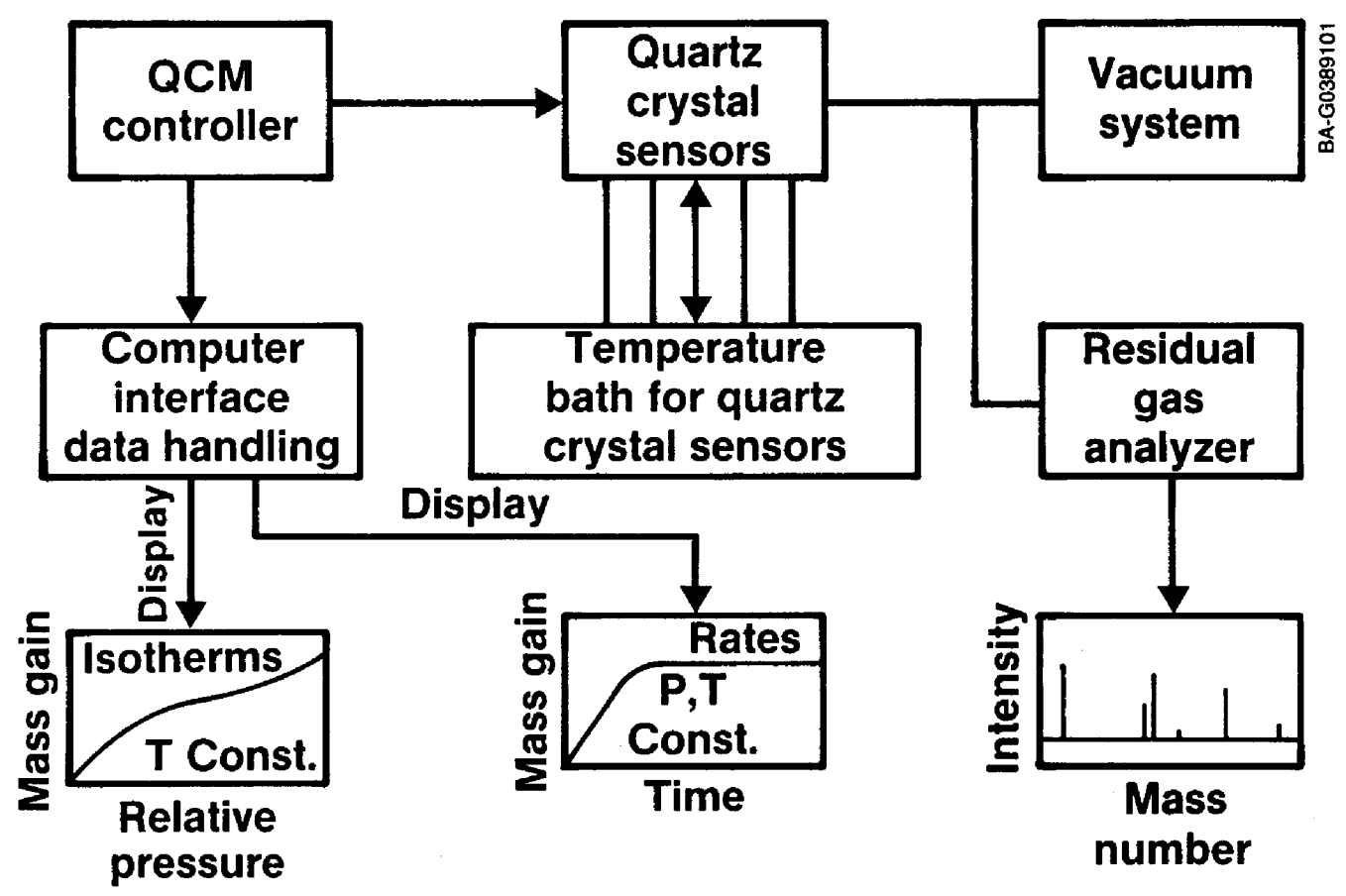

Figure 3-1. Block Diagram Showing the Principal Components of a Quartz Crystal Microbalance Apparatus

to $1000 \mathrm{~nm}$ thick, 3 to $8 \mathrm{~mm}$ in diameter, and made of gold, nickel, silver, or aluminum. The frequency of the quartz crystal depends on the physical dimensions of the quartz plate and on the thickness of electrodes placed on it. The resonant frequency of a crystal is normally obtained using a frequency meter attached to the output of an oscillator circuit (Czanderna and Thomas 1986a).

Using an idealized model, a relationship was developed (Sauerbrey 1959) between the mass of metal films deposited on quartz crystals and the change in frequency. The relationship, which was derived for quartz (AT-cut) crystals vibrating in the thickness shear mode, is

$$
\Delta f=-2.3 \times 10^{-6} \mathrm{f}^{2} \Delta \mathrm{m} / \mathrm{A},
$$

where $\Delta f$ is the change in frequency due to the coating ( $H z)$, $f$ is the frequency of the quartz plate $(\mathrm{MHz}), \Delta \mathrm{m}$ is the mass of deposited coating $(\mathrm{g})$, and $A$ is the area coated $\left(\mathrm{cm}^{2}\right)$. The constant includes the density of quartz and the velocity of a wave in the shear mode. Equation 3-1 predicts that a commercially available $6-\mathrm{MHz}$ crystal, which has been chosen in this research, would have a mass sensitivity of about $12 \mathrm{ng} / \mathrm{Hz}$ for a coated area of $1 \mathrm{~cm}^{2}$. The sensitivity factor for crystals used in our research is actually $14 \mathrm{ng} / \mathrm{Hz}$.

If a desiccant material with an overall density of $1.4 \mathrm{~g} / \mathrm{cm}^{3}$ is placed on a quartz crystal, then a desiccant film $0.1 \mu \mathrm{m}$ thick with an area of $1 \mathrm{~cm}^{2}$ would have a mass of $14 \mu \mathrm{g}$, so the limit of detectability of mass change would be $0.01 \% / \mathrm{Hz}[100 \% \times(14 \mathrm{ng} / \mathrm{Hz}) / 14 \mu \mathrm{g}]$, where $\pm 0.1 \mathrm{~Hz}$ can be routinely monitored with our commercially available oscillator circuits. For thicker desiccant 
films, the percent mass sensitivity is even smaller. Since the interest is for desiccants with percent mass gains in water of over $5 \%$, the QCM sensitivity is more than sufficient, even if an active quartz crystal area of only $0.25 \mathrm{~cm}^{2}$ is used. The mass measuring range of the QCM will permit studying polymer thicknesses that vary by more than 100 times, so permeation rates can also be deduced.

For operation in a vacuum, the quartz crystal holder is an integral part of a vacuum system apparatus as shown in Fig. 3-2. The essential components of this holder include a 2.75-in. stainless steel Conflat ${ }^{\circledR}$ vacuum flange with feedthroughs for a thermocouple, cooling water, and the electrical leads needed for operating the oscillator. The essential components of the vacuum system include a source of pure water vapor, capacitance manometer, valves for manipulating gas pressures, pumps, and low pressure gauges. Sample temperatures are measured with thermocouples. Detailed descriptions of the QCM and vacuum chamber components are available (Czanderna and Thomas 1986a).

The advantages of the QCM for measuring the sorption of water vapor by advanced desiccant materials are as follows:

- The fundamental water sorption properties of desiccant materials can be studied in the absence of any engineering design restrictions.

- An appropriate mass sensitivity $\left(14 \mathrm{ng} / \mathrm{Hz} \mathrm{cm}{ }^{2}\right)$ is obtained using commercially available equipment. For example, a $100 \mathrm{~nm}$-thick polymer film with a mass of $14 \mathrm{ng}$ on a $1-\mathrm{cm}^{2}$ QCM results in detectable mass changes of $0.01 \%$, or $10 \%$ of a single monolayer of an adsorbed gas is detectable for contaminant studies (a precision of $\pm 0.1 \mathrm{~Hz}$ is obtained with our QCM).

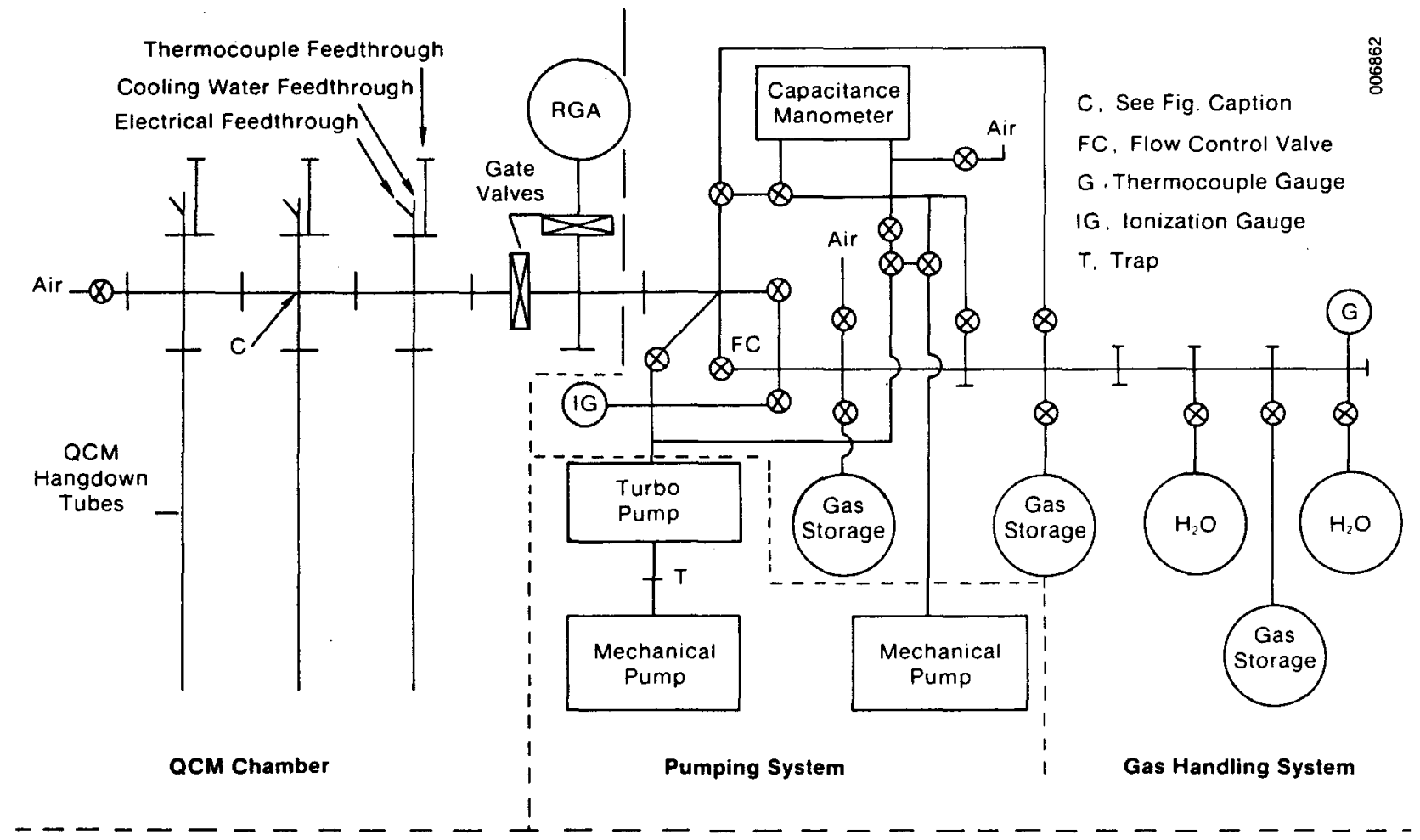

Figure 3-2. Schematic of Vacuum System for QCM Apparatus 
- The response time is fast; i.e., 2 s per point.

- It can be used in pure water vapor at pressures comparable to the relative humidity in actual desiccant systems. Thus, the sorption kinetics of the desiccant can be studied in the absence of any gas-side diffusion effects.

- It is simple to use and is not sensitive to shock or vibration.

- An accuracy of $<2 \%$ can be achieved.

- It can be easily adapted for simultaneous use with IR or surface analysis equipment.

Some of the principal 1imitations of the QCM are the following:

- Samples must be coated onto the quartz crystal and must adhere to it, which presents a particular challenge when studying particulate materials.

- Only one temperature (or a narrow temperature range) can be studied with a given crystal at the maximum sensitivity.

- Liquid samples are not easily studied.

- Condensation of unknown gases on the sample or volatile materials in the sample may cause problems in securing the actual water sorption.

\subsection{Procedures Used for Determining Isotherms and Rates of Mass Change}

After mounting the polymers of interest onto quartz crystals and obtaining the mass of the attached polymer (Section 2.0), the crystal is then attached to the oscillator head and bolted onto the vacuum system. The sample chamber is pumped to the $10^{-8}$ torr range with the sample at about $22^{\circ} \mathrm{C}$, and the oscillator mass is zeroed after the mass loss or gain has equilibrated. The system temperature is equilibrated to $22.1^{\circ} \mathrm{C}$, and water is admitted to the samples to a pressure of 1 torr. The system is allowed to equilibrate (both pressure and mass measurements). The water vapor pressure is then increased in about 2-torr increments, and the pressure and mass measurements are taken during the approach to equilibrium and after equilibrium is reached. After reaching the desired maximum pressure (16 torr in this work), the process is reversed by decreasing the water vapor pressure in about 2-torr decrements followed by equilibration intervals. (There is no design restriction for making pressure changes of about 2 torr, which were chosen for our convenience; any desired pressure change can be chosen up to 20 torr at $22.1^{\circ} \mathrm{C}$. Higher pressures can be studied by increasing the ambient temperatures of the entire QCM and vacuum apparatus.)

The percent of water uptake is calculated by multiplying the area of polymer times the mass of water gained (or 1ost) times $100 \%$ and dividing by the mass of the polymer on the crystal. The percent of relative humidity is calculated by multiplying the Baratron pressure reading times $100 \%$ and dividing by the saturation pressure of water at the system temperature.

These calculations have been simplified by carrying out our sorption studies at $22.1^{\circ} \mathrm{C}$ where the saturation vapor pressure of water is taken as 20.0 torr. The actual vapor pressure at $22.1^{\circ} \mathrm{C}$ is 19.95 torr. Thus, each 1 torr corresponds to $5 \%$ in R.H., where R.H. is the most widely used representation of the partial pressure of water in desiccant cooling research, development, and applications. 


\subsection{SELECTION AND PREPARATION OF POLYMERS FOR SORPTION CHARACTERIZATION WITH THE QCM APPARATUS}

\subsection{Polymer Selection}

A ranked 1 isting of potential polymeric advanced desiccant materials is given in Appendix A. This listing was based on the relatively sparse information available in the open 1 iterature (Czanderna and Thomas 1986a). The only primary information that we were able to use was the sorption capacity and, in most cases, the isotherm shape. There were no permeation or diffusivity data given when isotherm data were given. The permeation coefficients available were typically in the $10^{-10}$ to $10^{-12} \mathrm{~m}^{2} / \mathrm{s}$ range, or slower than desired in the primary criteria. The permeation rates in polymers depend strongly on the properties, but no evidence was found for any systematic synthesis effort to improve the diffusivities of water in polymers. In fact, synthesis efforts have been concentrated on retarding diffusivities for the obvious applications in corrosion protection. Finally, no important data published about the kinetics of water adsorption or desorption were found nor were any studies of the cyclic reproducibility for either the capacity or sorption rate reported. The only type of comments found were "adsorption is fast" or the isotherms were reproducible after "several cycles of measurement." Some polymers swell during water vapor adsorption, and this could be detrimental to the pressure drop of air in a working system.

The polymers chosen for study are those 1isted in Appendix A plus others identified during FY 1987 as potential ADM. The polymers studied to date, the acronym used in the remainder of this report and commercial source are listed in Table 4-1. The solvent evaporation procedure was used to mount all the polymers on a QC that are listed in Table 4-1.

\subsection{Preparation of Polymers for QCM Studies}

The following standard procedure has been generally followed for mounting the polymers onto quartz crystals for subsequent study in the QCM apparatus. The quartz crystals (QC) are part No. 008-010, "Crystals," and were obtained in boxes from Inficon Leybold-Heraeus (LH), Inc., 6500 Fly Road, Syracuse, NY, 13057. The crystals are not reused under any circumstances.

Before mounting a polymer, we cleaned these crystals by removing a new crystal from the LH box, rinsing three times with methanol, rinsing three times with ethanol, and drying between halves of lint-free absorbent towels.

The crystals are handled with tweezers cleaned in the same way. After cleaning, a crystal is weighed three times to the nearest 5-10 $\mathrm{\mu g}$. The polymer mass is determined by weighing the crystal in air again after applying the polymer by a solvent casting process. The sample mass determination currently 1 imits the accuracy of all our sorption data to between $4 \%$ and $20 \%$. The accuracy can be improved to better than $2 \%$ (Section 3.2 ) by using a better microbalance than the one currently available. For an initial screening, we strive to apply 100-500 $\mathrm{\mu g}$ of polymer from a solution of the polymer.

The standard procedure we have adopted for dissolving a polymer (before mounting) is to weigh out $0.1 \mathrm{~g}$ of polymer, add it to $15 \mathrm{ml}$ of 200 proof ethanol in a disposable specimen cup and rinse the boat with $10 \mathrm{ml}$ of ethanol, and stir 
Table 4-1. Polymers Characterized for Water Vapor Sorption Performance

\begin{tabular}{|c|c|c|c|}
\hline Acronym & Source & Pol ymer & Comments \\
\hline AMBH & $\begin{array}{l}\text { Polysciences, Inc. } \\
\text { Cat. 非 } 4698\end{array}$ & amberlite IR-120 $\mathrm{H}$ form & \\
\hline $\mathrm{CA}$ & $\begin{array}{l}\text { Aldrich Chem. Co. } \\
\text { Cat. 非 } 18,095-5\end{array}$ & cellulose acetate & \\
\hline $\operatorname{csss}$ & $\begin{array}{l}\text { Scientific Polymer } \\
\text { Prod., Inc. } \\
\text { Cat. } 023\end{array}$ & cellulose sulfate sodium salt & \\
\hline MC & $\begin{array}{l}\text { Scientific Polymer } \\
\text { Prod., Inc. } \\
\text { Cat. \#144 }\end{array}$ & methyl cellulose & MW 86,000 (GPC) \\
\hline $\mathbf{N}$ & $\begin{array}{l}\text { Scientific Polymer } \\
\text { Prod., Inc. } \\
\text { Cat. \#033 }\end{array}$ & nylon $6^{\prime}, 6$ & $\begin{array}{l}\text { Crosslinked; could not be } \\
\text { studied with QCM }\end{array}$ \\
\hline PAA & $\begin{array}{l}\text { Scientific Polymer } \\
\text { Prod., Inc. } \\
\text { Cat. 非598 }\end{array}$ & polyacrylic acid & MW $3,000,000$ \\
\hline PAAAS & $\begin{array}{l}\text { Polysciences, Inc. } \\
\text { Cat. 非 } 311\end{array}$ & polyacrylic acid ammonium salt & MW 250,000 \\
\hline PAASS & $\begin{array}{l}\text { Scientific Polymer } \\
\text { Prod., Inc. }\end{array}$ & polyacrylic acid sodium salt & \\
\hline PACM & $\begin{array}{l}\text { Scientific Polymer } \\
\text { Prod., Inc. } \\
\text { Cat. \#376 }\end{array}$ & polyacrylamide - carboxyl modified & MW 200,000 \\
\hline PBM & Polysciences, Inc. & poly(butylmethacrylate) & \\
\hline
\end{tabular}


Table 4-1. Polymers Characterized for Water Vapor Sorption Performance (Continued)

\begin{tabular}{|c|c|c|c|}
\hline $\mathrm{PC}$ & $\begin{array}{l}\text { Scientific Polymer } \\
\text { Prod., Inc. } \\
\text { Cat. \#035 }\end{array}$ & polycarbonate & MW $20-25,000$ \\
\hline PEG & $\begin{array}{l}\text { Scientific Polymer } \\
\text { Prod. Inc. } \\
\text { Cat. \#491 }\end{array}$ & polyethylene glycol & MW 6800 \\
\hline PEO & $\begin{array}{l}\text { Scientific Polymer } \\
\text { Prod., Inc. } \\
\text { MW } 100,000-\text { Cat. } \# 136 \mathrm{~A}\end{array}$ & polyethylene oxide & $\begin{array}{l}\text { Studied with MW } 3,400 \\
18,000 ; \text { and } 100,000 \\
\text { (A11 from STD-3 kit) }\end{array}$ \\
\hline PMAASS & $\begin{array}{l}\text { Polysciences, Inc. } \\
\text { Cat. \#0503 }\end{array}$ & poly(methacrylic acid) sodium salt & MW 15,000 \\
\hline PSMQ & $\begin{array}{l}\text { Scientific Polymer } \\
\text { Prod., Inc. } \\
\text { Cat. } 1715\end{array}$ & $\begin{array}{l}\text { polystyrene, crosslinked, mixed } \\
\text { quartenary ammonium (hydroxide form) } \\
\text { and sulfonic acid (H form) }\end{array}$ & \\
\hline PSSASS & $\begin{array}{l}\text { Polysciences, Inc. } \\
\text { Cat. 非 } 8773\end{array}$ & polystyrenesulfonic acid sodium salt & $\begin{array}{l}\text { Available in both water sol- } \\
\text { uble form and crosslinked } \\
\text { beads. The latter could not } \\
\text { be studied with the QCM. } \\
\text { MW } 500,000 \text { (powder) }\end{array}$ \\
\hline
\end{tabular}


Table 4-1. Polymers Characterized for Water Vapor Sorption Performance (Concluded)

\begin{tabular}{|c|c|c|c|c|}
\hline Acronym & Source & Pol ymer & Comments & \\
\hline SPSS & $\begin{array}{l}\text { Scientific Polymer } \\
\text { Prod., Inc. } \\
\text { Cat. 非' } 619,623 \text {, } \\
625,628\end{array}$ & sodium polystyrene sulfonate & $\begin{array}{l}\text { MW } 178,000(\text { (\#625) } \\
\text { MW 60,000 (非623) } \\
\text { MW 4,600 (非19) } \\
\text { MW } 1,200,000(\text { (\#628) }\end{array}$ & \\
\hline PVAVSSS & $\begin{array}{l}\text { Polysciences, Inc. } \\
\text { Cat. \#15662 }\end{array}$ & $\begin{array}{l}\text { poly(n-vinylacetamide, vinyl sulfonate) } \\
\text { sodium salt }\end{array}$ & & \\
\hline PVP & $\begin{array}{l}\text { Scientific Polymer } \\
\text { Prod., Inc. } \\
\text { Cat. 非 } 328\end{array}$ & polyvinylpyrrolidone & $\mathrm{MW} 10,000$ & . \\
\hline PVSASS & $\begin{array}{l}\text { Polysciences, Inc. } \\
\text { Cat. \$4392 }\end{array}$ & poly(vinylsulfonic acid) sodium salt & MW 2,000 & . \\
\hline PVSPS & $\begin{array}{l}\text { Aldrich } \\
\text { Cat. \# } 27,196-9\end{array}$ & poly(vinyl sulfate) potassium salt & & \\
\hline
\end{tabular}


the polymer/solvent mixture with a magnetic stirrer until the polymer dissolves. After $3 \mathrm{~h}$, if the polymer does not dissolve, water is added in $5-\mathrm{ml}$ increments where the first increment $=15 \% \mathrm{H}_{2} \mathrm{O} / 85 \% \mathrm{Alc}$; the second increment = $30 \% \mathrm{H}_{2} \mathrm{O} / 70 \% \mathrm{Alc}$; the third increment $=37.5 \% \mathrm{H}_{2} \mathrm{O} / 62.5 \% \mathrm{Alc}$; and the fourth increment $=45 \% \mathrm{H}_{2} \mathrm{O} / 55 \%$ Alc. The procedure for preparing several different polymers is given in Appendix B as examples of the effort required to secure satisfactory solutions of polymers.

For the cases where some of the polymer dissolves and some remains in solution, the undissolved component may be cross-linked and is filtered or the solution decanted as needed. This was necessary for several of the polymers tested so far.

The procedure for obtaining a uniform deposition of polymers onto the QC is basically a solvent evaporation process. Only two drops of polymer solution are initially deposited onto the center of the crystal before the initial weighing. The polymer is deposited onto the gold-covered crystal and care is taken to prevent any material from depositing onto the side of the crystal with the electrode configuration. Uniform coverage is essential so the polymer solution is added drop-by-drop onto the center of the QC. Our experience is that uniform coverage is obtained when the polymer solution wets the crystal. The solution concentration is chosen so that 50-100 $\mu \mathrm{g}$ of polymer will be obtained from each drop. Additional drops are added as needed for the targeted mass range.

After determining the mass of polymer mounted on a QC (in room air), we mount the QC on an auxiliary oscillator head to establish that the polymer-coated QC operates when a high frequency oscillator is used to drive the crystal. Many times, a mounted polymer will result in a "fail" indication by the QC display of the QC power supply. When this occurs, another sample is prepared as described above. (Since the "fail" has only been a minor annoyance to progress on the project, we have not made an effort to establish what causes the "fail" indication but presume it is because the adhesion is insufficient between the QC surface and the polymer coating). After obtaining a mass reading by the QCM power supply, the polymer coating is inspected visually and microscopically for lateral uniformity. The adverse influence of non-uniform coatings on the accuracy is discussed in Section 5.4 .

For improved accuracy of the isotherm capacity data, the polymer mass determined in laboratory air needs to be corrected for the loss in mass during outgassing. This correction in mass may be as much as $15 \%-20 \%$ of the sample mass for the most hygroscopic polymers and will be made in future work. However, for the purposes of the initial screening, the additional procedures required were not implemented to expedite completion of the initial work. By using uncorrected sample masses, we understate the actual per cent weight gains. 


\subsection{EXPERIMENTAL RESULTS AND DISCUSSION}

\subsection{Isotherms of Polymers Studied}

Of the criteria for a candidate ADM, the determination of an adsorption isotherm provides four important pieces of data: (1) the shape, (2) the capacity and possible capacity change between $5 \%$ and $60 \%$ R.H., (3) the absence or presence of hysteresis between the adsorption and desorption legs of the isotherm, and (4) the kinetics of the sorption or desorption process after each pressure change.

For screening the polymers 1 isted in Table 4-1, isotherms were determined at $22.1^{\circ} \mathrm{C}$ in pure water vapor using the QCM. The polymer-coated QC was mounted on the crystal holder and evacuated to $<10^{-7}$ torr, which was usually $2 \times 10^{-8}$ torr, until constant mass readings were observed. The mass lost during evacuation is not presented because its significance is questionable. This is because the mass loss could consist of water vapor and other gases and vapors still remaining in the polymer after the solvent evaporation process. As indicated in the last paragraph of Section 4.2, the mass 1 ost should be used to correct the mass of the polymer measured in air.

In general, data for the first isotherm determination were obtained at about $5 \%, 10 \%, 20 \%, 30 \%, 40 \%, 50 \%, 60 \%, 70 \%$, and $80 \% \mathrm{R} . \mathrm{H}$. by increasing the water vapor pressure from a vacuum of less than $10^{-7}$ torr to an initial pressure of about 1 torr ( $5 \%$ R.H.) and monitoring the uptake for 4-8 h. The capacity changes reported in the isotherms for all polymers are relative to the sample mass after evacuation at $22.1^{\circ} \mathrm{C}$. Capacity changes in addition to those reported might result from outgassing (or regenerating the desiccant with a dry air stream) at higher temperatures; e.g., $80^{\circ} \mathrm{C}$. For the candidate polymers, outgassing at higher temperatures is planned as part of the future activities on this project. The percent water vapor uptake is given by

$$
\% \mathrm{H}_{2} \mathrm{O}=\frac{0.0785 \mathrm{~d}^{2}(\Delta \mathrm{m})}{\mathrm{M}}
$$

where $\mathrm{d}$ is the diameter in $\mathrm{cm}$ of the polymer coating on the QC, $\Delta \mathrm{m}$ is the change in $\mathrm{ng} / \mathrm{cm}^{2}$ of the QCM readings between vacuum and at any water vapor pressure, and $M$ is the sample mass in $\mu g$. (For future work, $M$ will be corrected for the loss during outgassing by using $M=M_{0}-\pi d^{2} \Delta m_{0} / 4$ where $M_{0}$ is the sample mass measured in air and $\Delta \mathrm{m}_{0}$ is the $\mathrm{ng} / \mathrm{cm}^{2}$ loss during outgassing.) The factor $0.0785 \mathrm{~d}^{2}$ results from the polymer coating covering a larger area than the sensing area $\left(0.58 \mathrm{~cm}^{2}\right)$ of the QC that yields the mass reading in $\mathrm{ng} / \mathrm{cm}^{2}$. This factor then corrects the polymer mass (M) to the fraction of $M$ that is coating the sensing area of the QC. The maximum value for $d$ is $1.4 \mathrm{~cm}$, the diameter of the crystals used in this work. The actual value for $d$, which is obtained by combined visual and optical inspection of the polymer coating, has typically ranged between 1.2 and $1.3 \mathrm{~cm}$.

The isotherms determined with the QCM apparatus are shown in Figs. 5-1 through 5-21. The sample masses given on each figure is the mass measured in air and uncorrected for losses on outgassing. The isotherms are presented in two categories. Those that have a favorable isotherm shape, capacity, absence of hysteresis, and rapid kinetics of adsorption and desorption are presented in Figs. 5-1 through 5-9. The polymers used to obtain these isotherms are considered to be promising as candidate ADM. The isotherms of the remaining 
polymers are presented in Figs. 5-10 through 5-21. These polymers are not considered interesting as ADM for DCS. Table 5-1 gives brief comments about the isotherm for each polymer that provide the rationale for continuing to include the polymers for further study as candidate ADM or for not including them in this category. The desorption behavior of SPSS (Fig. 5-2) and PSMQ (Fig. 5-18) are clearly not equilibrium data; the most likely explanation is that morphological changes in the polymer occur in the initial cycle(s) that is changing the sorption properties while the isotherms are being obtained.

\subsection{Rinetics of Sorption and Desorption by Polymers That Are Candidate ADM}

After each pressure increment or decrement while obtaining the isotherm data, the approach to the equilibrium mass gain or loss was recorded at 2-min intervals through the first $20 \mathrm{~min}$ and then at $10-, 20-$, or $30-\mathrm{min}$ intervals for 4-6 h. In the semi-automatic operational mode of the QCM, these data are printed but are not plotted for visual display or interfaced to a graphics terminal. Thus, all sorption-desorption kinetic curves must be plotted manually or evaluated by inspecting the printout of the data. The latter was chosen, and the qualitative statements of fast, intermediate, and slow were assigned after visual inspection of the data. These statements are listed in Column 7 of Table 5-1. The definitions are as follows: fast, over $90 \%$ of the incremental or decremental mass change occurred in the first $10 \mathrm{~min}$; intermediate, over $90 \%$ of the mass incremental or decremental change occurred in the first $60 \mathrm{~min}$; and slow, less than $90 \%$ of the incremental or decremental mass change occurred during the first $60 \mathrm{~min}$. For CDCS, only fast kinetics will qualify a material as a candidate ADM. Intermediate kinetics do not necessarily disqualify a material as a candidate, and slow kinetics probably disqualify a material.

To illustrate the type of data that can be retrieved for the materials 1 isted in Tables 4-1 and 5-1, plots of the sorption and desorption kinetics are shown in Figs. 5-22 and 5-23 for several different polymers after increasing the water vapor pressure from $5 \%, 30 \%$, or $60 \% \mathrm{R} . \mathrm{H}$. , or decreasing it from $60 \%$ or $80 \% \mathrm{R} . \mathrm{H}$. These curves show that the kinetics are fast at all pressures. Similar data are archived in several thousand pages of printer output secured while measuring the isotherms. The data for the materials in Figs. 5-1 through 5-9 are especially important for planning future experiments and for potential technological use of these polymers as ADM.

The data in Figs. 5-22 and 5-23 are intended only to show most of the capacity change occurs in less than 2 min; discussing the "fine structure" of the curves would only involve needless speculation at this time. The graphs show that with computerized data techniques diffusivity calculations could be made, but it is premature to attempt calculations from the current data. Finally, some of the kinetic data were taken from duplicate samples of polymers where the isotherms have not been plotted.

\subsection{Cyclic Stability Studies}

As discussed in Section 2.0, a candidate ADM must exhibit reproducible sorption behavior after being subjected to several tens of thousands of adsorption and desorption cycles. From our study of the literature, major changes in the sorption behavior of many polymers occur in the first one or two cycles. 
Repeated measurements of sorption isotherms have not been undertaken in previous work given in the literature or in this research. We have subjected several polymers to 3-9 sorption cycles by simply remeasuring the isotherms. Typical results for the cyclic adsorption and desorption of water vapor are shown for SPSS, PAAAS, and CSSS in Figs. 5-24 through 5-29 for the first three cycles. As is seen, the cyclic reproducibility is excellent for the first three cycles. In contrast, similar adsorption data are shown in Fig. 5-30 for four cycles of PEO. As shown, there is a dramatic change in adsorption behavior from the first to second cycle, and continuing changes for the next two cycles. The changes quite likely result from physical processes occurring within the polymer because of the adsorption and desorption cycles.

\subsection{Accuracy of Measurements and Need for Measurements on Larger Samples}

The advantages and limitations of using the QCM apparatus for studies of ADM were understood prior to deciding to construct the equipment. Most of the results obtained and presented in this report have been efficiently obtained because of the advantages of the QCM apparatus. The limitations concerning the sample size, accuracy, and types of materials that can be studied and the needs for further improvements and for additional equipment are discussed briefly in this section.

The QCM has a fundamental 1 imit of $10 \mathrm{mg}$ for the polymer sample mass based on the design of the control unit and the cut of the crystal for operation at $6 \mathrm{MHz}$. Our experience has been that a practical limit of less than $1 \mathrm{mg}$ apparently is imposed by polymers with a large sorption capacity. When polymers reach sorption capacities of more than $20 \%-40 \%$, depending on the polymer, the apparatus indicates "fail." The reason for "fail" in this case probably results from the polymer plus sorbed water changing its behavior from a solid to a "liquid-1ike" material at the largest sorption capacities. Isotherm determination is lost from the pressure where a "fail" is obtained and at all higher pressures. These data could be routinely obtained by incorporating a beam microbalance into the present apparatus as described below.

The accuracy of the QCM data (i.e., the sorption capacity and kinetics of capacity changes) is limited by two principal uncertainties. The first is the sample mass itself. The sample mass is determined from weighing a QC before and after coating it with a polymer. Each weighing is now 1 imited to $\pm 5-10 \mu g$ so the uncertainty for the sample mass determination depends on the difference between two large numbers or $\pm 10-20 \mu g$ for a single weighing. This 1 imits the accuracy of $M$ in Eq. (3-1) to $10 \%-20 \%$ for a $100-\mu g$ sample or $2 \%-4 \%$ for a 500- $\mu$ gample, which are the typical sample masses studied thus far. There are several solutions to the limitation on accuracy imposed by the value of M: (1) to adopt statistical procedures for repeated weighing of the QC with and without polymer, (2) to purchase a microbalance that has a weighing precision of $1 \mathrm{\mu g}$ or better, and (3) to study much larger samples, as would be the case with a beam microbalance.

Finally, the most serious limitation on using the QCM is that samples must be adherently mounted onto a QC. The techniques adopted for the sample preparation were described in Section 4.0. Polymers that cannot be dissolved, highly cross-linked polymers, polymers cast as films, etc.--all are difficult or impossible for study with the QCM because they cannot be mounted on a QC. All the forms of polymers anticipated as potential ADM can be studied using beam microbalance techniques. 
The need for placing an existing Sartorius beam microbalance (SM) into operation is now well established. It can be attached to the gas handling and pumping station of the present QCM apparatus. The SM will retain all the essential advantages of the QCM cited in Section 3.2 and eliminate all the limitations cited. The principal limitation of the SM, or any other beam microbalance, is that only one sample can be studied at a time. The capacity of the balance is $5 \mathrm{~g}$ with a sensibility of less than $1 \mu \mathrm{g}$, samples of any configuration can be suspended in an appropriate container (e.g., a hemispherical gold cup), and accuracy to better than $0.01 \%$ can be easily assured. A block diagram of how both the QCM and an SM can be used with the existing gas-handling station is sketched in Fig. 5-31.

\subsection{Literature Search Update}

The 1iterature search completed in early 1985 that led to the polymers 1 isted in Appendices A and B was updated in August 1987. Our follow-up on all the leads is not complete, primarily because of delays caused by translating a number of Japanese and Russian articles. However, a few additional polymers seem worth screening with the QCM and/or the SM; these are 1 isted in Appendix D.

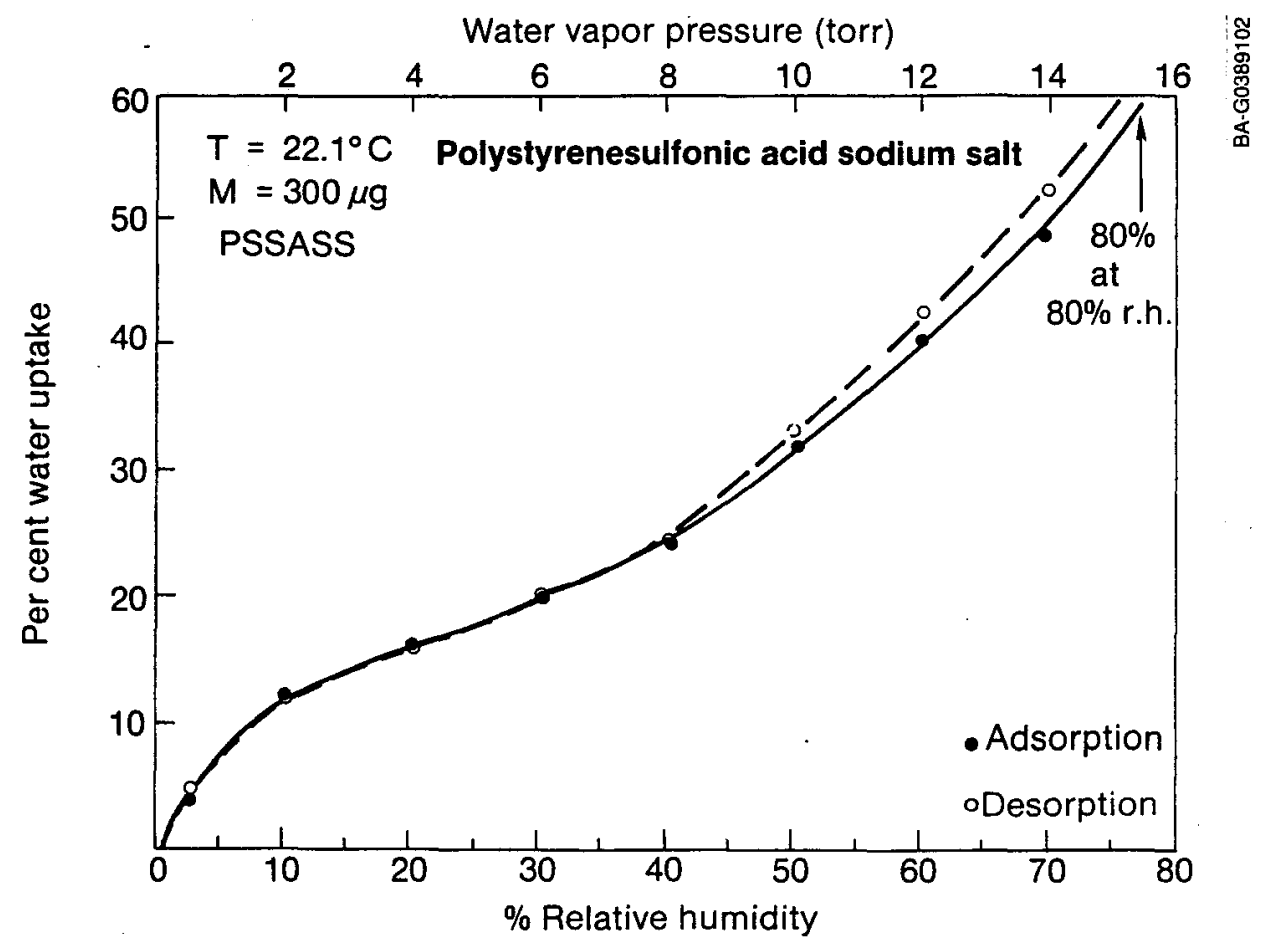

Figure 5-1. Water Vapor Sorption Isotherm for PSSASS at $22.1^{\circ} \mathrm{C}$ 


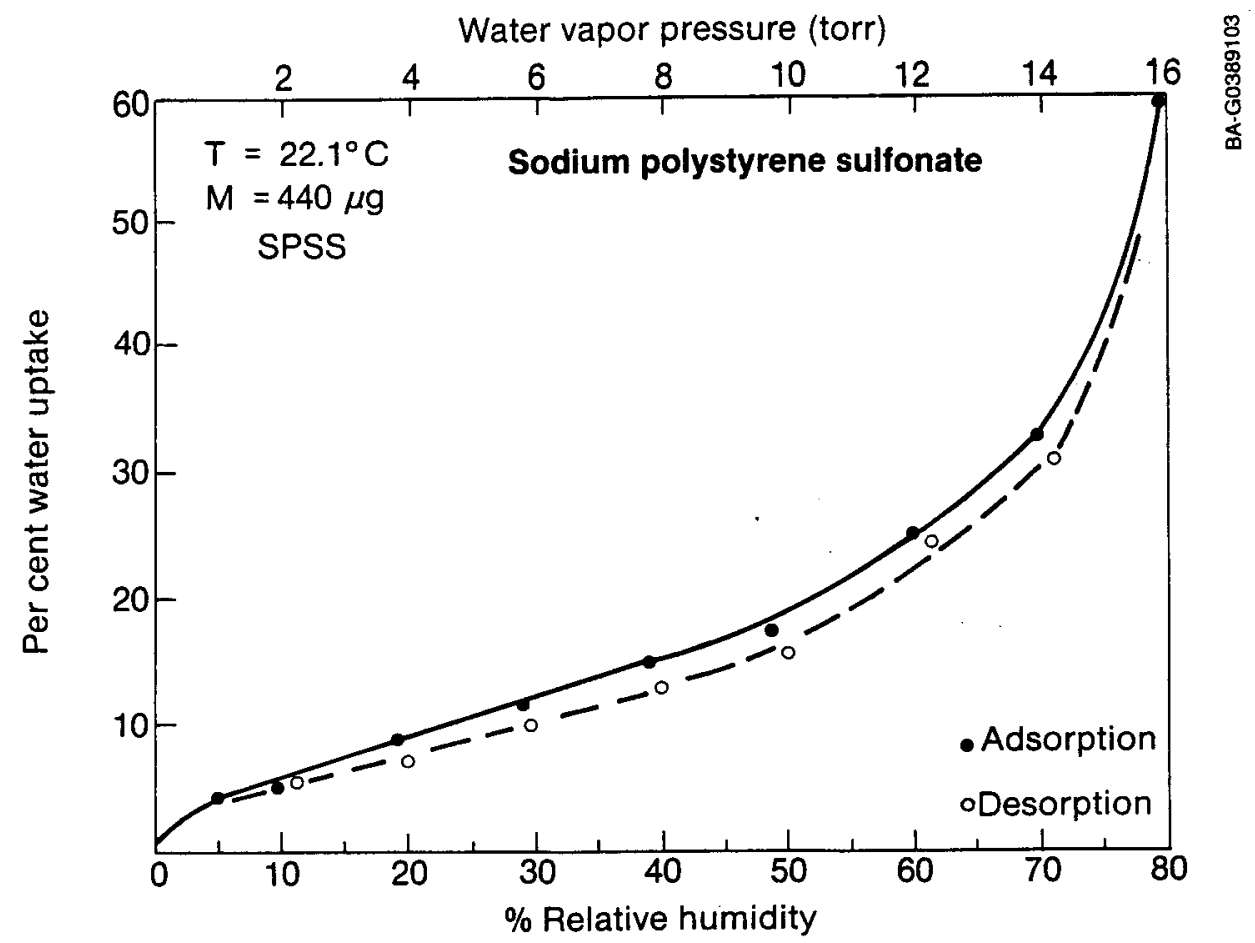

Figure 5-2. Water Vapor Sorption Isotherm for SPSS at $22.1^{\circ} \mathrm{C}$

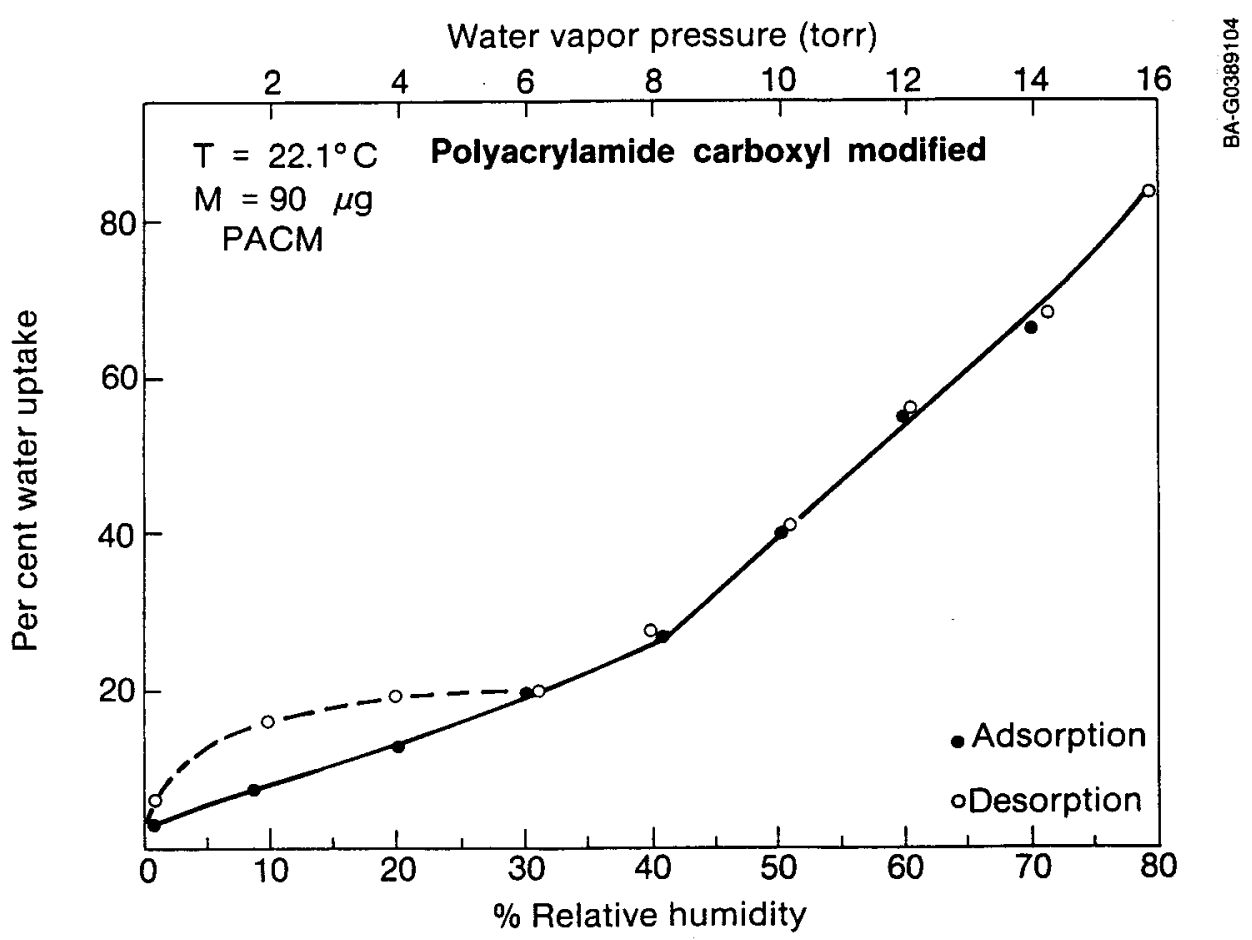

Figure 5-3. Water Vapor Sorption Isotherm for PACM at $22.1^{\circ} \mathrm{C}$ 


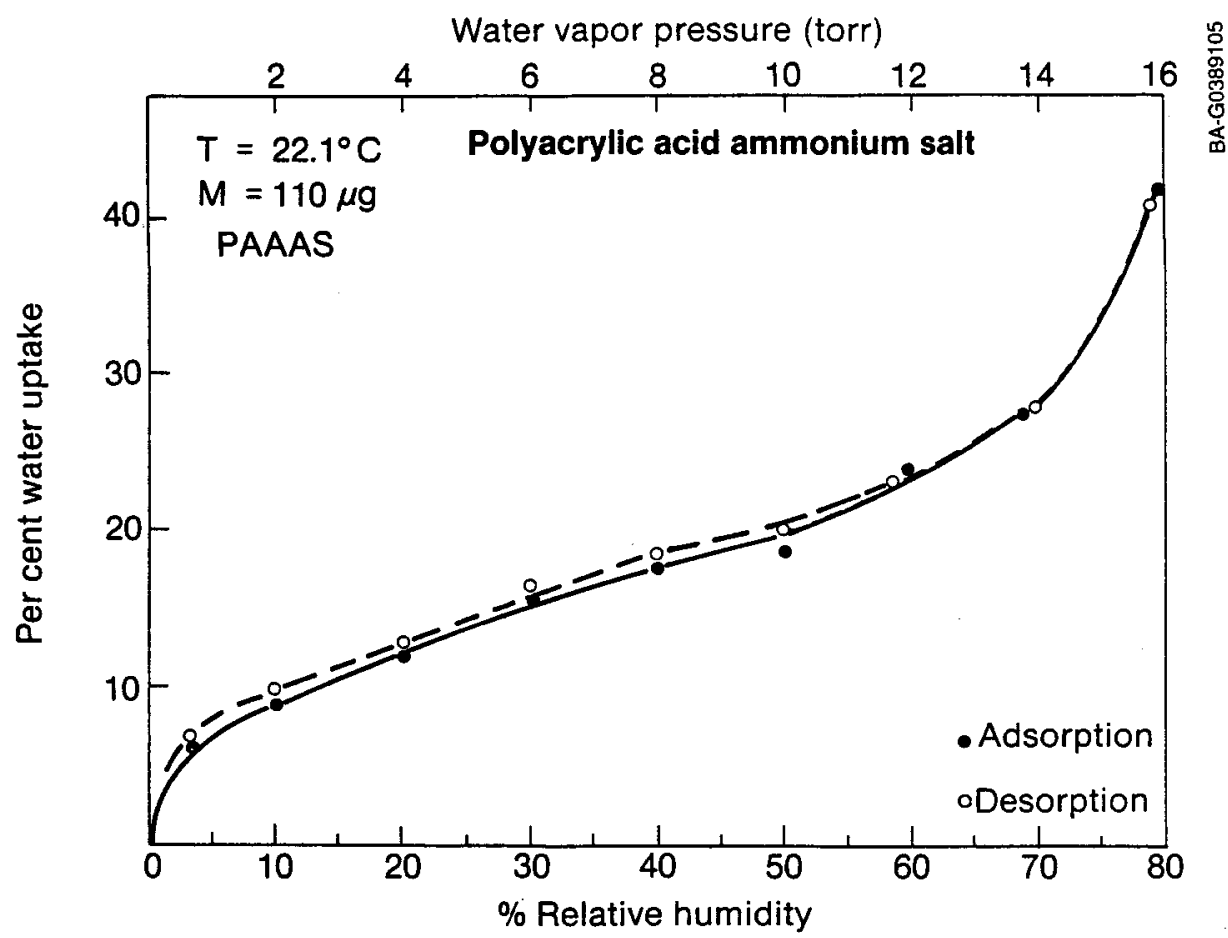

Figure 5-4. Water Vapor Sorption Isotherm for PAAAS at $22.1^{\circ} \mathrm{C}$

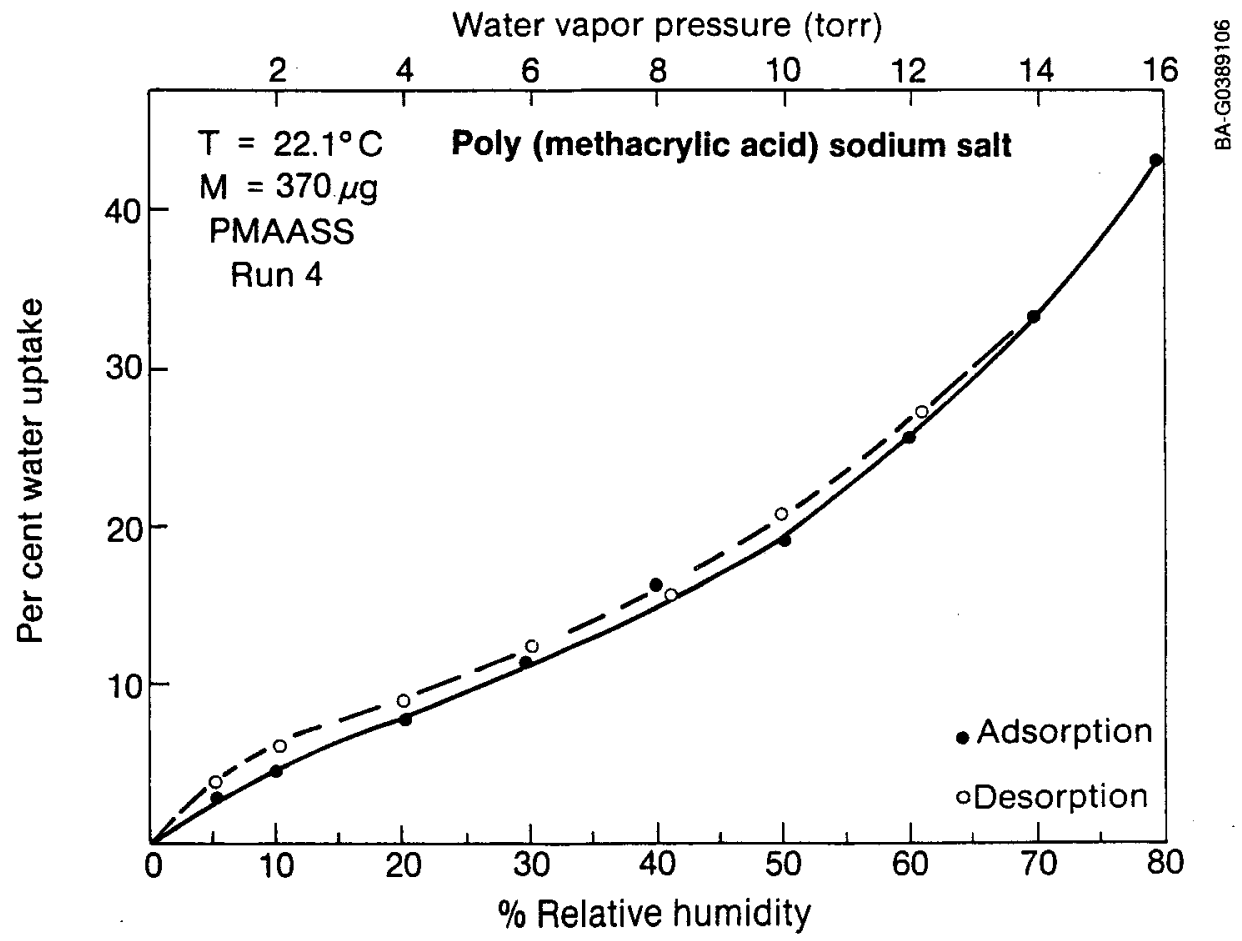

Figure 5-5. Water Vapor Sorption Isotherm for PMAASS at $22.1^{\circ} \mathrm{C}$ 


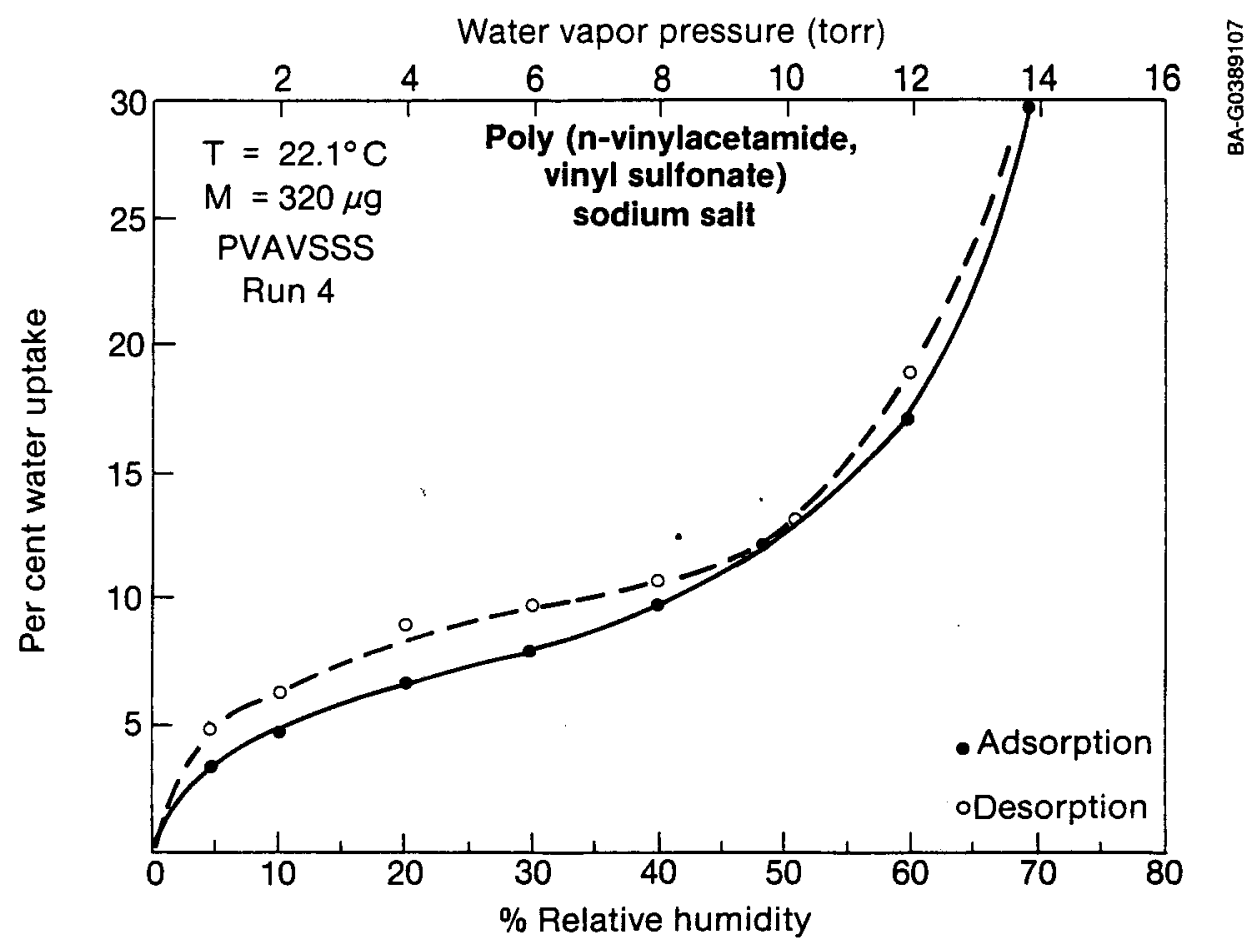

Figure 5-6. Water Vapor Sorption Isotherm for PVAVSSS at $22.1^{\circ} \mathrm{C}$

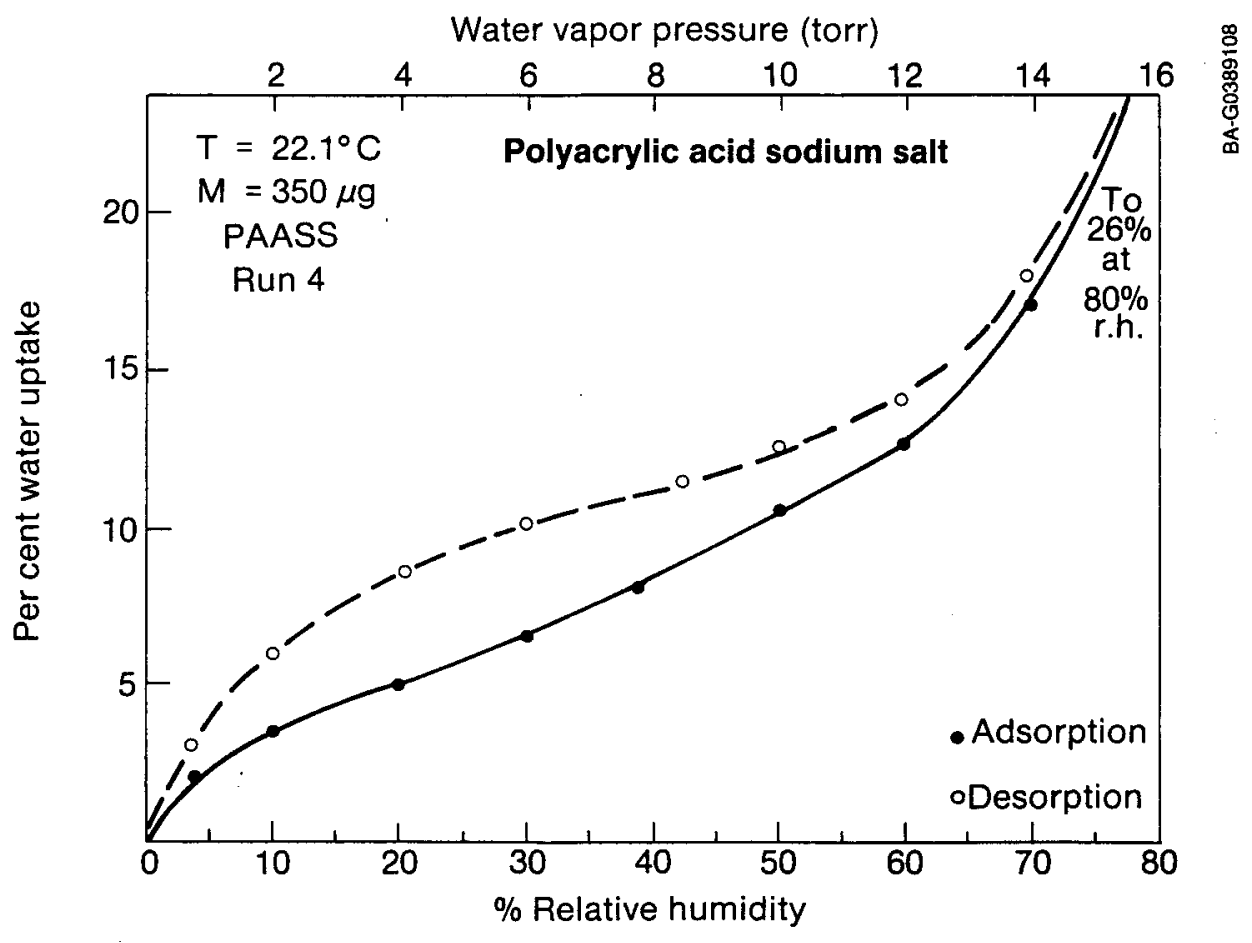

Figure 5-7. Water Vapor Sorption Isotherm for PAASS at $22.1^{\circ} \mathrm{C}$ 


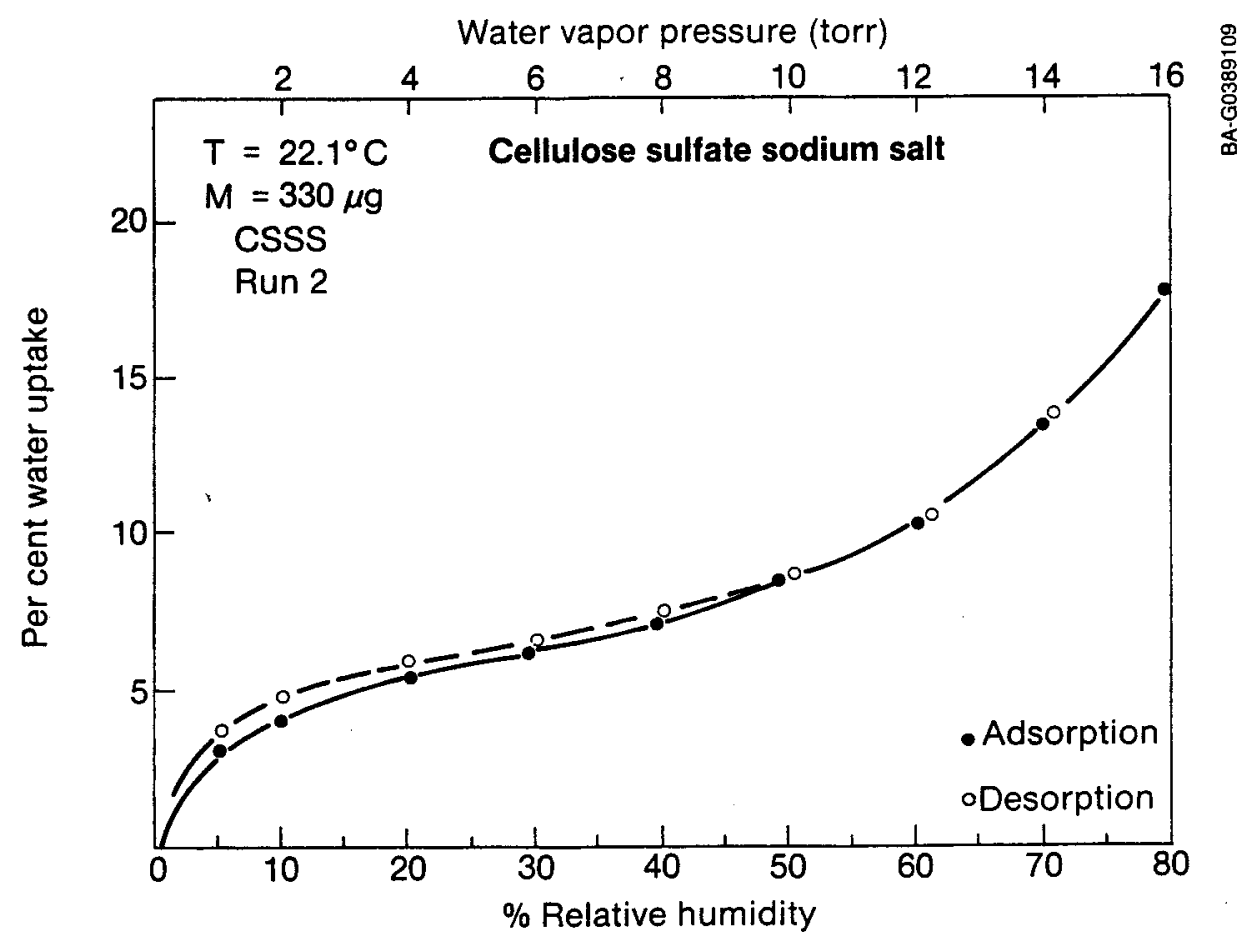

Figure 5-8. Water Vapor Sorption Isotherm for CSSS at $22.1^{\circ} \mathrm{C}$

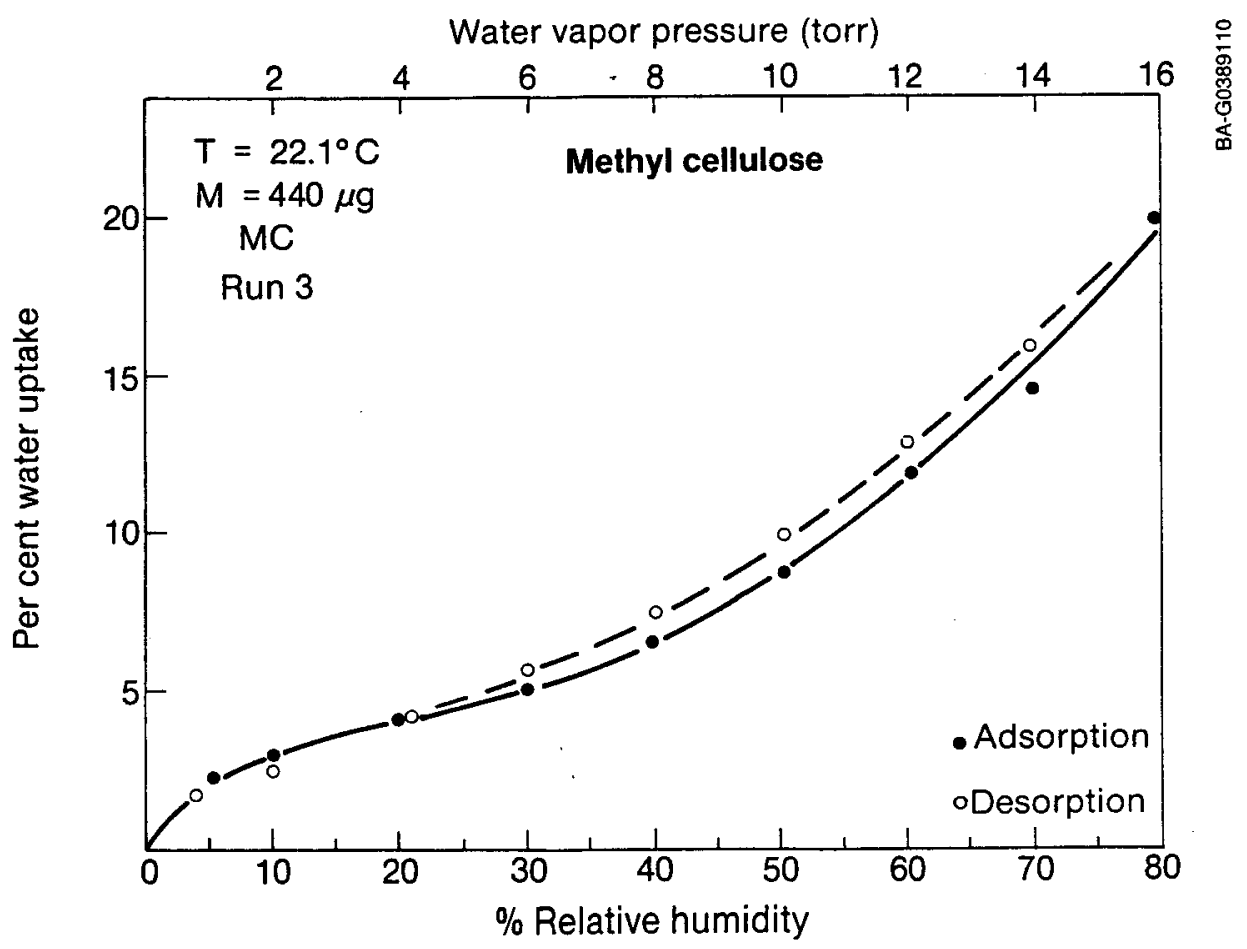

Figure 5-9. Water Vapor Sorption Isotherm for MC at $22.1^{\circ} \mathrm{C}$ 


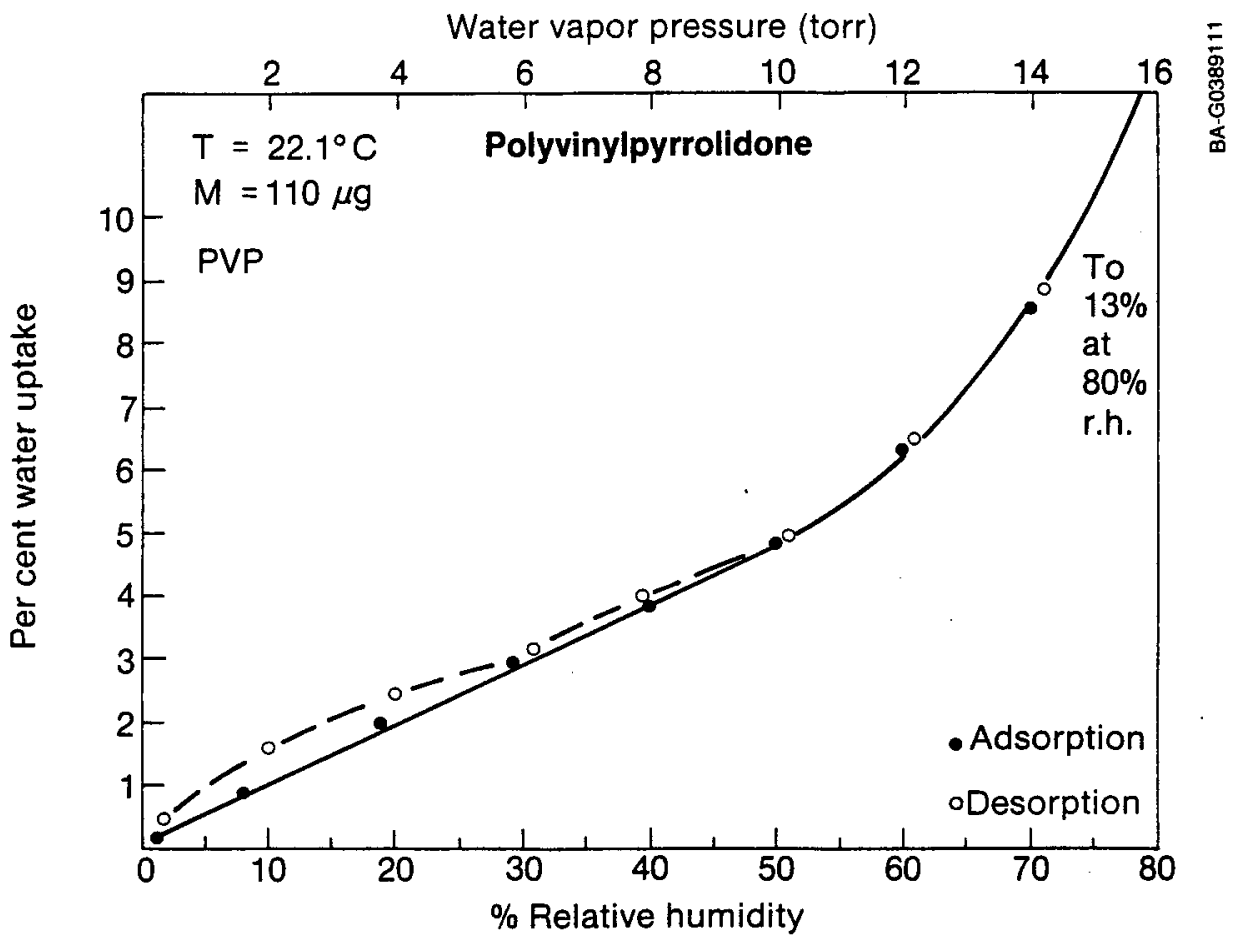

Figure 5-10. Water Vapor Sorption Isotherm for PVP at $22.1^{\circ} \mathrm{C}$

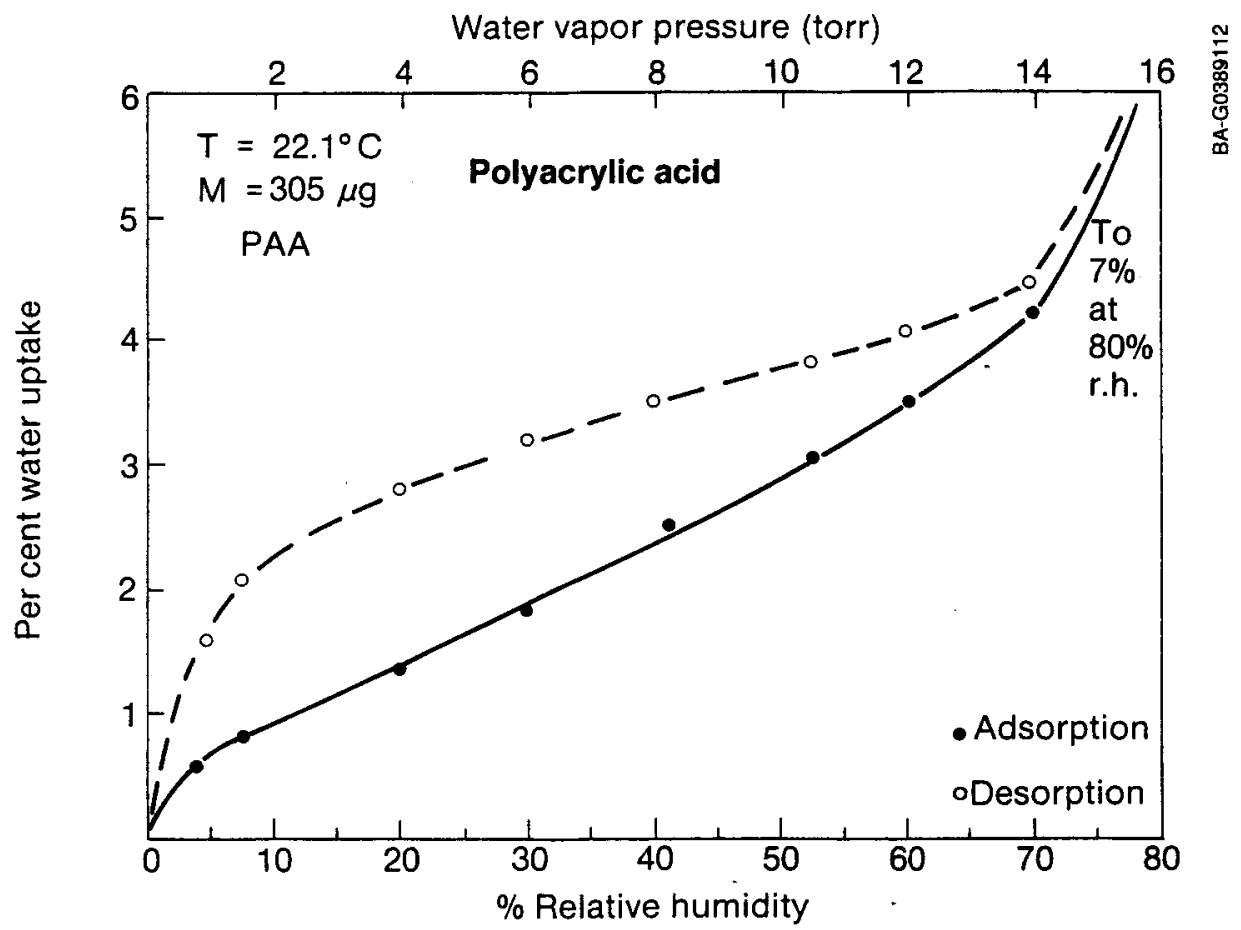

Figure 5-11. Water Vapor Sorption Isotherm for PAA at $22.1^{\circ} \mathrm{C}$ 


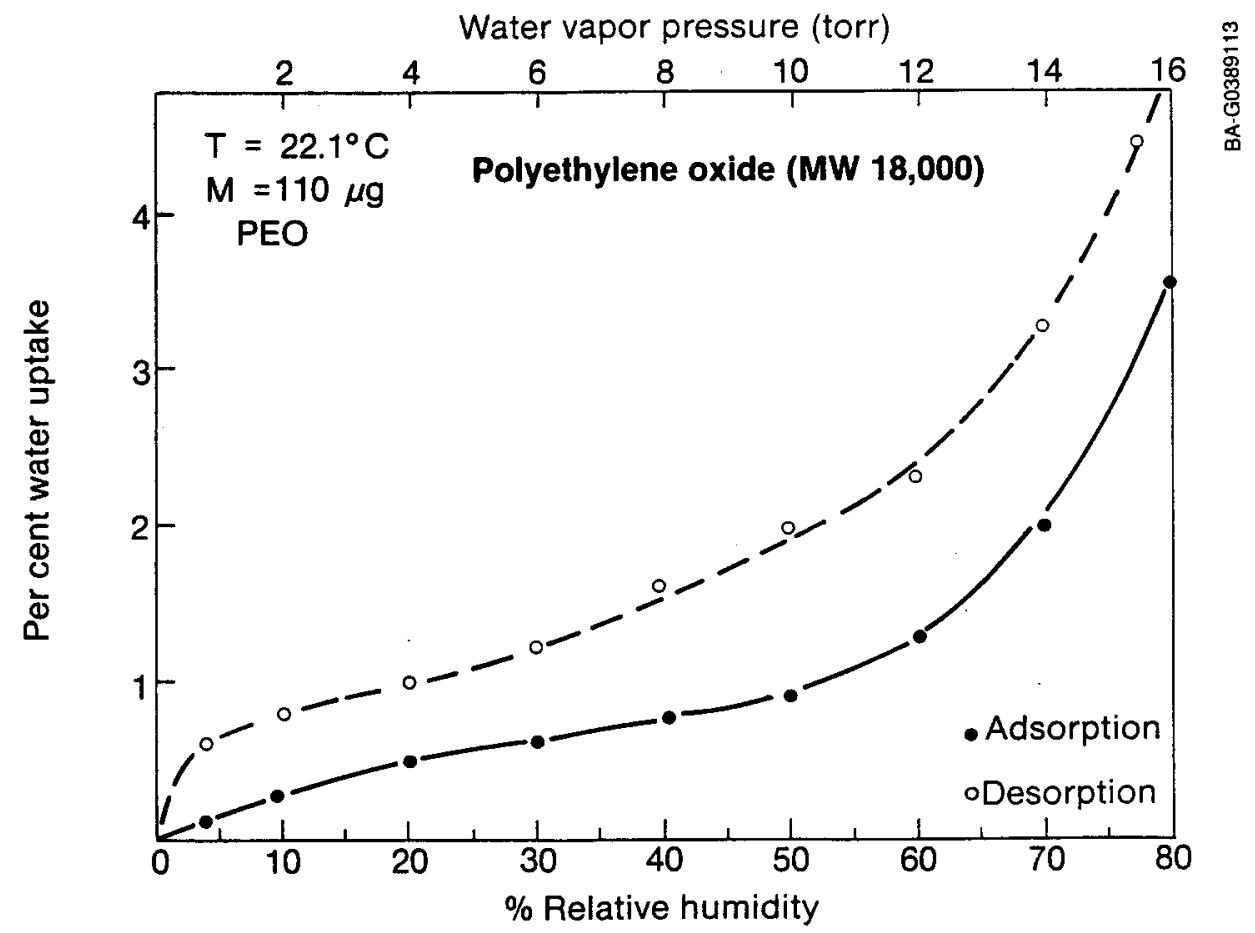

Figure 5-12. Water Vapor Sorption Isotherm for PEO at $22.1^{\circ} \mathrm{C}$

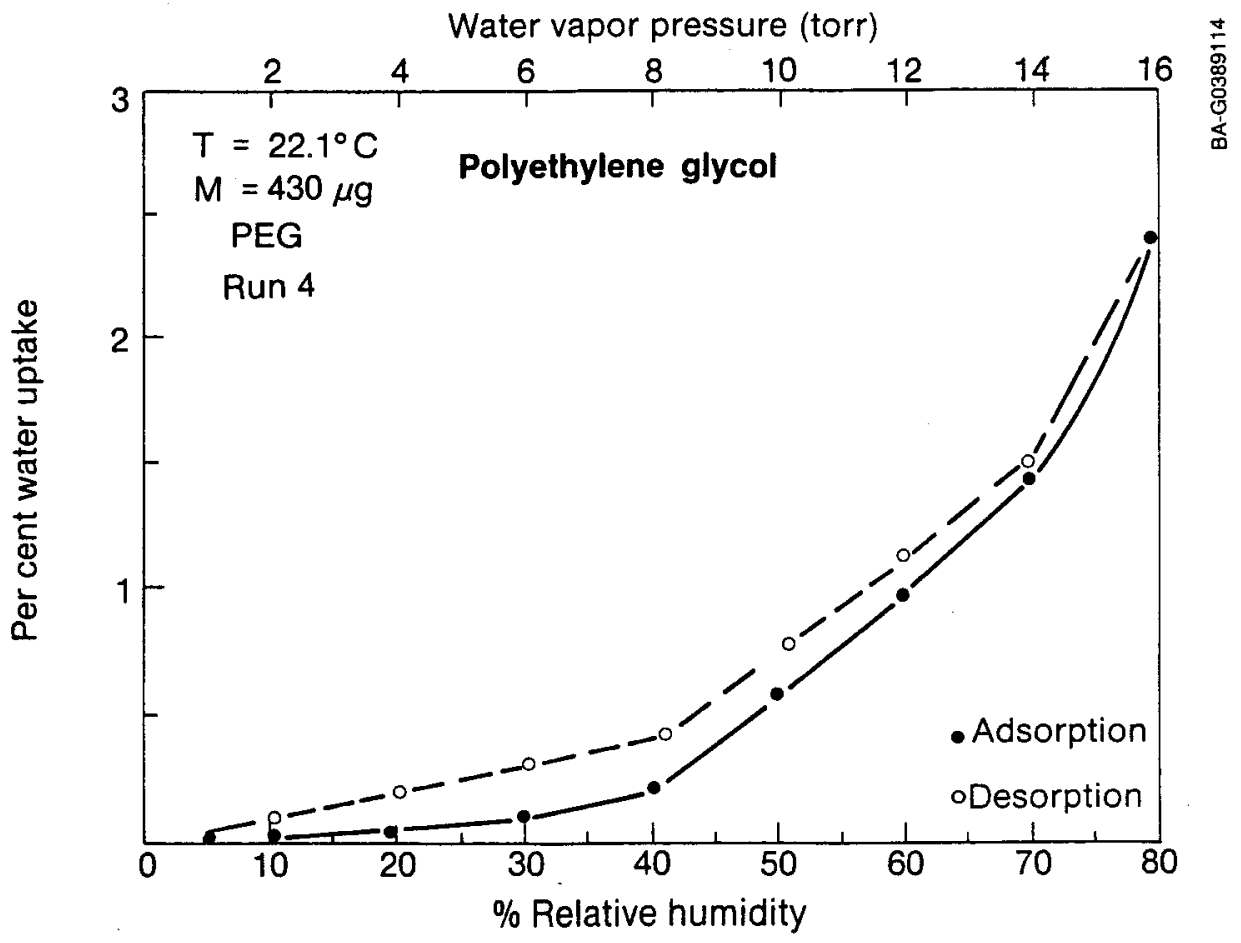

Figure 5-13. Water Vapor Sorption Isotherm for PEG at $22.1^{\circ} \mathrm{C}$ 


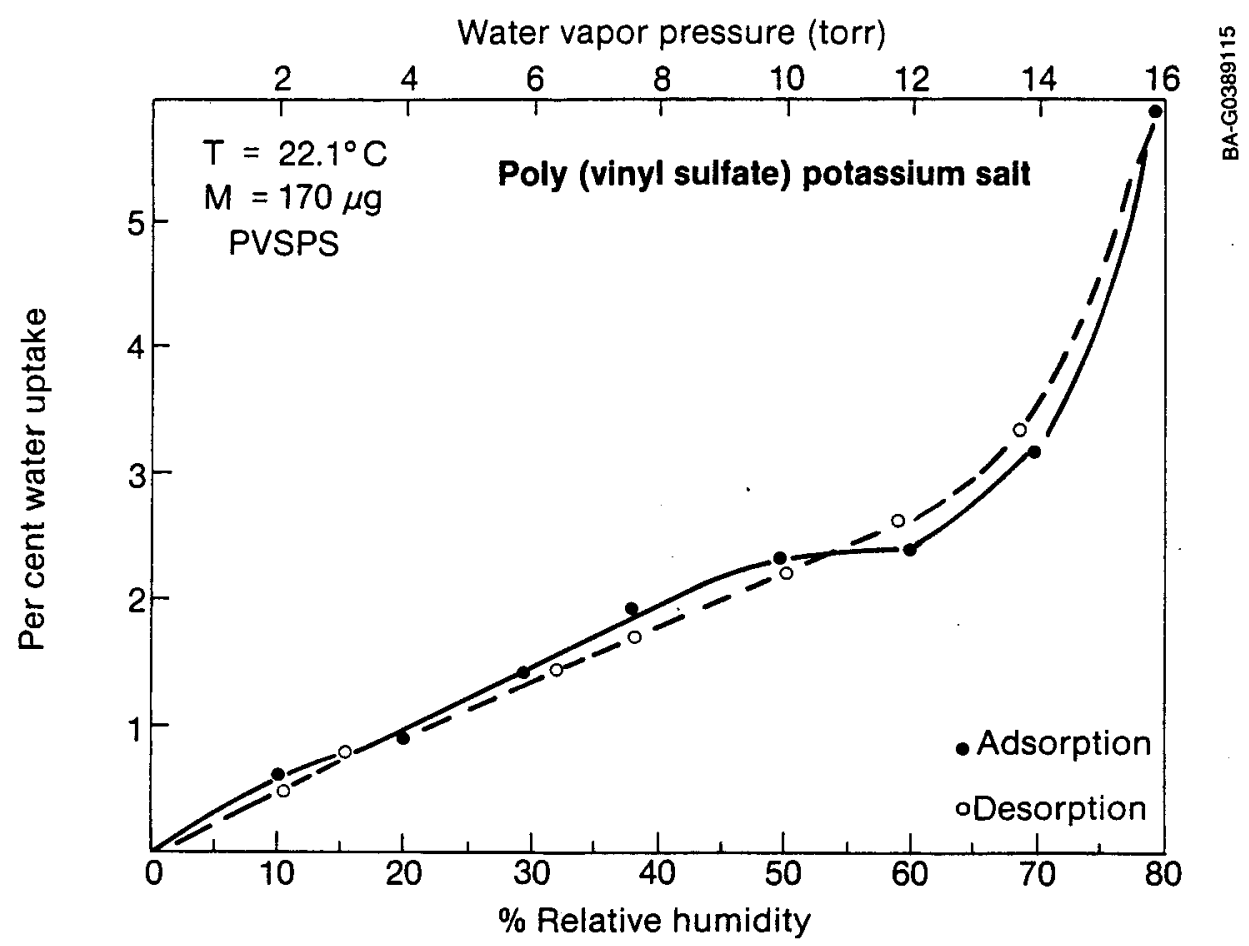

Figure 5-14. Water Vapor Sorption Isotherm for PVSPS at $22.1^{\circ} \mathrm{C}$

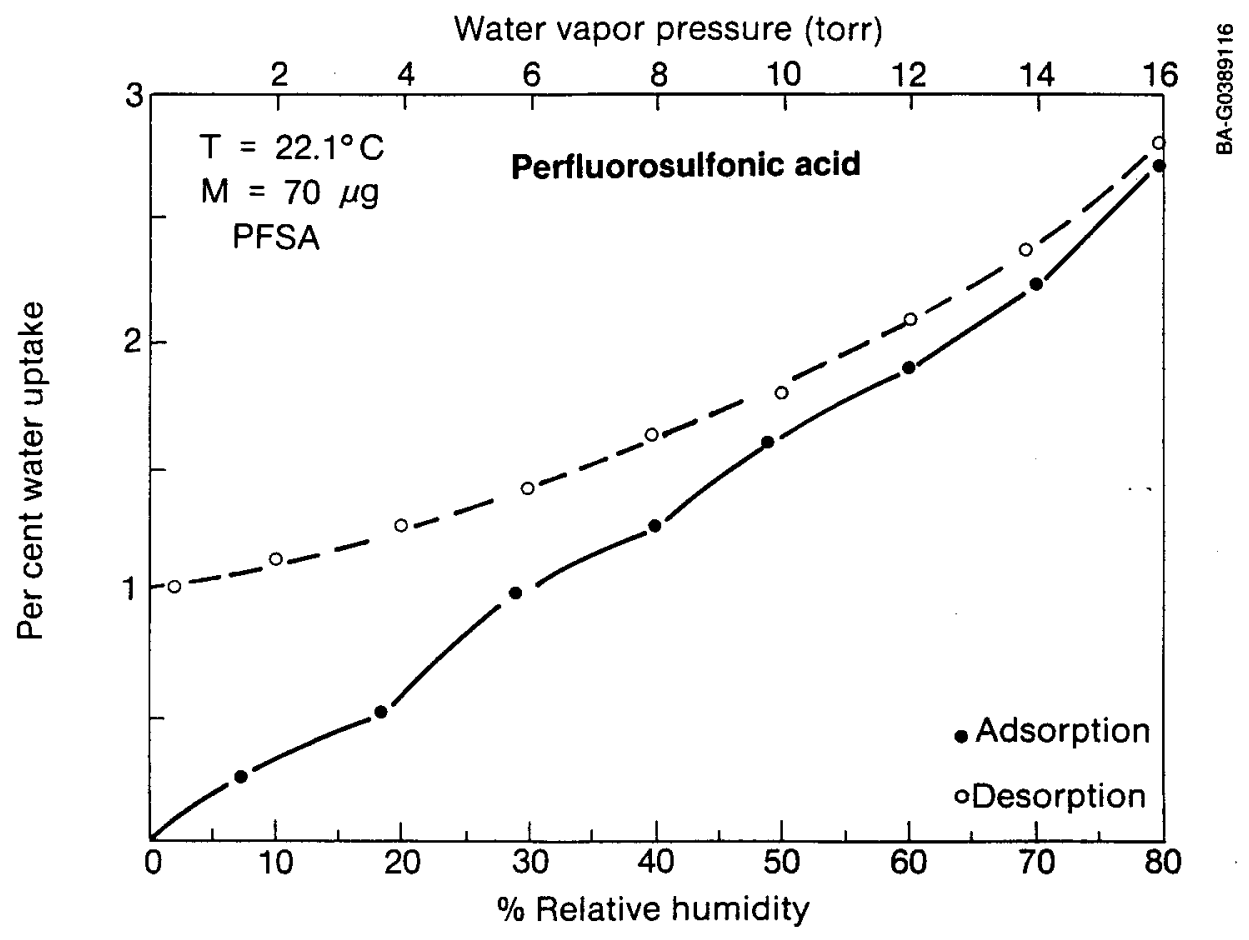

Figure 5-15. Water Vapor Sorption Isotherm for PFSA at $22.1^{\circ} \mathrm{C}$ 


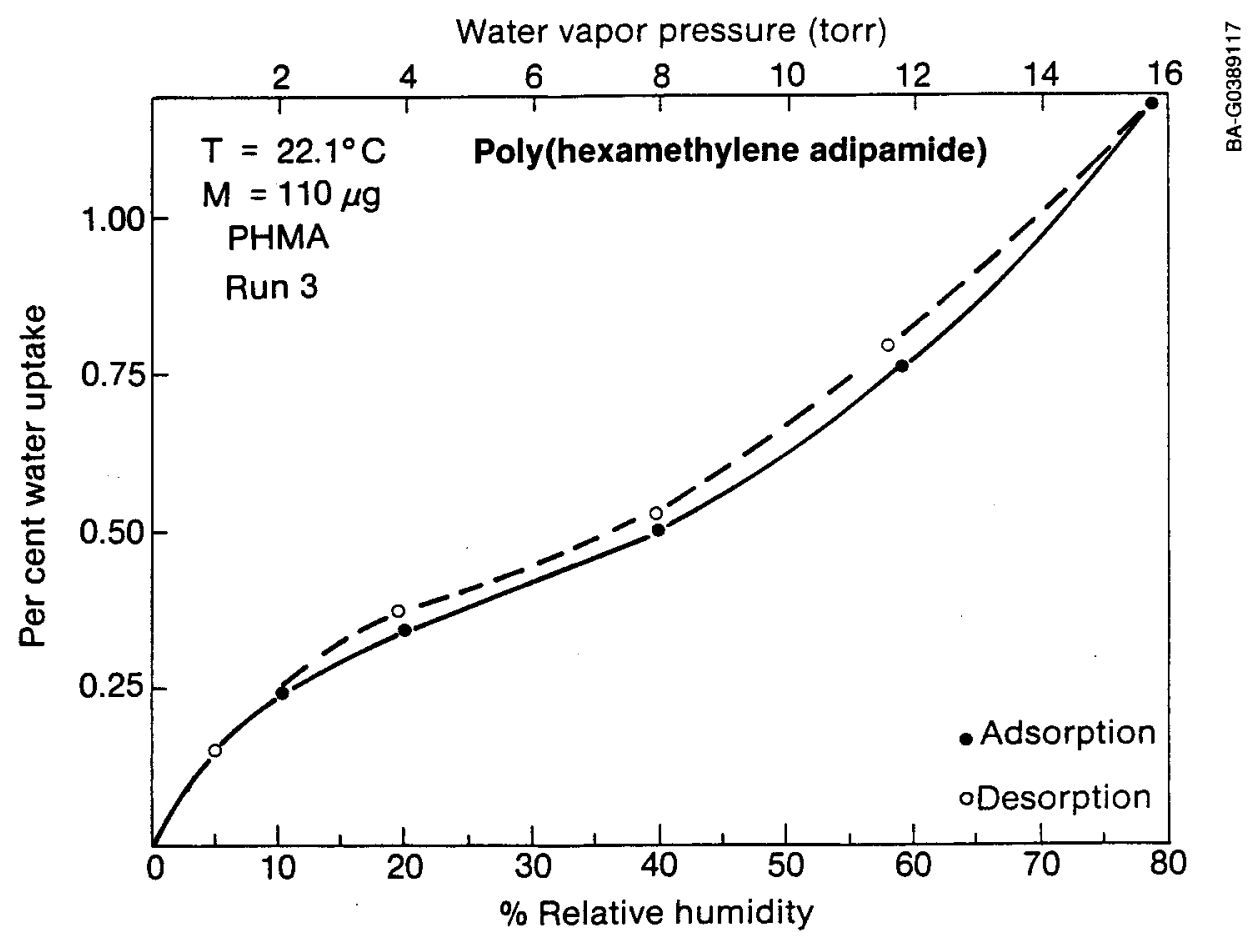

Figure 5-16. Water Vapor Sorption Isotherm for PHMA at $22.1^{\circ} \mathrm{C}$

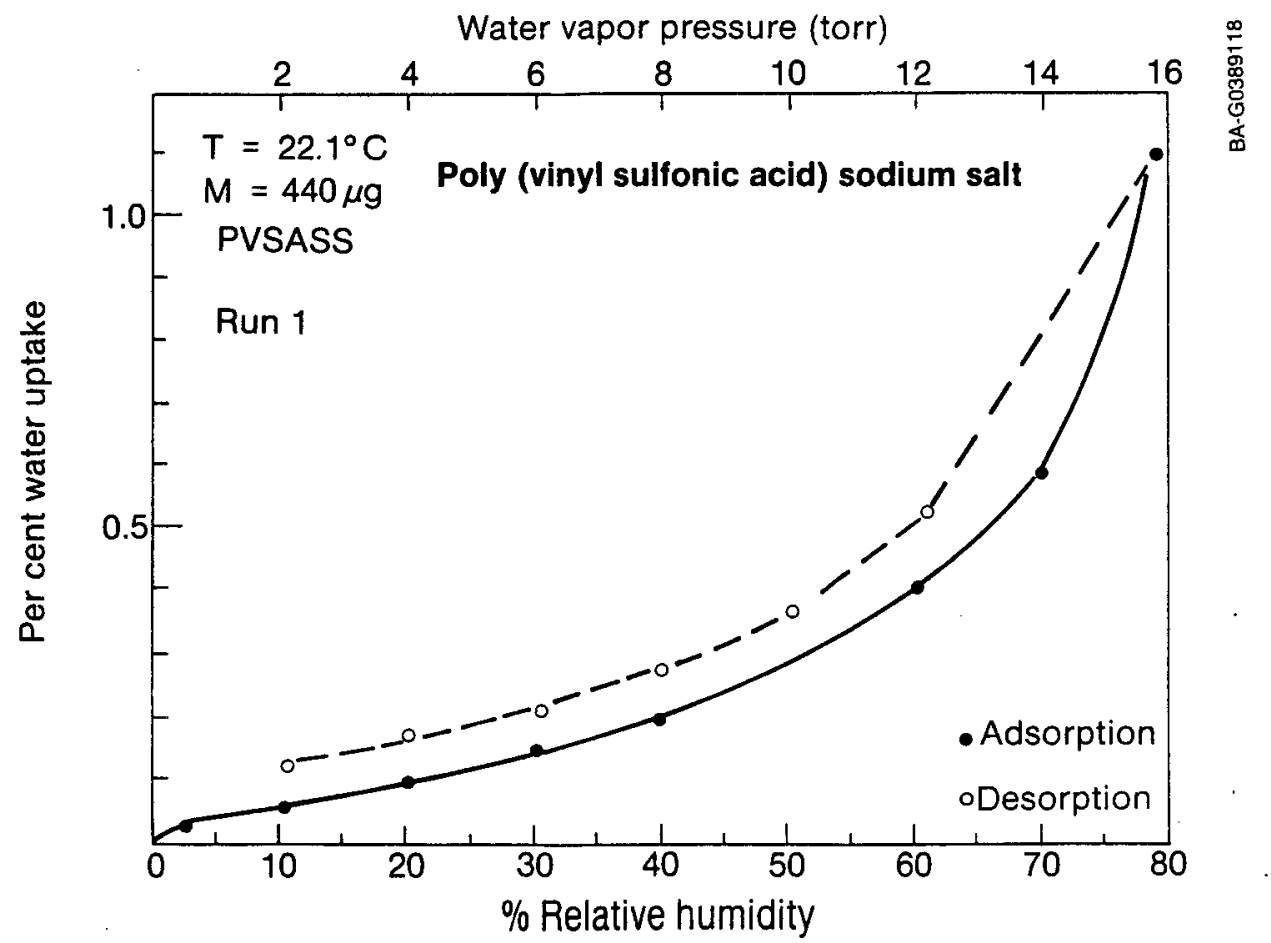

Figure 5-17. Water Vapor Sorption Isotherm for PVSASS at $22.1^{\circ} \mathrm{C}$ 


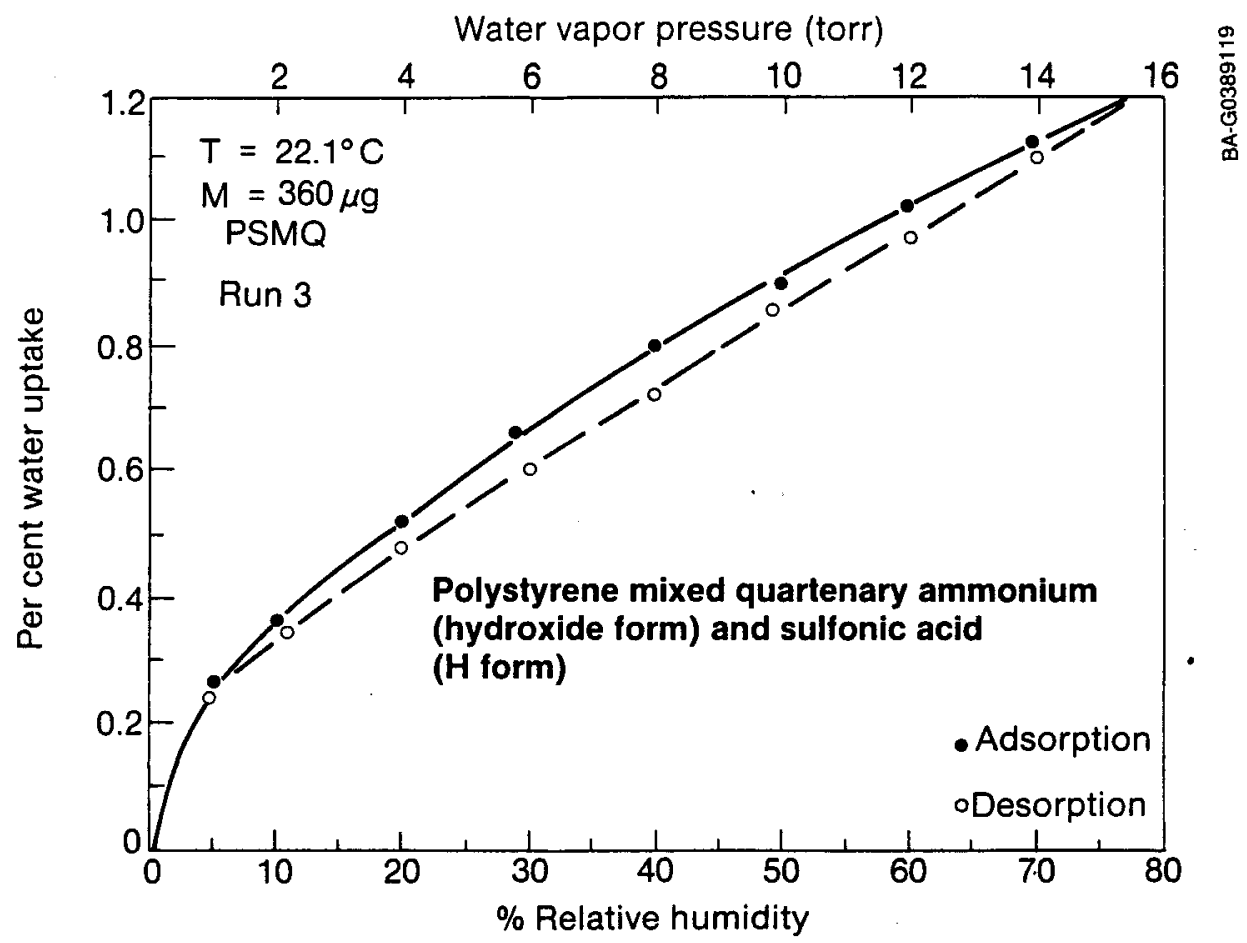

Figure 5-18. Water Vapor Sorption Isotherm for PSMQ at $22.1^{\circ} \mathrm{C}$

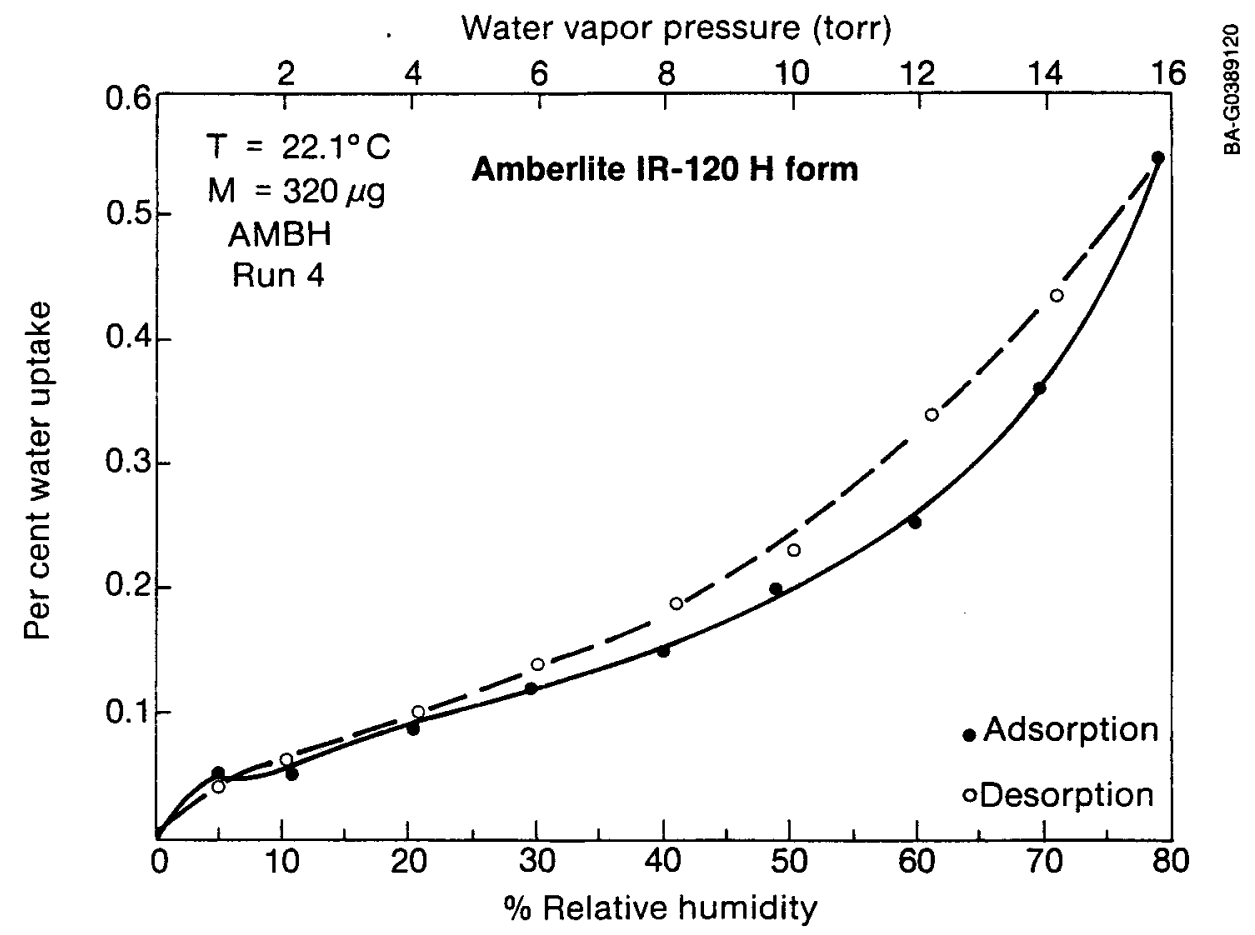

Figure 5-19. Water Vapor Sorption Isotherm for AMBH at $22.1^{\circ} \mathrm{C}$ 


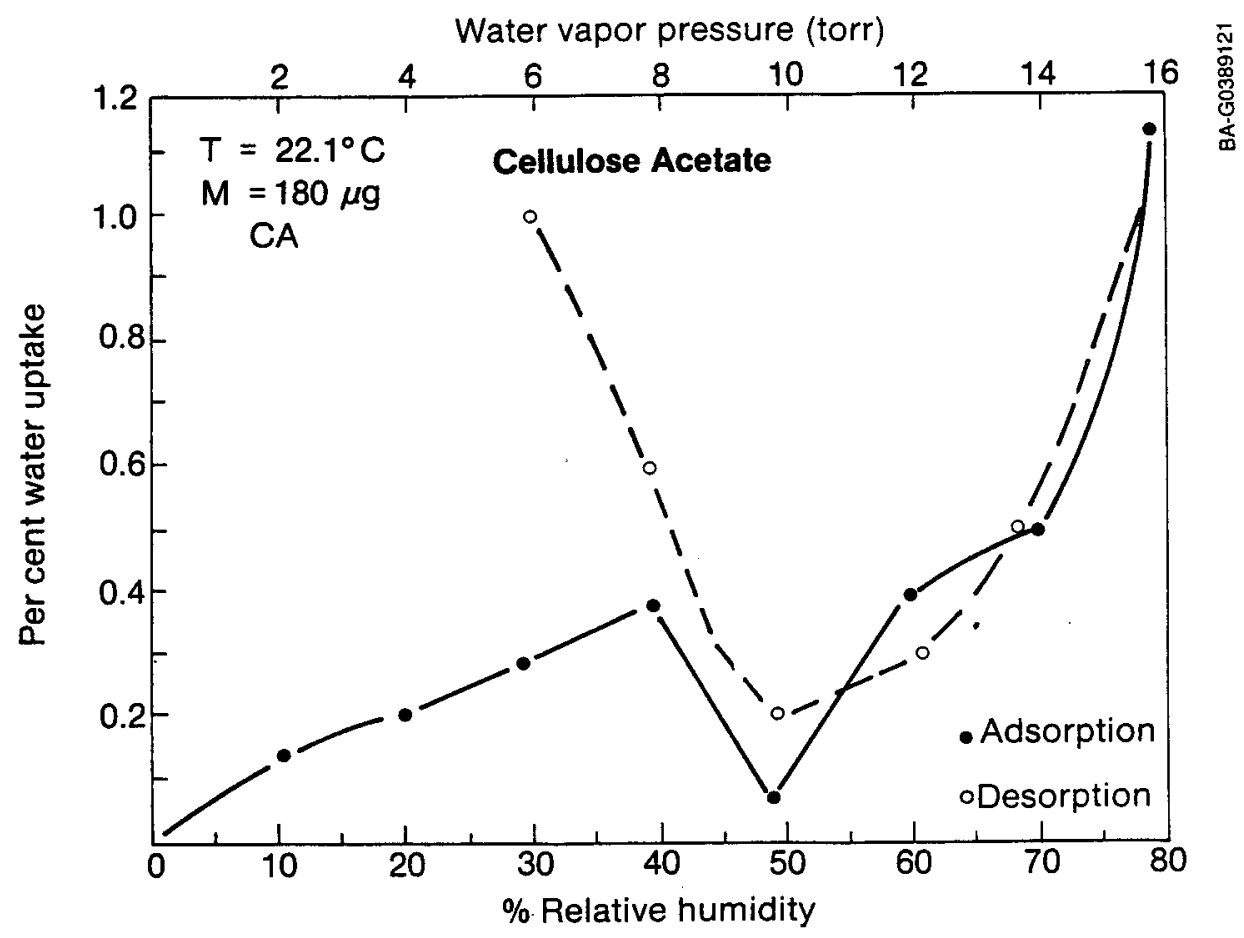

Figure 5-20. Water Vapor Sorption Isotherm for CA at $22.1^{\circ} \mathrm{C}$

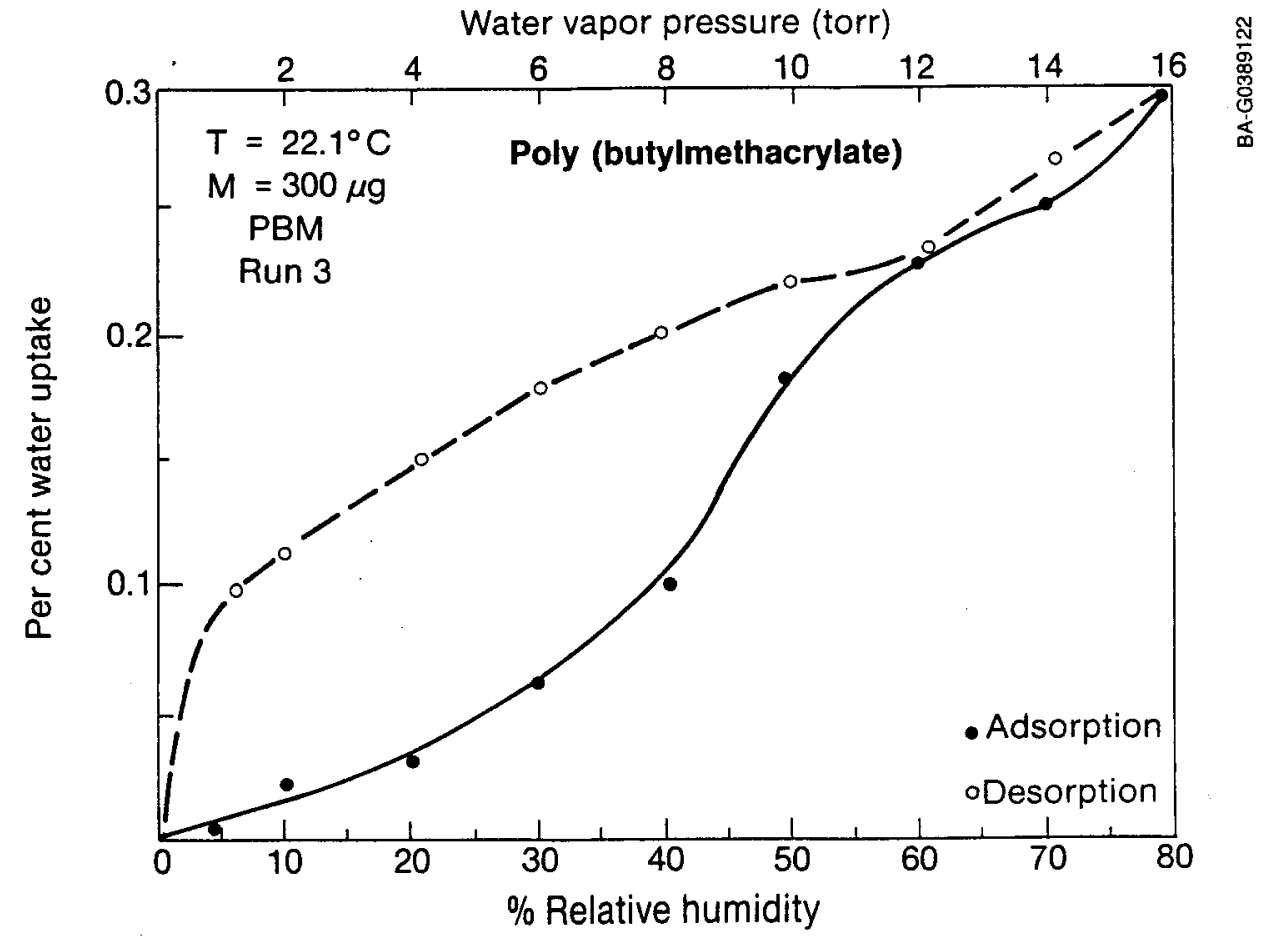

Figure 5-21. Water Vapor Sorption Isotherm for PBM at $22.1^{\circ} \mathrm{C}$ 


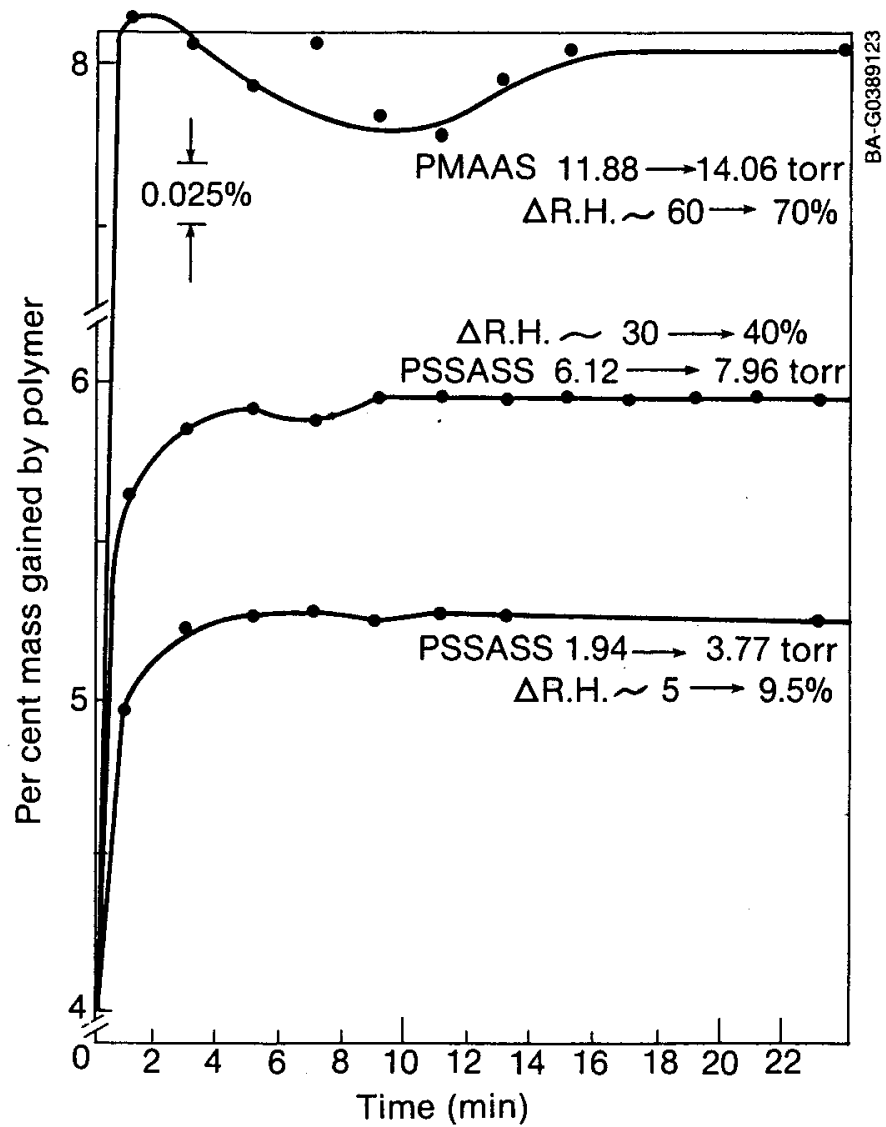

Figure 5-22. Water Vapor Adsorption by PMAASS and PSSASS at 70\%, $40 \%$ and 9.57 R.H. after Pressure Increases from $60 \%, 30 \%$, and $5 \%$ R.H., Respectively

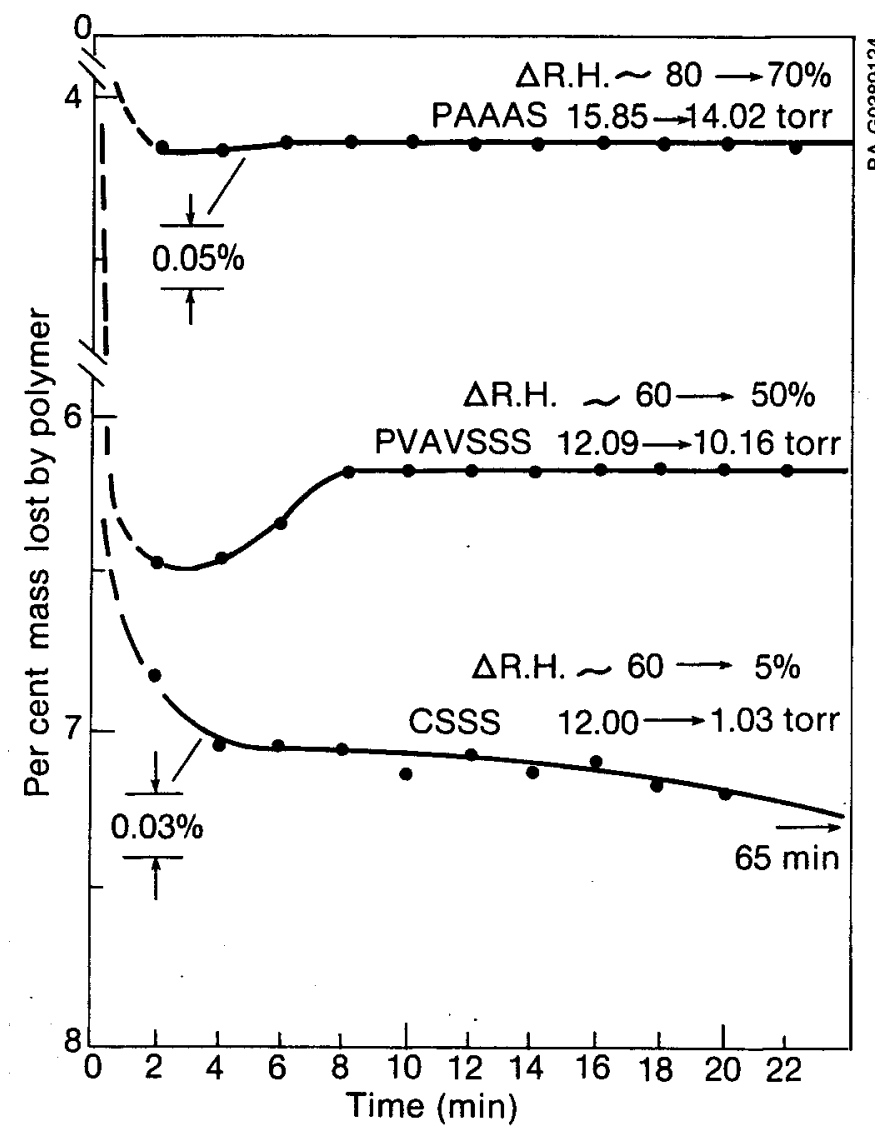

Figure 5-23. Water Vapor Desorption by PAAAS, PVAVSS and CSSS at 70\%, 50\%, and 5Z R.H. after Pressure Decreases from $807,60 \%$, and $60 \%$ R.H., Respectively 


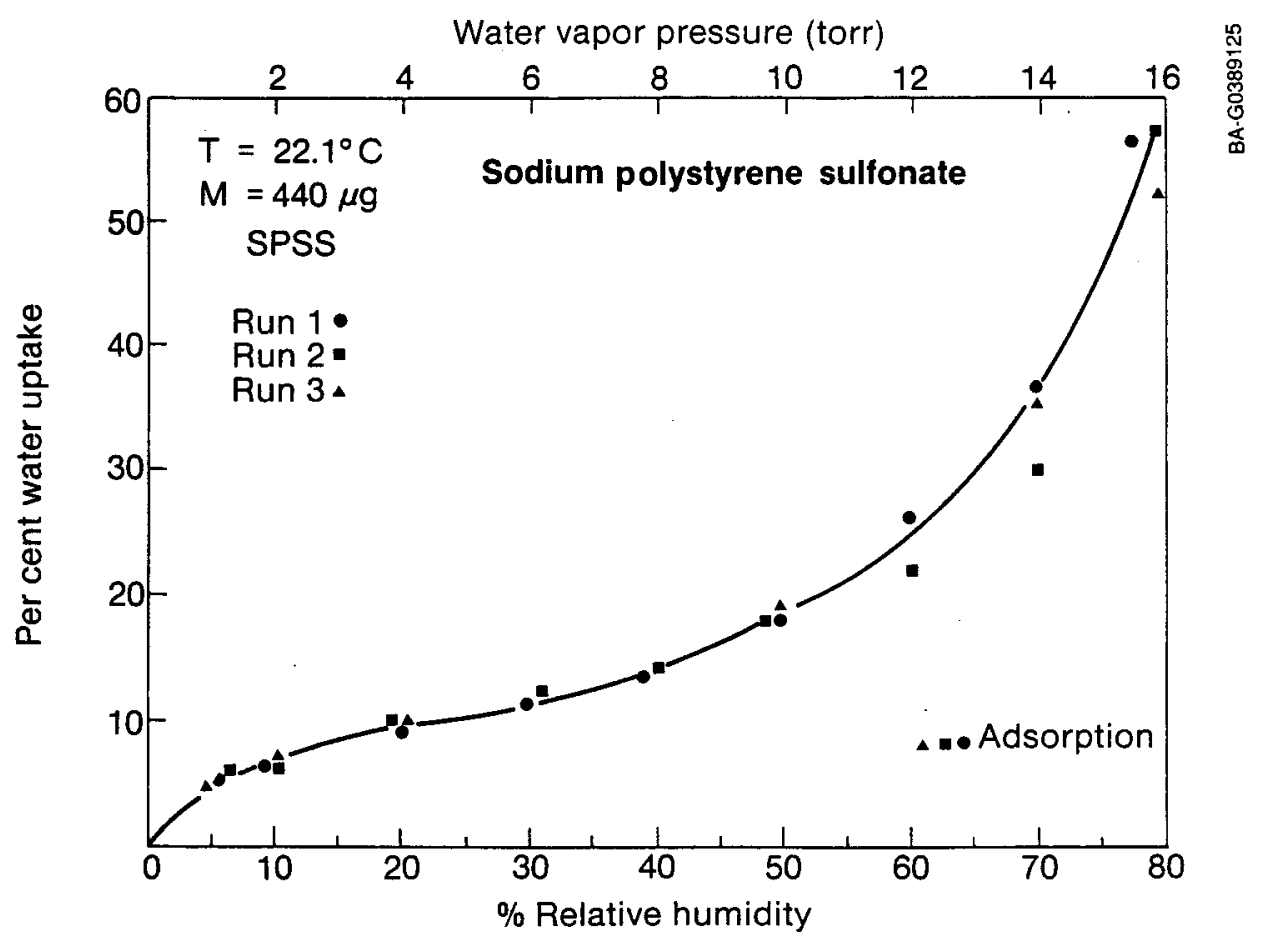

Figure 5-24. Water Vapor Sorption Isotherms for SPSS at $22.1^{\circ} \mathrm{C}$ (Three cycles)

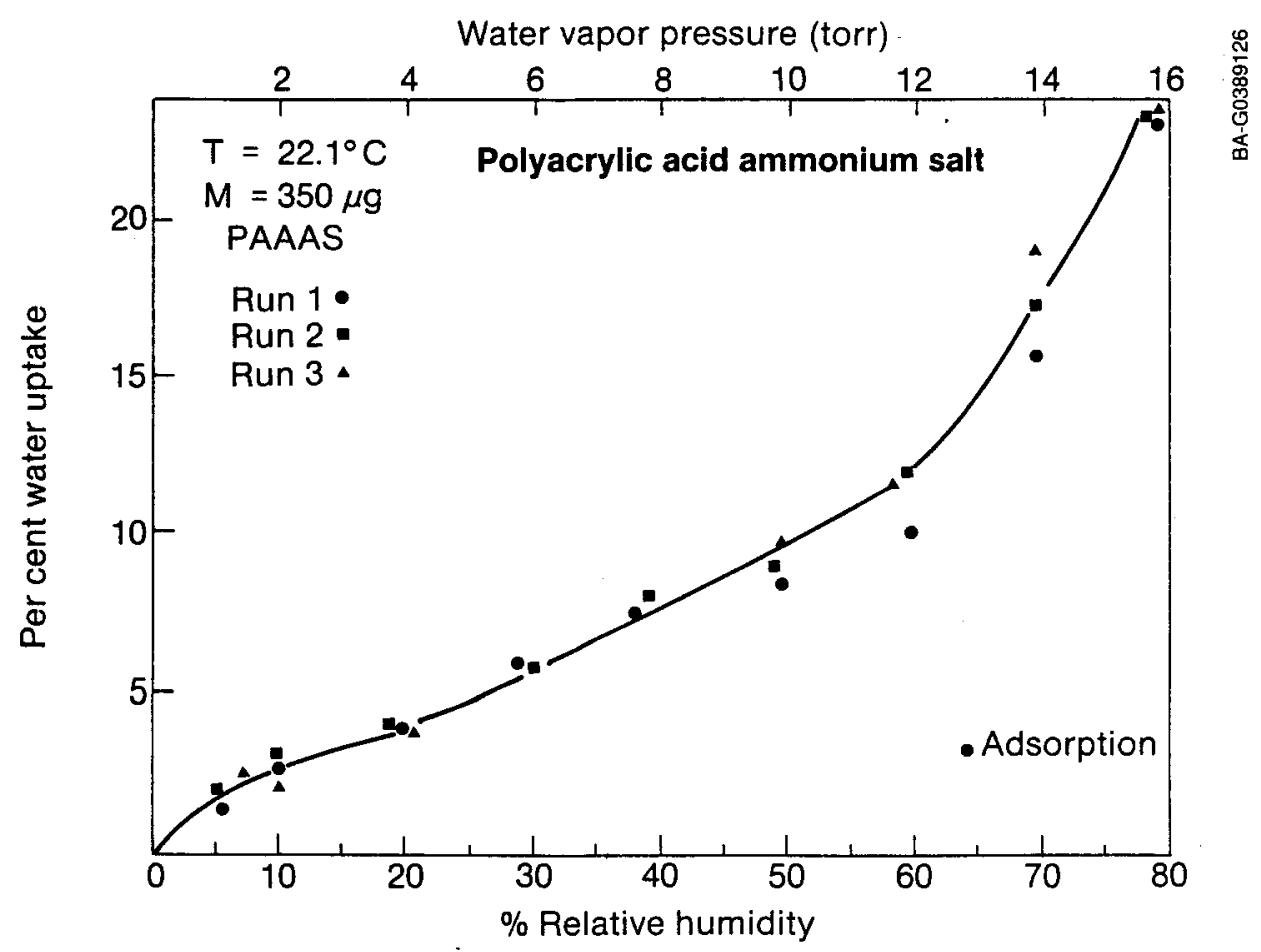

Figure 5-25. Water Vapor Sorption Isotherms for PAAAS at $22.1^{\circ} \mathrm{C}$ (Three cycles) 


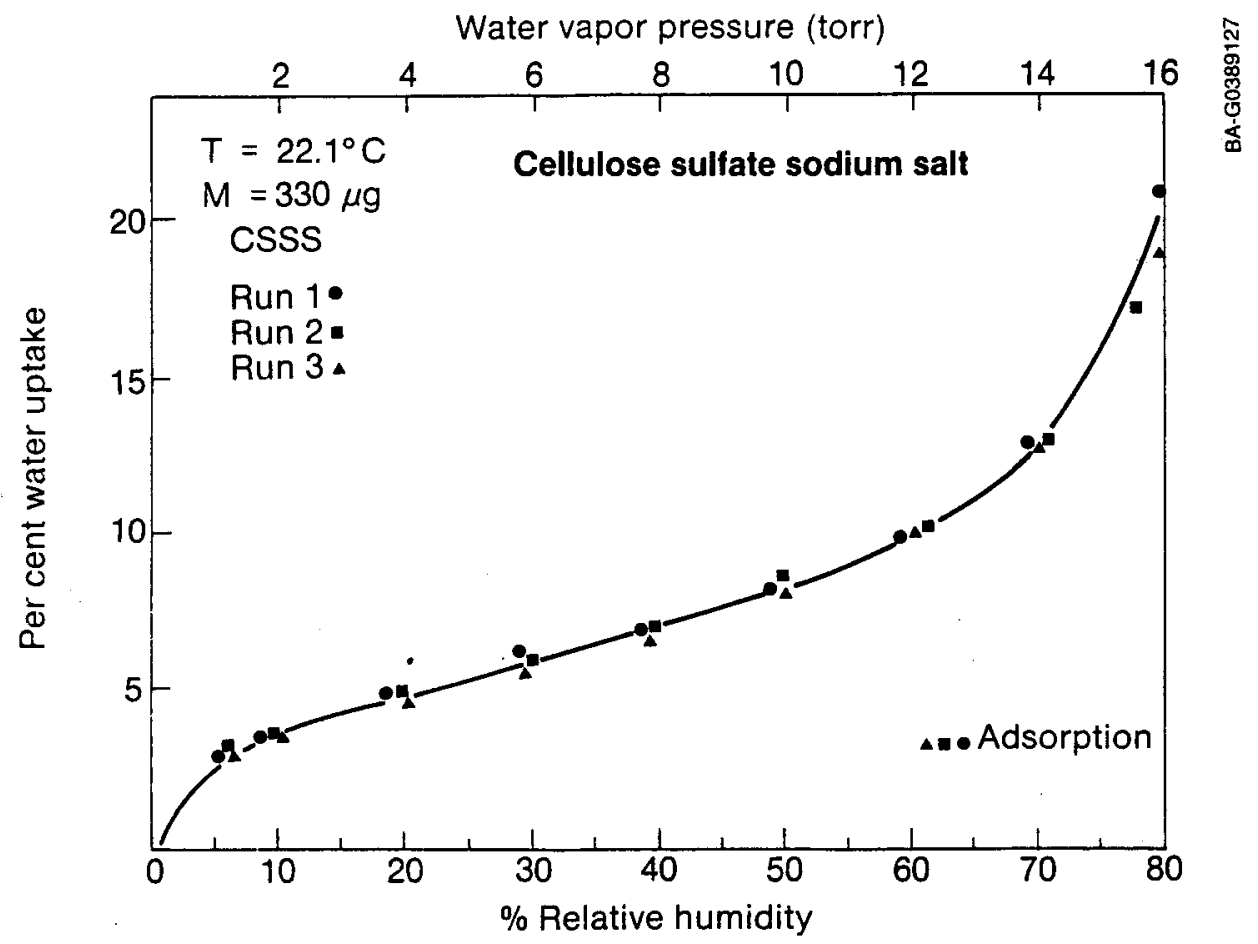

Figure 5-26. Water Vapor Sorption Isotherms for CSSS at $22.1^{\circ} \mathrm{C}$ (Three cycles)

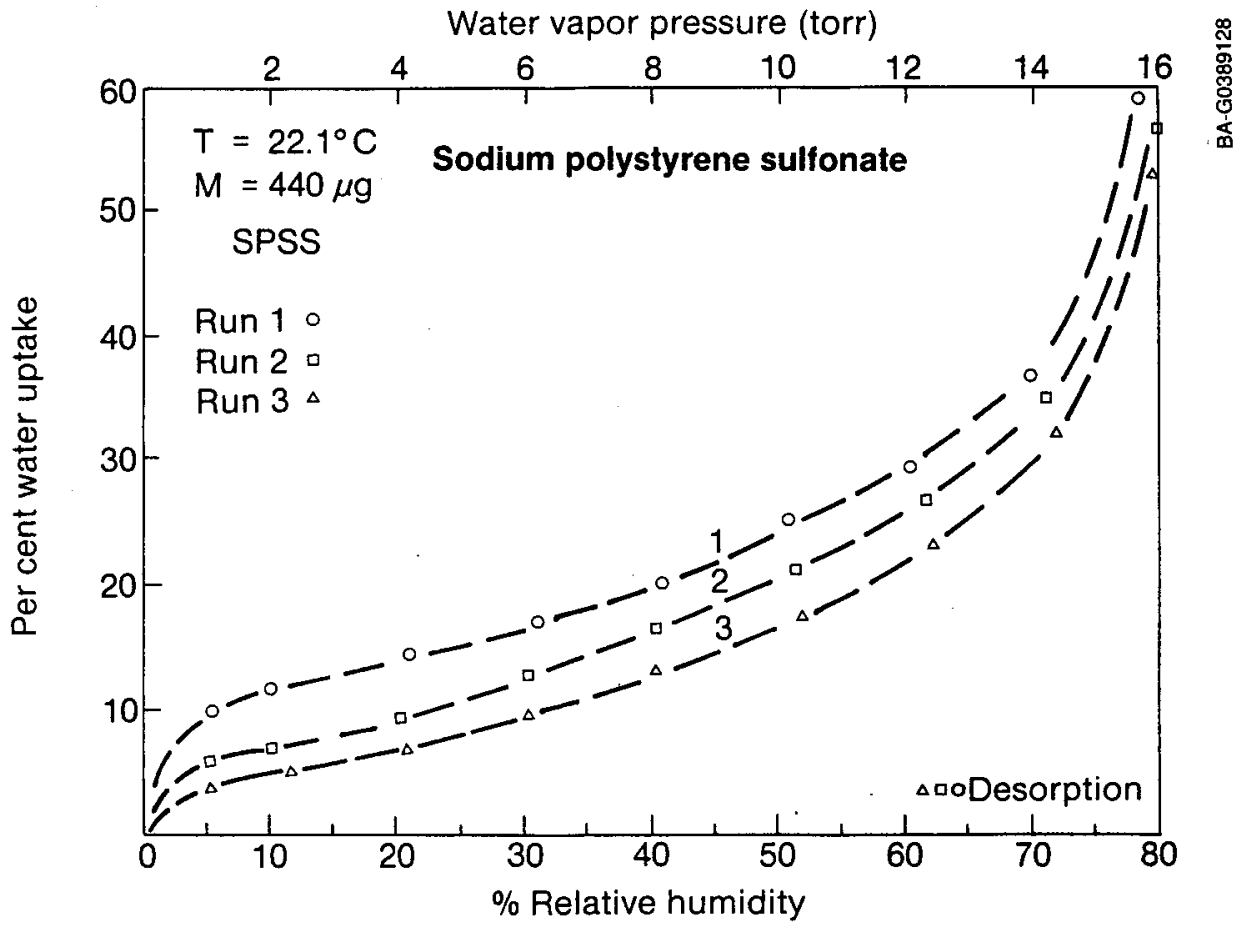

Figure 5-27. Water Vapor Desorption Isotherms for SPSS at $22.1^{\circ} \mathrm{C}$ (Three cycles) 


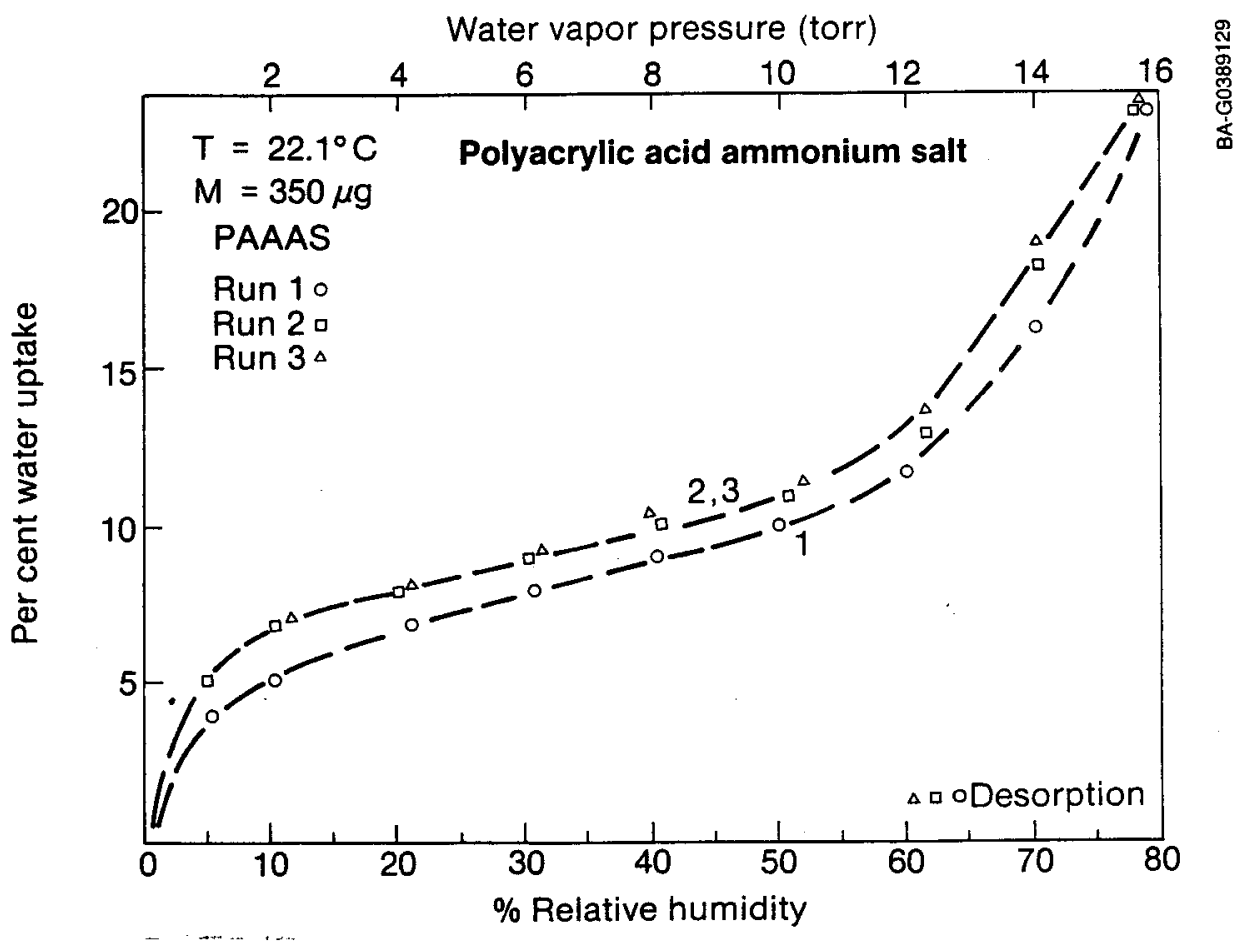

Figure 5-28. Water Vapor Desorption Isotherms for PAAAS at $22.1^{\circ} \mathrm{C}$ (Three cycles)

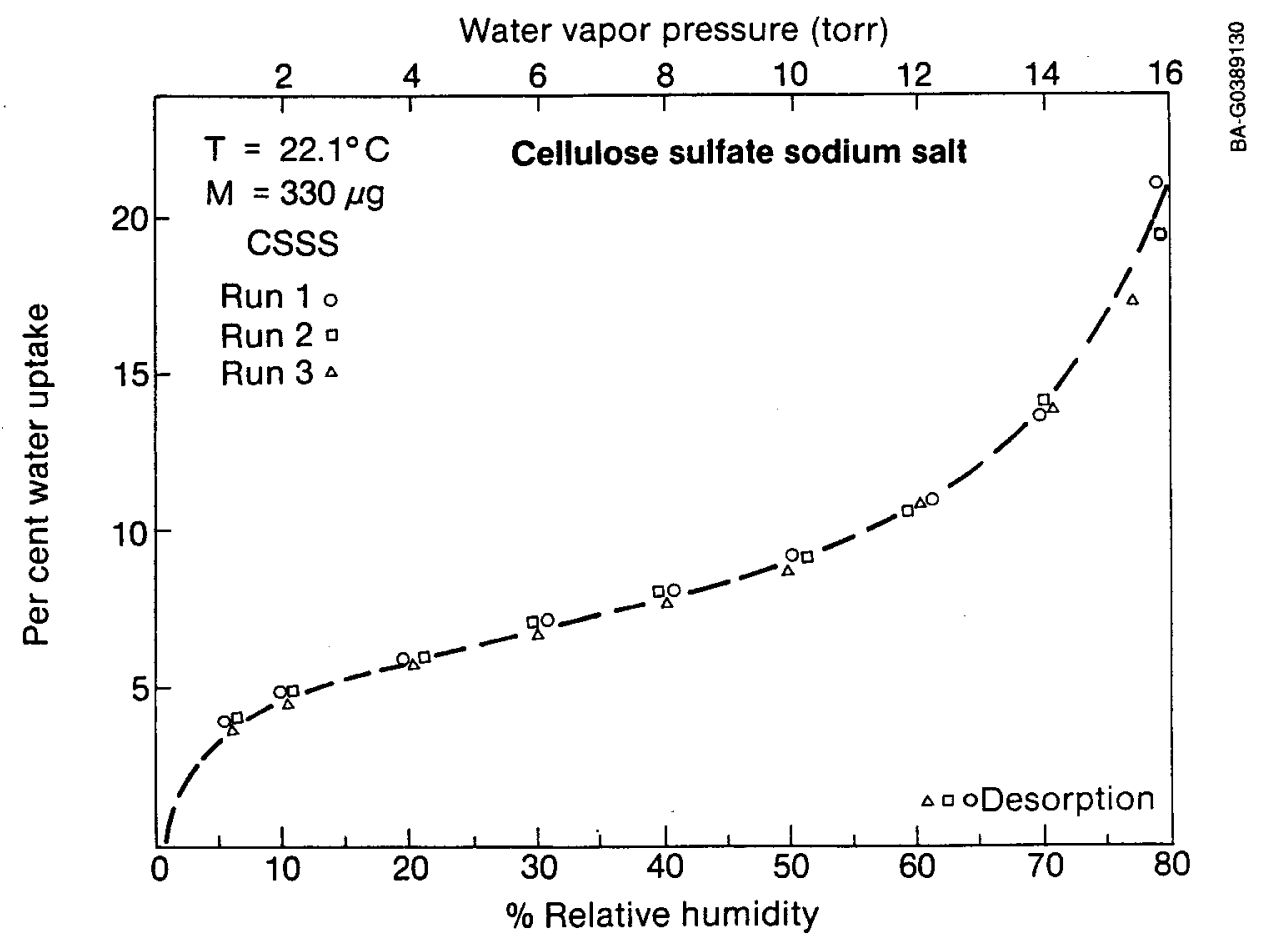

Figure 5-29. Water Vapor Desorption Isotherms for CSSS at $22.1^{\circ} \mathrm{C}$ (Three cycles) 


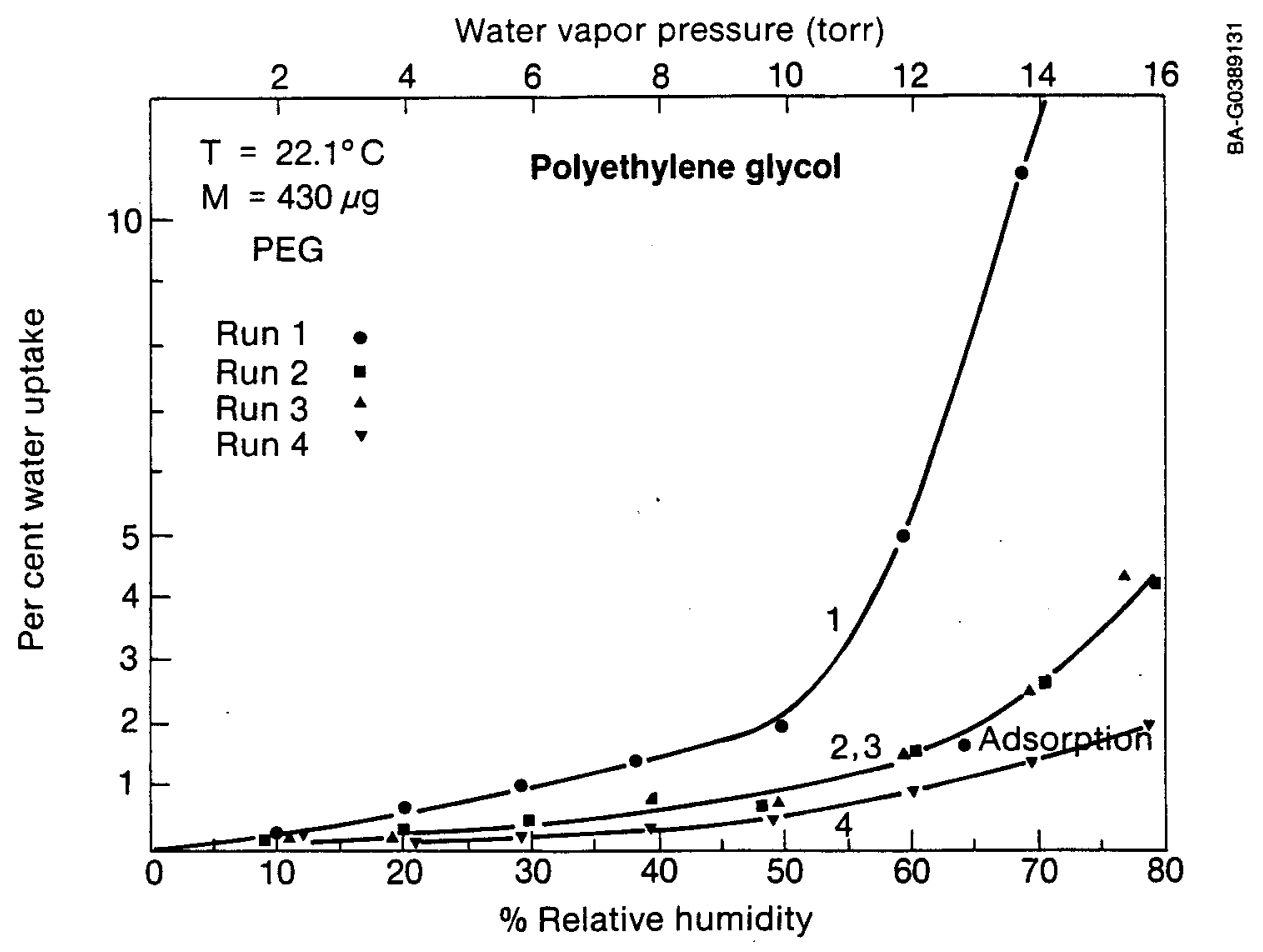

Figure 5-30. Water Vapor Sorption Isotherms for PEO at $22.1^{\circ} \mathrm{C}$ (Four cycles)

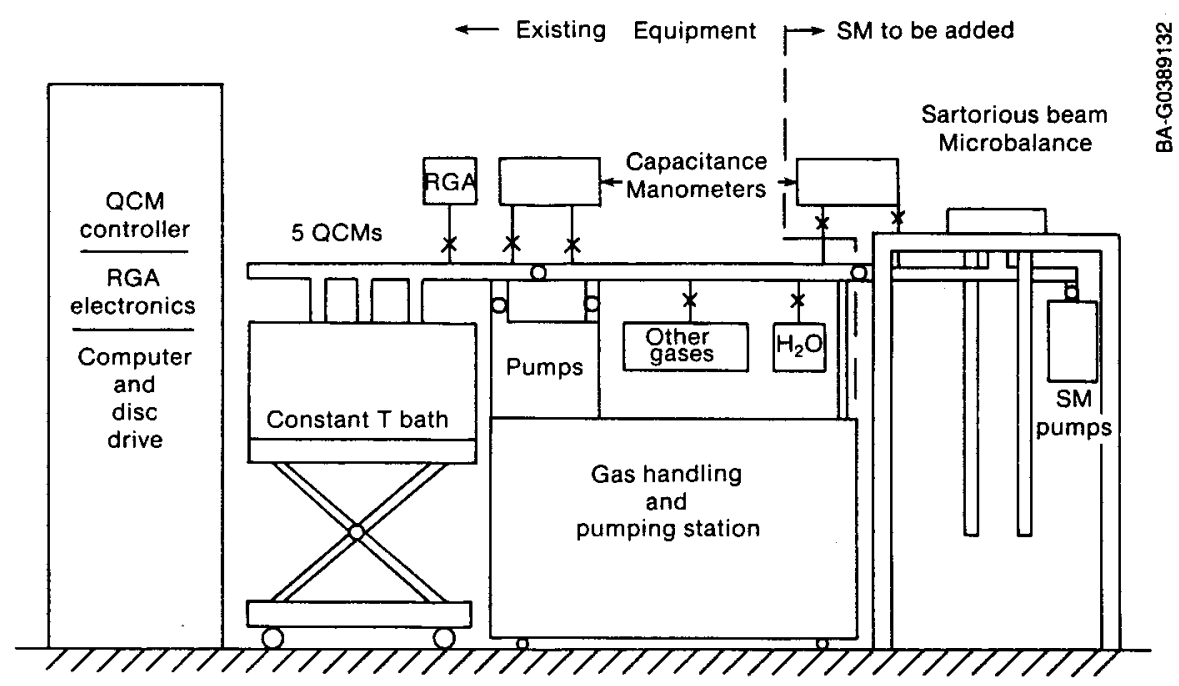

Figure 5-31. Block Diagram of Arrangement of a Combined QCM and SM Apparatus 
Table 5-1. Summary of Isotherm Data for 23 Polymers Studied as Potential Advanced Desiccant Materials

\begin{tabular}{|c|c|c|c|c|c|c|c|c|}
\hline Acronym & $\begin{array}{l}\text { Fig. } \\
\text { No. }\end{array}$ & $\begin{array}{l}\text { Mass. } \\
(\mu \mathrm{g})\end{array}$ & $\begin{array}{l}\text { Isotherm } \\
\text { Type }\end{array}$ & $\begin{array}{l}z \\
\text { Capacity } \\
\text { at } \\
80 \text { R.H. }\end{array}$ & $\begin{array}{l}\text { Capacity } \\
\text { Change } \\
\text { from } \\
5 \% \text { to } 60 \%\end{array}$ & Hysteresis & Kinetics & Other Comments \\
\hline PSSASS & $5-1$ & 300 & 2 & 80 & 31 & Above $50 \%$ R.H. & Fast & $\begin{array}{l}\text { Excellent repeatability on numer- } \\
\text { ous multicycle runs. }\end{array}$ \\
\hline SPSS & $5-2$ & 440 & 2 & 60 & 21 & Yes & Fast & $\begin{array}{l}\text { Hysteresis disappeared on run } 4 ; \\
\text { capacity dropped from } 60 \% \text { to } 30 \% \text {. }\end{array}$ \\
\hline PACM & $5-3$ & 90 & 2 or 3 & 85 & 45 & $\begin{array}{l}\text { Yes; } \\
\text { Low R.H. }\end{array}$ & $\begin{array}{l}\text { Slow, } \\
\text { low R.H. }\end{array}$ & $\begin{array}{l}\text { Hysteresis occurs only below } 30 \% \\
\text { R.H. accompanied by slow kinetics. }\end{array}$ \\
\hline PAAAS & $5-4$ & 110 & 2 & 42 & 17 & Yes & East & $\begin{array}{l}\text { Hysteresis becomes less pronounced } \\
\text { with cycling; capacity decreases } \\
\text { by a factor of } 2 \text { through } 4 \text { cycles. }\end{array}$ \\
\hline PMAASS & $5-5$ & 370 & 2 & 43 & 22 & Negligible & Fast & $\begin{array}{l}\text { Hysteresis decreases on cycling; } \\
\text { capacity increases slightly } \\
\text { through } 4 \text { cycles. }\end{array}$ \\
\hline PVAVSSS & $5-6$ & 320 & 2 & $40+$ Exp. & 13 & Yes & Fast & $\begin{array}{l}\text { Hysteresis maintained on cycling; } \\
\text { capacity increases from } 1 \text { through } \\
4 \text { cycles. }\end{array}$ \\
\hline PAASS & $5-7$ & 350 & 2 & 26 & 9 & Yes & Fast & $\begin{array}{l}\text { Hysteresis maintained through } 4 \\
\text { cycles; no change after } 2 \text { nd cycle. }\end{array}$ \\
\hline csss & $5-8$ & 330 & 2 & 18 & 7 & No & Fast & $\begin{array}{l}\text { Negligible hysteresis and capacity } \\
\text { change through } 4 \text { cycles. }\end{array}$ \\
\hline MC & $5-9$ & 440 & 2 & 20 & 10 & Yes & Fast & $\begin{array}{l}\text { Stabilized for runs } 2 \text { and } 3 \text {; } \\
\text { desorption erratic in run } 1 \text {. }\end{array}$ \\
\hline PVP & $5-10$ & 110 & 3 & 13 & 5.5 & Yes & Fast & $\begin{array}{l}\text { Hygteresis minimal; isotherm is } \\
\text { at crossover from type } 2 \text { to } 3 \text {. }\end{array}$ \\
\hline PAA & $5-11$ & 305 & 2 & 7 & 2.6 & Yes & Fast & $\begin{array}{l}\text { Compare hysteresis with PAASS } \\
\text { PAAAS. }\end{array}$ \\
\hline
\end{tabular}


Table 5-1. Summary of Isotherm Data for 23 Polymers Studied as Potential Advanced Desiccant Materials (Concluded)

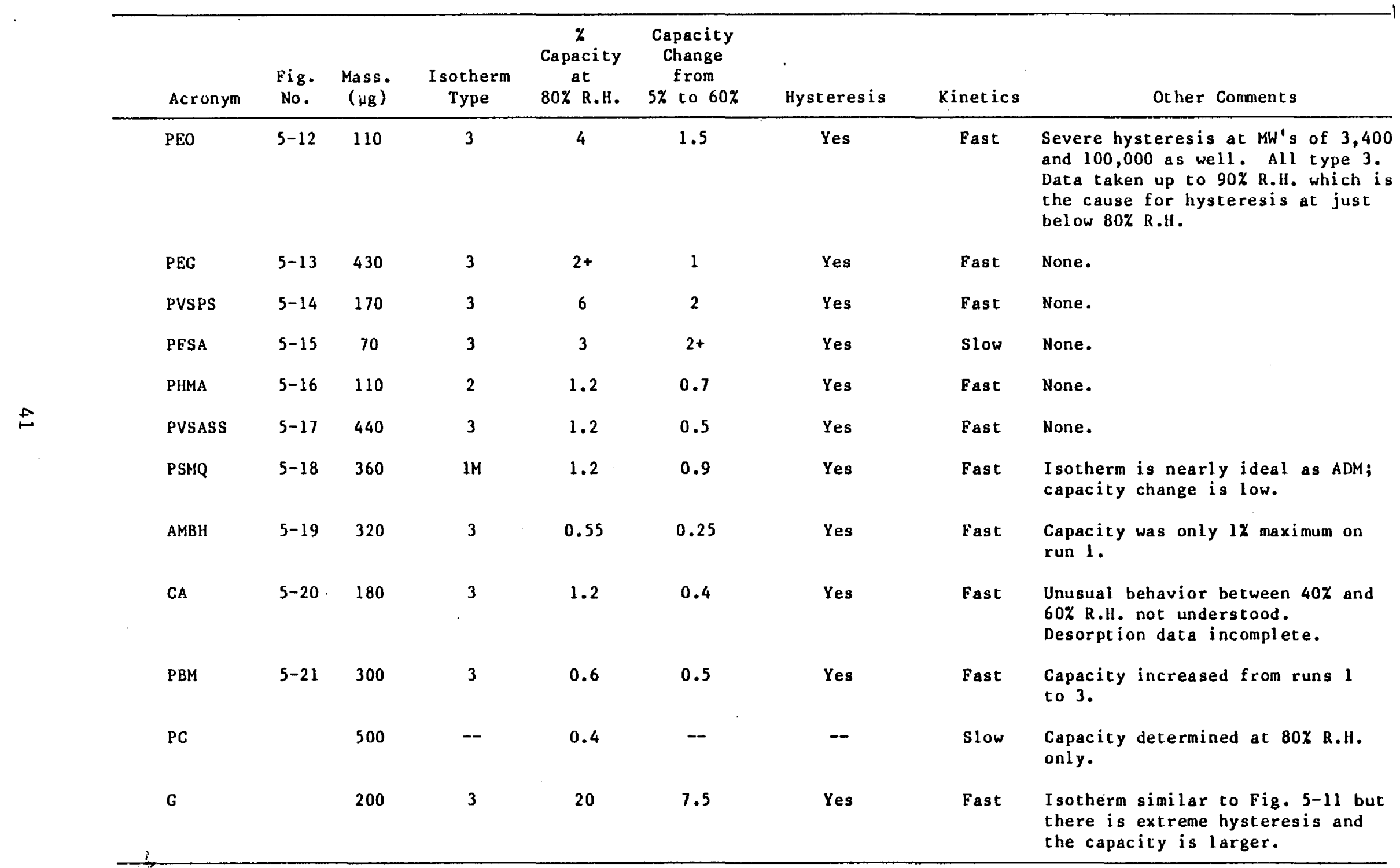




\subsection{CANDIDATE ADVANCED DESICCANT MATERIALS/SYNTHESIS OF NEW MATERIALS}

\subsection{Candidate Advanced Desiccant Materials}

A project summary covering 1985 through 1987 is attached as Appendix E. One of the key issues identified early in the project was to identify the candidate ADM from the long list of potential ADM. Based on the results given in Section 5.0, the listing is given in Appendix F.

There are now nine candidate advanced desiccant materials of the commercially available polymers studied so far. These are

- polystyrenesulfonic acid sodium salt (PSSASS)

- sodium polystyrene sulfonate (SPSS)

- polyacrylamide - carboxyl modified (PACM)

- polyacrylic acid ammonium salt (PAAAS)

- poly(methacrylic acid) sodium salt (PMAASS)

- $p o l y$ (n-vinylacetamide, vinyl sulfonate) sodium salt (PVAVSSS)

- polyacrylic acid sodium salt (PAASS)

- cellulose sulfate sodium salt (CSSS)

- methyl cellulose (MC).

The desirable properties of these polymers are summarized in Table 5-1.

\subsection{Synthesis of New Polymeric Materials}

Although nine polymers appear very promising as ADM for CDCS, none has an isotherm that is ideal as defined by Collier (Collier 1986). Since no effort has ever been undertaken to prepare a polymer with properties that are "molecularly engineered" to serve as an ideal ADM, it is crucial that this type of work be undertaken as an activity in 1988. 


\subsection{FUTURE ACTIVITIES}

As given in Section 1.8, the long-term technical approach for studying the water vapor sorption by advanced desiccant materials for use in regenerative DCS includes conducting experimental work and interpreting the data to secure the necessary understanding. The following parts of the technical approach are particularly relevant for 1988 .

1. Identify, select, rank, and prepare for study potential ADM.

2. Determine the effect of chemical modification of candidate ADM and their surfaces on the sorption performance.

3. Modify polymeric materials to improve their sorption performance and synthesize new polymeric materials that are "molecularly engineered". to function as an "idea1" ADM.

4. Design, purchase, construct, install, and use experimental apparatus necessary for characterizing the sorption performance and establishing the durability of ADM.

5. Measure the sorption performance and determine relevant physical parameters of potential ADM to establish which materials are candidate ADM based on the criteria discussed in Section 2.0 .

6. Determine the repeatability of the sorption performance of candidate ADM as a function of sorption-desorption cycles at time intervals corresponding to DCS.

For (6), the candidate commercially available polymers listed in section 6.0 should be subjected to durability studies with an objective of reducing the number of candidate polymers. This would be the final sorption screening of these materials. For (1), the updated literature search begun late in FY 1987 will be completed. It is expected that about ten potential candidate polymers will be identified, and these must be screened for their suitability as candidate ADM in the same manner as those discussed in Section 4.0. For (2), chemical modification of candidate polymers will be attempted with an objective of improving the isotherm shape and sorption capacity without compromising the other desirable properties of the polymer. For (3), initial efforts to synthesize and modify polymeric materials with an objective of making an "ideal" ADM will be started. Both (2) and (3) will require that additional polymer synthesis expertise be added to the project.

For (4), the QCM apparatus needs to be improved for fully automatic operation to carry out the studies in (6) in a more cost-effective manner, a SM needs to be added to the project as discussed in section 5.4, and a "weighing" microbalance needs to be purchased to improve the accuracy of our results as discussed in section 5.4. The SM will also be used to evaluate samples of candidate polymers that are 100-1000 times the sample size used for the QCM apparatus. The data in (5) are necessary for the materials identified in (1) in the same way as the data in Section 5.0 are necessary to find the candidate ADM from potential candidate ADM. 


\subsection{REFERENCES}

Barlow, R. S., 1982, (December) Analysis of the Adsorption Process and of Desiccant Cooling Systems - A Pseudo-Steady-State Model for Coupled Heat and Mass Transfer, SERI/TR-631-1330, Golden, CO: Solar Energy Research Institute.

Bry-Air and Cargocaire, 1984, for example, manufacture air driers; American Solar King Manufactures Sunaire. "Solar King's Cooling Gambit," Solar Age, October 1984, pp. 25-27.

Bulygin, A. N. et al., 1983, "Study of the Structure of Polymeric Sorbents," Polymer Sci., SSSR, Vo1. 25, No. 3, pp. 1179-1187.

Collier, K., 1986, Advanced Desiccant Materials Assessment, GRI-86/0181, Final Report, Feb. 1985-May 1986, Chicago, IL: Gas Research Institute.

Collier, R. K.; R. S. Barlow; and F. H. Arnold, 1982, "An Overview of OpenCycle Desiccant Cooling Systems and Materials," J. Solar Energy Engr., Vol. 104, pp. 28-34.

Czanderna, A. W. and R. Vasofsky, 1982, "Surface Studies with the Vacuum Ultramicrobalance," Prog. Surface Sci., Vol. 9 (No. 2), pp. 45-82.

Czanderna, A. W. and S. P. Wolsky (eds.), 1980, Microweighing in Vacuum and Controlled Environments, Elsevier, Amsterdam.

Czanderna, A. W., and T. M. Thomas, 1986a, (May) Advanced Desiccant Materials Research, SERI/PR-255-2887, Golden, CO: Solar Energy Research Institute.

Czanderna, A. W., and T. M. Thomas, 1986b, "Polymers: Options as Advanced Desiccant Materials," Proceedings of the Desiccant Cooling and Dehumidification Workshop, Chattanooga, TN, June 1986, In Press (See Appendix A of 1987a).

Czanderna, A. W., and T. M. Thomas, 1987a, (June) Advanced Desiccant Materials Research-1986 SERI/PR-255-3102, Golden, CO: Solar Energy Research Institute.

Czanderna, A. W., and T. M. Thomas, 1987b, "A Quartz Crystal Microbalance Apparatus for Water Sorption by Polymers," J. Vac. Sci. Technol., Vol. A5,. pp. 2412-17.

Fraioli, A. V., 1983, March, Investigation of Manganese Dioxide as an Improved Solid Desiccant, ANL-83-22, Argonne, IL: Argonne National Laboratory.

Gregg, S. J. and K.S.W. Sing, 1982, Adsorption, Surface Area, and Porosity, NY: Academic Press.

Jurinak, S., 1982, Open Cycle Solid Desiccant Cooling Component Models and Simulations, Ph.D. Dissertation, Madison, WI: University of Wisconsin.

Lu, C., and A. W. Czanderna (eds.), 1984, Applications of Piezoelectric Quartz Crystal Microbalance, E1sevier, Amsterdam.

Parent, Y., Davison Division, W. R. Grace, private communication, 1985. 
Pesaran, A. A. and A. F. Mills, 1984, (February), Modeling of Solid-Side Mass Transfer in Desiccant Particle Beds, SERI/TP-255-2170, Golden, CO: Solar Energy Research Institute.

Pesaran, A. A.; T. M. Thomas; T. R. Penney; and A. W. Czanderna, 1986c (September) Methods to Quantify Contamination Efects on Silica Gel Samples, SERI/TR-252-2802, Golden, CO: Solar Energy Research Institute.

Sauerbrey, G., Z. Physik, Vol. 155, 1959, p. 206.

Schlepp, D. R. and K. J. Schultz, 1984, (September), High Performance Solar Desiccant Cooling Systems SERI/TR-252-2497, Golden, CO: Solar Energy Research Institute.

Schlepp, D. R. and R. Barlow, 1984, (September), Performance of the SERI Parallel Passage Dehumidifier, SERI/TR-252-1951, Golden, CO: Solar Energy Research Institute. 
Appendix A. Leading Organic Polymers as Potential Advanced Desiccant Materials for Use in Desiccant Cooling Systems

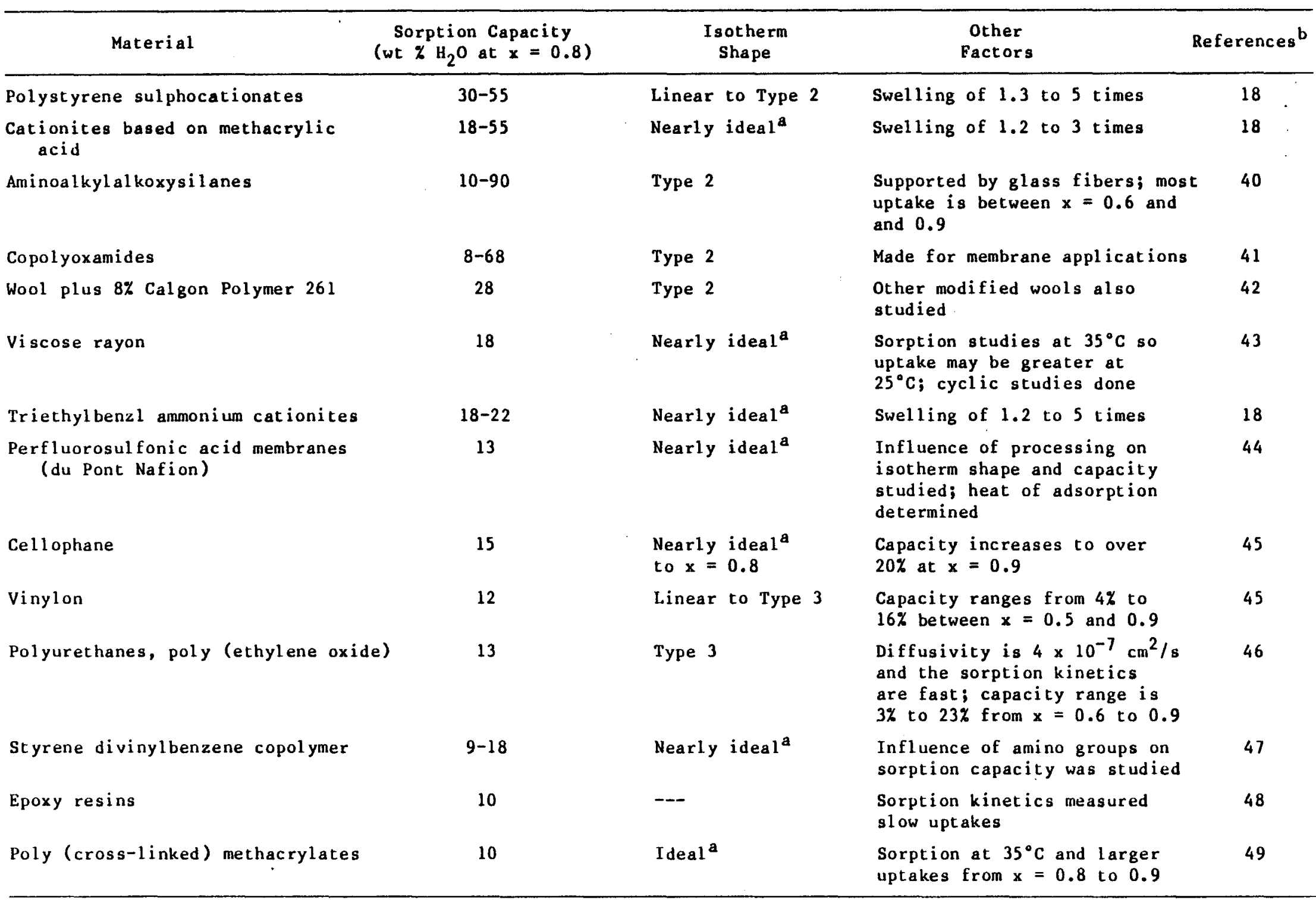

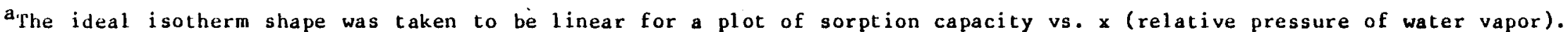
Most of the "nearly ideal" isotherms had slight curvatures of a type 2 isotherm with a small BET "c" value. These i sotherms might be excellent fits to those modeled in the most recent systems study 11 .

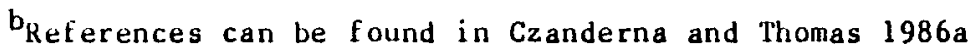


Appendix B. Possible Candidates for an Advanced Material for Use in Desiccant Cooling Systems

\begin{tabular}{|c|c|c|c|c|}
\hline Material & $\begin{array}{l}\text { Sorption Capacity } \\
\text { (wt } \% \mathrm{H}_{2} \mathrm{O} \text { at } \mathrm{x}=0.8 \text { ) }\end{array}$ & $\begin{array}{l}\text { Isotherm } \\
\text { Shapes }\end{array}$ & $\begin{array}{l}\text { Other } \\
\text { Factors }\end{array}$ & Reference ${ }^{b}$ \\
\hline Polystyrene sulfonates & Over 20 & --- & $\begin{array}{l}\text { Ion exchange resins known to } \\
\text { be good water sorbers }\end{array}$ & 50 \\
\hline Nylon 6,6 & 9.5 & --- & Good diffusivity & 51 \\
\hline Polyurethanes & $5-7$ & Type 3 & $\begin{array}{l}\text { Diffusivity and sorption } \\
\text { isotherms }\end{array}$ & 52 \\
\hline Polycarbonate & 4 & Type 3 & $\begin{array}{l}\text { Compositional and block length } \\
\text { studies on capacity }\end{array}$ & 53 \\
\hline Polyester & 8 & Type 2 & Measured at $30^{\circ} \mathrm{C}$ & 42,45 \\
\hline Cellulose acetate & 7 & Type 2 & Measured at $30^{\circ} \mathrm{C}$ & 45 \\
\hline Polyacrylonitrile & 4 & ---- & Sorption kinetics measured & 54 \\
\hline Chromia gels & 32 & ---- & Water content from outgassing & 55 \\
\hline Carbon blacks & $20-40$ & Close to ideal ${ }^{a}$ & Depends on preparation method & 56 \\
\hline
\end{tabular}

$\mathrm{a}_{\text {See Table A. }}$

References can be found in Czanderna and Thomas 1986a. 


\section{APPENDIX C \\ PROCEDURES USED TO DISSOLVE SEVERAL POLYMERS BEFORE COATING THEM ONTO A QUARTZ CRYSTAL}

AMBH: The material was stirred in an aqueous solution for 3 days at room temperature and it was not completely dissolved. However, the solution was decanted and a sufficient quantity of polymer was dissolved to prepare a sample.

CA: The material was stirred in an aqueous solution for 4 days at room temperature and it was not completely dissolved. However, the solution was decanted and a sufficient quantity of polymer was dissolved to prepare a sample.

PHMA: The material was stirred in an aqueous solution for 4 days at room temperature and it was not completely dissolved. However, the solution was decanted and a sufficient quantity of polymer was dissolved to prepare a sample.

PSMQ: The material was stirred in an aqueous solution for 2 weeks at $80^{\circ} \mathrm{C}$. The solution was decanted and filtered because the polymer was not completely dissolved. However, a sufficient quantity did dissolve to prepare a sample.

SPSS \#1625: The material was stirred in an aqueous solution for 2 weeks at $80^{\circ} \mathrm{C}$. It was allowed to set in a closed container at room temperature for an additional 2 weeks. Although the sample did not completely dissolve, a sufficient quantity did dissolve to prepare a sample.

N: $\quad$ The material was stirred in an aqueous solution for 3 days at $80^{\circ} \mathrm{C}$. An insufficient quantity dissolved, even after progressive additions of distilled $\mathrm{H}_{2} \mathrm{O}$ to a 50/50 mixture of ethanol and distilled $\mathrm{H}_{2} \mathrm{O}$. Thus, this material was not studied with the QCM. 


\section{APPENDIX D \\ ADDITIONAL CLASSES OF POLYMERS IDENTIFIED \\ IN 1987 AS POTENTIAL ADM}

- Ionic Salts of Polystyrene Sulfonates

- Ionic Salts of Polystyrene Sulfonic Acid

- Ionic Salts of Polyacrylic Acids

- Ionic Salts of Cellulose

- Effects of $\mathrm{Mg}, \mathrm{Ca}, \mathrm{Li}$, and $\mathrm{K}$ versus $\mathrm{Na}$ 


\author{
APPENDIX E \\ PROJECT SUMMARY (1985-1987) \\ Advanced Desiccant Materials Research \\ Materials Research Branch, SERI, Golden, CO \\ Principal Investigator, A. W. Czanderna
}

\title{
1. Research Scope
}

\section{1a. Scope/Background}

An advanced desiccant material (ADM) can advance solar buildings technology not only by lowering the cost of commercial solid desiccant cooling systems (DCS) to compete with conventional air conditioning, but also by eliminating the need for adding peak-load generating capacity by electric utili ties.

The optimum sorption properties of the desiccant materials in dessicant cooling systems (DCS) were identified in a recent study of systems analysis. If an ideal desiccant can be identified, the coefficient of performance of a DCS can be improved from 0.85 to 1.05 , which can now be obtained with silica gel the present industrial standard, up to 1.3 to 1.4 or close to the theoretical maximum. At the same time, the $\mathrm{cfm} /$ ton can be reduced from a range of 310 to 400 for silica gel to a range of 200 to 250 for an ideal desiccant. If both of these factors are achieved, DCS could be cost competitive with other current air-conditioning systems, and this is not possible for silica gel (Collier, GRI report). Prior to Colliers' conclusions, this project was initiated to identify new low-cost, new generation materials with the desired water vapor sorption performance, i.e., isotherm shape, sorption capacity, heat of adsorption and desorption kinetics, and cyclic stability. Of the commercially available inorganic (e.g., alumina gel, chromia gel, charcoal) and organic materials, over twenty-five commercially available polymeric materials have been selected as potential candidates for use in desiccant cooling systems (DCS). By considering the available polymeric desiccants, scientists note or have demonstrated that:

- Polymers have the potential of being modified so sorption isotherms of the desired shape and heats of adsorption of about $10.8 \mathrm{kcal} / \mathrm{mol}$ are both obtained.

- Polymers have the potential for sorbing water from 5 to $70 \%$ of their own weight.

- Polymers have the potential for being readily fabricated into shapes for DCS, e.g., a honeycomb structure $10 \times 0.04 \times 0.06 "$.

- Polymer structures have the potential of being fabricated to provide high diffusivities of water vapor through the material, thus, permitting sorption and desorption to be completed within a few minutes,

- Polymers can be regenerated at temperatures below $80^{\circ} \mathrm{C}$ for thermally desorbing water.

- Polymers have the potential for maintaining long-term stability through thousands of sorption-desorption cycles.

- Commercial polyrners are available at less than $\$ 1.00$ per pound or comparable to the cost of commercial grade silica gel. 


\section{APPENDIX E (cont)}

Accordingly, polymeric materials could not only serve as both the desiccant and support structure in a desiccant wheel, but also could be replaced easily and inexpensively if their water sorption capacity degrades for any reason. Accordingly, the initial emphasis of this research has been to characterize the water sorption performance of polymeric materials that could serve in an economically competitive DCS.

\section{Ib. Scope/Statement of Work}

The Department of Energy has an interest in identifying next generation, low-cost materials as advanced desiccants for solar cooling applications and to understand the role of surface phenomena on the performance of advanced desiccant materials. Research in this area may lead to new and/or modified materials that will improve the COP of DCS and provide a scientific understanding of the water vapor/desiccant interactions to underpin the technological application of durable ADM. To accomplish the objectives of this research, the Solar Energy Research Institute will:

(1) Identify, select, prioritize, and prepare for study potential ADM;

(2) Modify polymers and/or inorganic materials to improve their sorption performance and synthesize new polymeric materials that are "molecularly engineered" to function as an "ideal" ADM;

(3) Identify the performance criteria of ADM including sorption performance and durability;

(4) Identify the necessary measurements for characterizing the water-vapor sorption performance of potential ADM;

(5) Design, purchase, construct, install, and use experimental apparatus necessary for characterizing the sorption performance and establishing the durability of ADM;

(6) Measure the sorption performance and determine relevant physical parameters of potential ADM to establish which materials are candidate ADM based on the criteria in (2);

(7) Determine the repeatability of the sorption performance of candidate ADM from (1), (2), (3), (4), and (6) as a function of sorption-desorption cycles at time intervals corresponding to DCS;

(8) Determine the effect of chemical modification of ADM and their surfaces on the sorption performance;

(9) Conduct fundamental scientific investigations to understand the interplay among composition, bonding, topography, surface area, pore volume, pore size distribution, morphology, and their changes during cycling and use in real environments;

(10) Perform analytical and theoretical work, as needed, to assess the opportunities and limitations of candidate ADM for use in the engineering configurations of contemporary DCS;

(11) Cooperate with others performing desiccant research and development to expedite the testing of candidate ADM in engineering configurations; and 


\section{APPENDIX E (cont)}

(12) Prepare reports, publications, and make presentations to disseminate the results of the work.

\section{1c. Objectives/Research Progress}

\section{Objectives}

The scientific objective of this task is to determine how the desired sorption performance of advanced desiccant materials can be predicted by understanding the role of their surface phenomena and the materials modifications. The technological objective is to identify a next generation, low-cost material with which solar radiation or heat from another low-cost energy source can be used for regenerating the water vapor sorption activity of the desiccant.

\section{Research Progress}

Referring to the numbered items in the Statement of Work and to references (1)-(5) in the Bibliography, we have:

1a. Completed a literature search (1), identified polymeric and inorganic materials as potential advanced desiccants (1), prioritized them for study (1), and prepared them for characterizing their sorption performance $(1,3,5)$;

1b. Developed in detail the opportunities for utilizing polymeric materials as ADM $(2,3)$;

2. Established the feasibility for synthesizing/modifying polymers as ADM;

3a. Identified the key materials parameters for prioritizing potential ADM (1), ranked all identified materials of over 300 possibilities (1);

3b. Identified the water vapor sorption performance criteria for narrowing the potential ADM to a few candidate ADM (5). The sorption performance includes the sorption capacity from 5 to $80 \%$ R.H., isotherm shape, rate of adsorption and desorption and cyclic stability of the ADM in water vapor;

4. Identified microgravimetric, compositional surface analytical, infrared spectroscopic, scanning electron microscopic, and thermal gravimetric measurements as the minimum number of techniques necessary for studying desiccant materials and understanding their morphological and surface properties (1);

5. Designed, purchased, assembled, constructed, installed, and used a quartz crystal microbalance (QCM) for characterizing the sorption performance of organic (polymeric) and inorganic materials $(3,4,5)$, and designed a Sartorius microbalance system for use on the project when funds are available for its assembly and completion (5);

6a. Measured the sorption performance of over 23 potential commercially available polymeric ADM materials with the PCM (1-5) and used the criteria in (2) to narrow the number to eight candidate ADM (5). The measurements include determining sorption isotherms, rate of adsorption and desorption at each pressure increment or decrement, cyclic stability, and qualitative evaluations of 


\section{APPENDIX E (cont)}

permeation rates (3-5). Measurements of the heat of adsorption, pore volume, morphology, etc. for more detailed materials characterization have not been made.

6b. Designed an experimental procedure with an existing thermal gravimetric apparatus for studying the cyclic stability of ADM in humid air;

6c. Demonstrated that surface compositional analysis using X-ray photoelectron spectroscopy and infrared spectroscopy will be useful for securing both fundamental and technological information about both present and advanced desiccant materials;

7. Initiated cyclic stability studies of several candidate polymeric ADM and established that eight polymers remain as serious candidate ADM (5); and

8. Prepared proposals for securing the funding necessary to pursue the other issues $(2-11)$ in the Statement of Work that have not been addressed or are only partly completed.

\section{Research History}

2a. Funding Levels for ADM Research (in K\$)

FY1985

\begin{tabular}{lcccc} 
& FY1985 & FY1986 & FY1987 & TOTAL \\
\hline Operating & 80 & 75 & 150 & 305 \\
Capital & $\underline{55}$ & None & None & $\underline{55}$ \\
TOTAL & 135 & 75 & 150 & 360
\end{tabular}

\section{2b. Technical Problems and Solutions Achieved or Planned}

The planned solutions are identified under future directions. From hundreds of potential commercially available polymeric desiccants, we have narrowed these to eight candidate ADM. A crucial problem for the future will be to synthesize polymeric materials with the properties tailored to the needs of an ADM. This has never been done, but should be realizable with a combined effort with a polymer scientist and continued characterization work. There is clearly a need for sorption performance characterization of ADM using beam microbalance techniques, and the project will be considerably constrained unless this planned work is funded. At the same time, the capital investment in SERI's QCM has resulted in a unique piece of apparatus that is now being copied by a number of industrial research laboratories as a result of publication 4 .

\section{2c. Bibliography}

1. A.W. Czanderna and T.M. Thomas, Advance Desiccant Materials Research, SERI/PR-255-2887, May, 1986 (Available NTIS).

2. A.W. Czanderna and T.M. Thomas, "Polymers: Options as Advanced Desiccant Materials," Proceedings of the Desiccant Cooling and Dehumidification Workshop, Chat tanooga, TN, June 1986, In Press (See Appendix A of ref. 3). 


\section{APPENDIX E (cont)}

3. A.W. Czanderna and T.M. Thomas, Advanced Desiccant Materials Research: 1986, SERI/PR-255-3012, June, 1987 (Available NTIS).

4. A.W. Czanderna and T.M. Thomas, A Quartz Crystal Microbalance Apparatus for Water Sorption by Polymers," J. Vac. Sci. Technol., A5 (1987) 2412.

5. A. W. Czanderna, Advanced Desiccant Materials Research - 1987, SERI/PR-255XXXX, February, 1987 (Draft in preparation).

\section{Future Direction}

The long-term technical approach for studying the water vapor sorption by ADM for use in regenerative DCS consists of carrying out experimental work and interpreting the data to secure the necessary understanding. The following variables are particularly relevant: (1) selection, preparation, and study of a particular material; (2) water vapor sorption capacity and heat of adsorption by the solid desiccant; (3) rate of adsorption at $\mathrm{ca}, 22^{\circ} \mathrm{C}$ and of desorption at a modestly elevated $\mathrm{T} ;(4)$ repeatability of (2) and (3) as a function of cycles with short time intervals; (5) effect of chemical modification of the desiccant on (2), (3), and (4); and (6) changes in the composition and topography of desiccant surfaces and the bonding of water vapor during cycling.

For pursuing the Statement of Work, we plan to continue using a quartz crystal microbalance (QCM) and initiate using a Sartorius microbalance (SM) to obtain the water sorption data required for (1)-(4). Specifically, we will (a) complete the final sorption screening of eight candidate commercially available polymers, (b) install and initiate using a SM to screen candidate polymers that can not be studied with the QCM; (c) complete the initial sorption screening of up to eight potential candidate commercially available polymers; (d) systematically modify and/or synthesize polymers and characterize them for sorption performance; (e) systematically modify inorganic materials and characterize them for sorption performance; ( $f$ ) initiate sorption screening of polymers modified at SERI; $(g)$ study the cyclic stability of candidate polymers after concluding initial sorption screening where real-time cyclic stability studies will be made to provide accelerated simulation of real-time use in a DCS; (h) design, purchase, and install additions to existing apparatus to upgrade their utility and improve operating efficiencies; (i) characterize sorption performance of SERI synthesized polymers; (j) determine heats of adsorption for candidate materials; (k) complete our efforts on a technique for studying inorganic powders (e.g., silca gel) with the QCM; (l) study inorganic materials and some polymers using the SM; $(m)$ perform theory and computer simulation for diffusivity measurements for the geometry of a polymer on a quartz crystal and compare prediction with actual measurements; $(n)$ perform controlled studies to identify causes of sorption degradation induced by contaminants (e.g., silca gel; sorption, composition, bonding); and (o) initiate studies to understand basic vaporsurface interactions between water and two or three candidate materials (sorption, bonding, surface composition, pore size, etc.).

The addition of (b), (h), and (l) is especially attractive because SERI will have the means for being a center of quality assurance for characterizing the sorption performance of both inorganic and organic materials, independent of an engineering configuration. Characterization work on other SERI tasks could then reveal the sorption performance in an engineering configuration. 


\section{APPENDIX F \\ Commercially Available Polymers That Have Been Characterized for Sorption Performance with the QCM}

Promising as Candidate ADM

1. polystyrenesulfonic acid sodium salt

PSSASS

2. sodium polystyrene sulfonate

3. polyacrylamide - carboxy1 modified

PACM

4. polyacrylic acid ammonium salt

PAAAS

5. poly(methacrylic acid) sodium salt

6. poly(n-vinylacetamide, vinyl sulfonate) sodium salt

PMAASS

7. polyacrylic acid sodium salt

PVAVSSS

8. cellulose sulfate sodium salt

PAASS

9. methyl cellulose

CSSA

MC

\section{Of Little Interest as ADM}

10. polyvinylpyrrolidone

11. polyacrylic acid

12. polyethylene oxide, MW 100,000, MW 18,000, MW 3,400

13. polyethylene glycol

14. poly(vinyl sulfate) potassium salt

15. perfluorosulfonic acid; duPont Nafion

16. poly (hexamethylene adipamide)

17. poly(vinyl sulfonic acid) sodium salt

18. polystyrene cross-linked mixed quartenary ammonium

(hydroxide form) and sulfonic acid (hydrogen form)

19. amberlite IR-120 H form

20. cellulose acetate

21. poly(buty1 methacrylate)

22. polycarbonate

23. gelamide

Of No Further Interest Based on Literature

24. polyurethanes

25. wool plus $8 \%$ Calgon Polymer 261

26. amino alkylalkoxysilanes

Crosslinked or Beads that Could Not Be Studied with a QCM

nylon, 6'6

polystyrene sulfonic acid sodium salt, crosslinked beads poly(ethylene-methacrylic acid) sodium salt 


\section{DISTRIBUTION LIST}

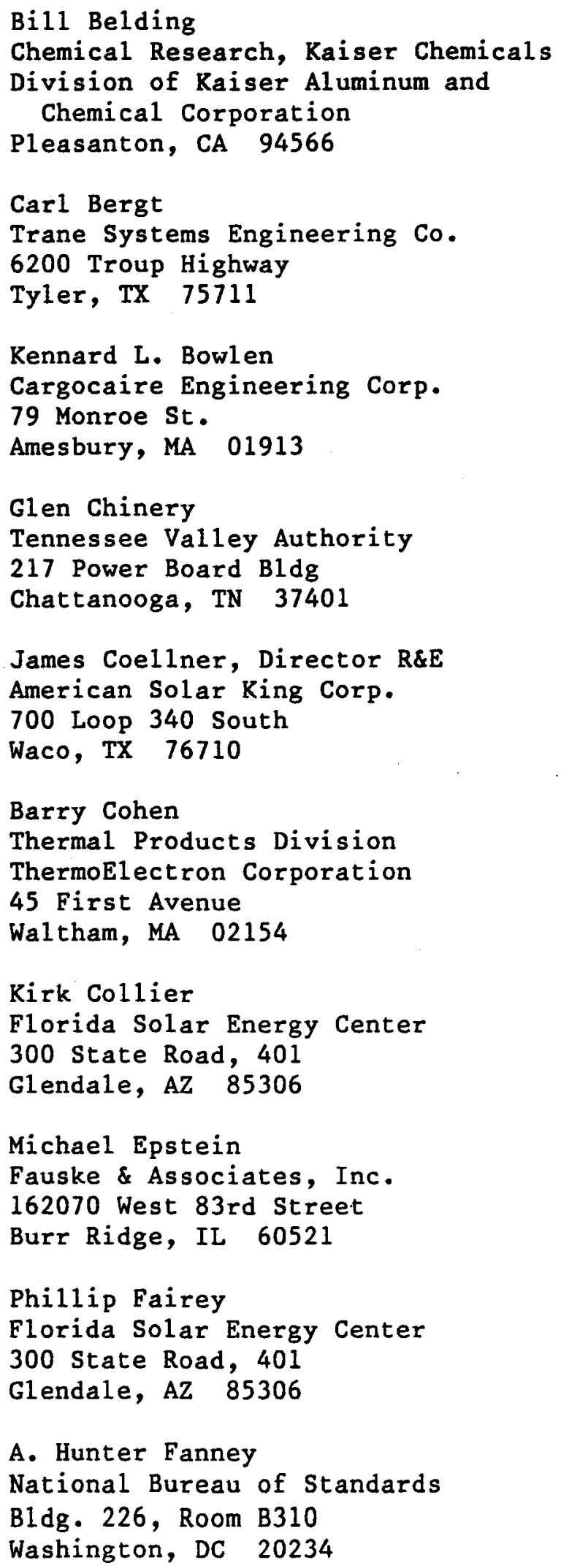

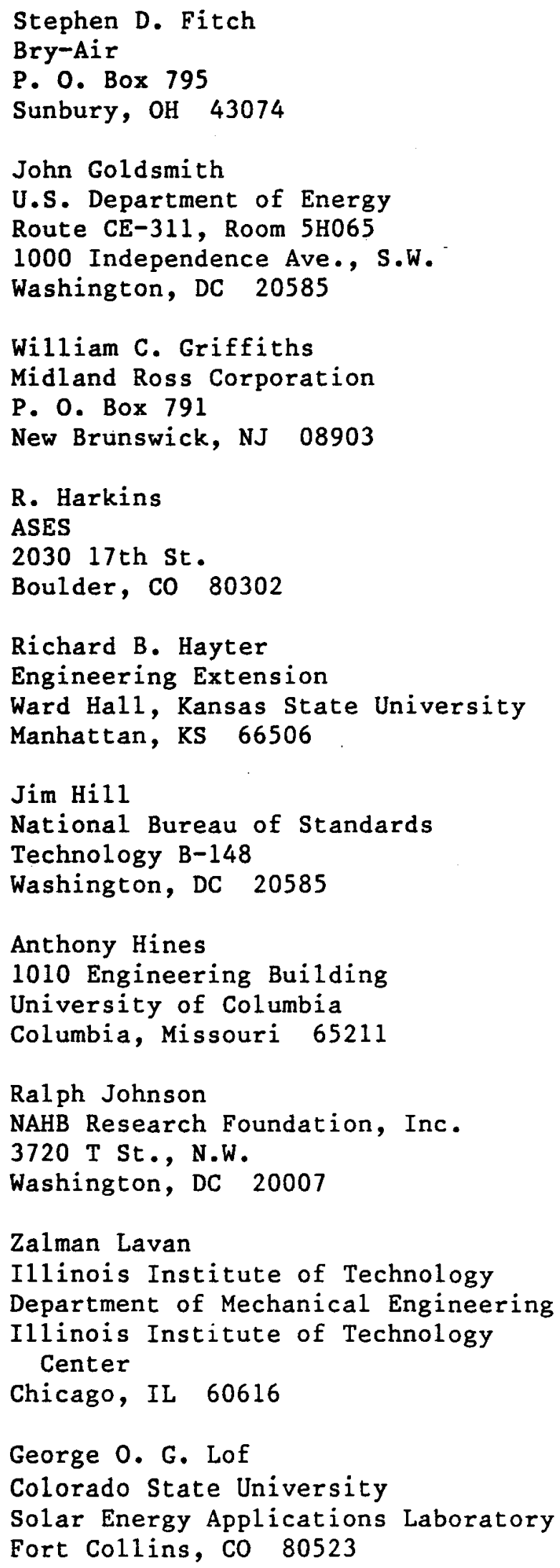


Ian Maclaine-cross

University of New South Wales

School of Mechanical and Industrial Engineering

P.0. Box 1

Kensington, NSW 2033 Australia

John Mitchell

University of Wisconsin-Madison Engineering Research Building 1500 Johnson Drive

Madison, WI 53706

Frederick Morse

U.S: Department of Energy

Route $\mathrm{CE}-31$, Room 5H-095

1000 Independence Ave., S.W.

Washington, DC 20585

Janet Neville

U.S. Department of Energy

San Francisco Operations Office

1333 Broadway

Oakland, CA 94612

Davor Novosel

Gas Research Institute

8600 West Bryn Mawr Avenue

Chicago, IL 60631

Yves 0. Parent

Res. Eng.

Industrial Chemicals Research

Davison Chemical Division

W. R. Grace \& Co.

Washington Research Center

7379 Route 32

Columbia, MD 21044
David Pellish

Solar Buildings Technology Division

Office of Solar Heat Technology

U.S. Department of Energy

Forrestal Building, Room 5H-041

1000 Independence Ave., S.W.

Washington, DC 20585

D. M. Ruthven

University of New Brunswick

P. 0. Box 4400

Fredericton, N.B.

Canada E58 5A3

William Seaton

ASHRAE

1791 Tullie Circle, NE

Atlanta, GA 30329

M. Wah1ig

Lawrence Berkeley Laboratories

University of California

1 Cyclotron Drive

Berkeley, CA 94720

Alex Willman

ACargocaire Resource and Management Foundation 1015 15th Street, N.W.

Washington, DC 20005 